\title{
O gênero Pfaffia Mart. (Amaranthaceae) no Brasil
}

\author{
Maria Salete Marchioretto ${ }^{1,4}$, Silvia Teresinha Sfoggia Miotto² e Josafá Carlos de Siqueira ${ }^{3}$
}

Recebido: 30.10.2008; aceito: 05.08.2010

\begin{abstract}
The genus Pfaffia Mart. (Amaranthaceae) in Brazil). A taxonopmic treatment of Pfaffia in Brazil is presented. It is a neotropical genus and Brazil is considered as the main diversity center. Pfaffia species occur mainly in open vegetation "cerrados", "campos rupestres", grasslands, forest edges, galery forests, and bruschwoods. The genus is represented in Brazil by 20 species. Descriptions, identification keys, nomenclatural comments, illustrations of the diagnostic caracters are presented together with information about geographic distibution and habitats.
\end{abstract}

Key words: Amaranthaceae, neotropics, Pfaffia, taxonomy

RESUMO - (O gênero Pfaffia Mart. (Amaranthaceae) no Brasil). Este trabalho consiste no estudo taxonômico das espécies do gênero Pfaffia Mart. (Amaranthaceae) no Brasil. O gênero é neotropical, sendo o Brasil considerado o centro de diversidade do mesmo. As espécies de Pfaffia são encontradas principalmente em formações vegetacionais como cerrados, campos rupestres, campos limpos, orla de matas, borda de rios e capoeiras. O gênero está representado no Brasil por 20 espécies. São apresentadas chaves para identificações das espécies de Pfaffia, descrições, ilustrações, dados sobre distribuição geográfica e hábitat, além de comentários sobre aspectos taxonômicos e nomenclaturais.

Palavras chave: Amaranthaceae, neotrópicos, Pfaffia, taxonomia

\section{Introdução}

A família Amaranthaceae Juss. é predominantemente tropical e subtropical. Segundo as características morfológicas (Judd et al. 2002) e moleculares (APG II 2003) pertence à ordem Caryophyllales. Judd et al. (2002) incluem na família as espécies anteriormente pertencentes a Chenopodiaceae sendo citados 169 gêneros e 2.360 espécies. De acordo com Müller \& Borsch (2005), as famílias Amaranthaceae e Chenopodiaceae representam um grupo monofilético, com o maior número de espécies dentro da ordem Caryophyllales. Para Souza \& Lorenzi (2005) as Amaranthaceae apresentam 170 gêneros e 2000 espécies, sendo que no Brasil ocorrem 20 gêneros e, aproximadamente, 100 espécies.

As espécies do gênero Pfaffia caracterizamse por serem ervas ou subarbustos eretos ou semi-prostrados, apresentando folhas opostas ou verticiladas, inflorescências capituliformes ou em espigas, flores perfeitas e fruto do tipo cápsula monospérmica.

Para o gênero Pfaffia não existe uma revisão taxonômica atualizada, nem tampouco foram levantados os aspectos fitogeográficos, importantes para o melhor conhecimento da distribuição das espécies no Brasil. Alguns trabalhos com o gênero foram realizados por Stützer (1935), Siqueira \& Grandi (1986), Vasconcellos (1986), Borsch \&

1. Instituto Anchietano de Pesquisas, Herbarium Anchieta, Caixa Postal 275, 93001-970 São Leopoldo, RS, Brasil

2. Universidade Federal do Rio Grande do Sul, Instituto de Biociências, Departamento de Botânica, Av. Bento Gonçalves 9500, Bloco IV, prédio 43433, 91501-970 Porto Alegre, RS, Brasil

3. Pontifícia Universidade Católica do Rio de Janeiro, Departamento de Geografia e Meio Ambiente, Rua Marquês de São Vicente 398, 22451-041 Rio de Janeiro, RJ, Brasil

4. Autor para correspondência: herbariopaca@unisinos.br ou saletemarchioretto@gmail.com 
Pedersen (1997), Pedersen (1997, 2000), entre outros e são atualmente referências fundamentais, porém, apresentam limitações em alguns aspectos, tais como informações sobre distribuição geográfica, morfologia e posição taxonômica das espécies, além de considerações filogenéticas.

As espécies do gênero distribuem-se na Região Neotropical, estendendo-se do sul do México através dos trópicos, incluindo a Bacia Amazônica até Baía Blanca, Argentina (Borsch 1995).

Existem muitas controvérsias entre os autores quanto ao número de espécies, sendo citadas de 30 até 40 espécies (Stützer 1935, Smith \& Downs 1972, Eliasson 1987, 1988, Townsend 1993, Borsch 1995). Estes autores são unânimes em afirmar que as espécies deste gênero ocorrem na América Central e América do Sul. O Brasil é considerado o centro de diversidade do gênero (Siqueira 1994/1995), sendo citadas 21 espécies, subdivididas em duas secções: Pfaffia, com cerca de 18 espécies e Serturnera com aproximadamente três espécies (Siqueira 1997/1998, 2002).

As espécies de Pfaffia são encontradas principalmente nas seguintes formações vegetacionais: cerrados, campos rupestres, campos limpos, orla de matas, borda de rios e capoeiras.

O presente estudo tem como objetivo a revisão taxonômica do gênero Pfaffia no Brasil, incluindo descrições, ilustrações, chave de identificação das espécies, dados de distribuição geográfica e hábitats e comentários.

\section{Material e métodos}

O trabalho foi baseado no exame de aproximadamente 2.080 exsicatas, pertencentes ao acervo de 43 herbários nacionais e internacionais. Foram consultados os seguintes herbários relacionados a seguir pelas siglas, de acordo com o Index Herbariorum (Thiers 2010): ALCB, B, BHCB, BHZB, C, CEN, CEPEC, CESJ, CH, CPAP, CTES, ECA, ESA, FCAB, GUA, HAS, HB, HBR, HRB, HRCB, HTO, HUEFS, IAC, IAN, IBGE, ICN, JPB, K, MBM, MG, NY, P, PACA, R, RB, S, SI, SJRP, SP, SPF, UB, VEN, VIC. Além disso, foram examinados tipos nomenclaturais procedentes dos herbários $\mathrm{B}, \mathrm{C}$, CTES, K, NY, P e S.

Também foram realizadas excursões no campo para coleta de material in situ em vários estados brasileiros, entre eles: Minas Gerais, Mato Grosso, Paraná, Rio Grande do Sul e Santa Catarina.
Estas coletas, muitas vezes, foram prejudicadas pela escassez de material no campo, associada à degradação dos hábitats. A coleção-testemunha do gênero Pfaffia foi depositada nos herbários PACA e ICN.

As condições ambientais em que ocorrem as espécies e a distribuição geral foram levantadas a partir dos dados encontrados nas fichas de coletas, das observações em campo e em bibliografia especializada, destacando-se: Rizzini (1979), Cabrera \& Willink (1980), Andrade-Lima (1981), Eiten (1977, 1990), Fernandes (1998), Rizzini et al. (1988) e Veloso et al. (1991).

A citação do material-tipo aparece apenas após a referência bibliográfica de cada basiônimo. O sinal (!) após a sigla do herbário onde está depositado, indica que o tipo ou a fotografia do tipo foram examinados.

As sinonímias das espécies estão baseadas em Pedersen (1967, 1976, 1990, 1999), que tece comentários, argumentando a posição tomada a respeito de cada uma delas.

Para as descrições das espécies seguiu-se o procedimento usual em taxonomia, através da análise morfológica, complementada com os dados de etiquetas das exsicatas e coletas a campo. A terminologia botânica utilizada nas descrições foi baseada em Hickey (1974) e Radford et al. (1974).

As ilustrações do hábito das espécies foram feitas a partir de fotocópias das exsicatas desenhadas à nanquim sobre papel vegetal. As demais ilustrações foram preparadas utilizandose material herborizado, hidratado, com auxílio de câmara-clara Zeiss e microscópios estereoscópicos Carl Zeiss e Olympus.

\section{Resultados e Discussão}

Histórico do gênero Pfaffia - O gênero Pfaffia foi estabelecido por Martius (1826), em homenagem ao professor alemão Christian Heinrich Pfaff (17741852). Este autor também foi um dos que mais contribuiu ao estudo das espécies brasileiras do gênero Pfaffia. Descreveu sete espécies, algumas com descrições completas e ilustrações, outras citando apenas algumas características e dados de distribuição geográfica e fenológicos (Martius 1826).

Endlicher (1837) fez a primeira divisão da família Amaranthaceae em tribos, incluiu Pfaffia Mart., Hebanthe Mart. e Serturnera Mart. como secções do gênero Gomphrena L., baseando-se somente na descrição de Martius (1826). Foi seguido por 
Moquin-Tandon (1849) e Seubert (1875), esse último apresentou pela primeira vez, chave para identificação das espécies das três secções encontradas no Brasil. A secção tipo, continha somente oito espécies.

Hooker (1880) manteve o gênero Pfaffia independente do gênero Gomphrena, incluindo em Pfaffia as espécies da secção Serturnera (Mart.) Endl. O autor citou 15 espécies para o Brasil.

Fries (1920) desconsiderou as secções criadas por Endlicher (1837) no gênero Gomphrena e também considerou três secções para o gênero Pfaffia: secção Serturnera (Mart.) R.E. Fr. secção Hebanthe (Mart.) R.E. Fr. e a secção Eupaffia R.E. Fr. O autor ainda descreveu três espécies para o gênero, e teceu comentários sobre algumas espécies e variedades.

Suessenguth (1934) estudou por muitos anos a família Amaranthaceae, estabelecendo novas espécies e variedades, principalmente para a América do Sul. Embora seguindo o mesmo estilo tipológico de Seubert (1875) e Fries (1920), no que se refere às categorias infraespecíficas, o autor examinou material de vários herbários da Europa e da América do Sul e apresentou 32 espécies sul-americanas para o gênero Pfaffia, citando 17 para o Brasil.

Stützer (1935) realizou um estudo das espécies sul-americanas do gênero Pfaffia. Considerou três secções já estabelecidas por Fries (1920), descreveu uma nova espécie, fez três novas combinações e estabeleceu 25 novas variedades. Das 33 espécies sul-americanas, 22 são encontradas no Brasil. A autora também apresentou mapa de distribuição geográfica e salientou a proximidade entre os gêneros Gomphrena, Iresine P. Browne e Pfaffia.

Suessenguth (1938), em seu estudo das Amaranthaceae da América, Ásia e Austrália, descreveu duas espécies novas para o gênero: Pfaffia aphylla Suess. e P. gleasoni Suess., ocorrentes respectivamente no Brasil e no Paraguai.

Pedersen (1967, 1976, 1987, 1990, 1997, 2000) descreveu novas espécies variedades e/ou formas, fez novas combinações, comentários e apresentou dados sobre a distribuição geográfica de algumas espécies de Pfaffia sul americanas.

Borsch (1995) realizou três novas combinações em espécies de Pfaffia ocorrentes nos trópicos do Novo Mundo, baseado na morfologia do pólen e na estrutura floral.

No Brasil vários autores realizaram estudos com a família Amaranthaceae, incluindo nestes o gênero Pfaffia entre eles, Rambo (1968) e Vasconcellos
(1986) para o Rio Grande do Sul; Smith \& Downs (1972) para Santa Catarina; Siqueira \& Grandi (1986) para Minas Gerais; Siqueira (2002) para São Paulo e Senna (2006) para a Bahia.

Pfaffia Mart. Nov. Gen. Sp. Pl. 2: 20.1826. Tipo: Pfaffia glabrata Mart. $\equiv$ Gomphrena L. sect. Pfaffia (Mart.) Endl., Gen. 302. 1837.

= Serturnera Mart., Nov. Gen. Sp. P1. 2: 36.1826 $\equiv$ Gomphrena L. sect. Serturnera (Mart.) Endl. Gen. 301. 1837.

Ervas ou subarbustos eretos ou semiprostrados, ramosos, estriados, glabros ou pilosos: lanosos ou tomentosos; sistemas subterrâneos gemíferos, fusiformes ou tuberiformes, lenhosos ou suculentos. Folhas opostas, raro verticiladas, elípticas, lanceoladas, lineares, linear-lanceoladas, oblongas, oblongo-lanceoladas, oblongo-lineares, oblongoovaladas, obovaladas, orbiculares, ovaladas, ovaladolanceoladas, ovalado-elípticas sésseis ou curtopecioladas, ápice agudo, acuminado, mucronado, aristado a cuspidado, base aguda, obtusa, atenuada, rotunda, decurrente, subcordada, glabras ou pilosas: lanosas, tomentosas, velutinas ou vilosas, tricomas estrigosos, hírtulos, hirsutos, híspidos, seríceos, setosos, membranáceas a cartáceas. Inflorescências capituliformes ou em espigas, isoladas ou reunidas em dicásios ou fascículos, ramificação simples, di ou tricotômica, axilares ou terminais, pedúnculo curto, médio ou longo, ráquis inflada a subinflada. Três brácteas hialinas, escariosas, geralmente desiguais, duas maiores e uma menor, glabras a pilosas. Flores perfeitas, cinco sépalas livres, paleáceas, oblongas, oblongo-ovaladas, oblongo-lanceoladas, lanceoladas, elíptico-lanceoladas, ovalado-lanceoladas, oblongoestreitas, glabras ou pilosas. Tubo estaminal menor ou quase do mesmo tamanho das sépalas, filamentos laterais, ciliados, crenulados, fimbriados ou subulados, filamento anterífero agudo, filiforme ou subulado, anteras elípticas, oblongas, lineares a linear-oblongas. Ovário bicarpelar, oblongo, obovalado, ovalado, oblongo-ovalado ou ovaladogloboso, um rudimento seminal, estilete curto, levemente manifesto ou ausente, estigma capitado, capitado-emarginado ou capitado-bilobado. Fruto cápsula monospérmica, inclusa nas sépalas; semente lenticular, embrião com radícula ascendente.

Das 20 espécies de Pfaffia confirmadas para o Brasil, 19 estão incluídas na secção Pfaffia e apenas uma, Pfaffia glomerata, na secção Serturnera. 
Chave para as secções do gênero Pfaffia

1. Inflorescências isoladas ou reunidas em fasículos Pfaffia

1. Inflorescências reunidas em dicásio Serturnera

Chave para identificação das espécies de Pfaffia no Brasil

1. Inflorescências reunidas em dicásios

P. glomerata

1. Inflorescências isoladas ou reunidas em fascículos

2. Plantas afilas P. aphylla

2. Plantas com folhas

3. Folhas opostas e verticiladas P. rupestris

3. Folhas opostas

4. Inflorescências somente capituliformes

5. Sépalas glabras

P. glabrata

5. Sépalas lanosas, pilosas, tomentosas ou vilosas

6. Folhas raras, quando presentes, localizadas na base do caule P. denudata

6. Folhas sempre presentes na base e nos ramos caulinares.

7. Plantas com tricomas hírtulos P. hirtula

7. Plantas com tricomas não hírtulos

8. Folhas com ápice mucronado P. acutifolia

8. Folhas com ápice não mucronado

9. Folhas com nervuras proeminentes

10. Ovário ovalado, estigma capitado P. siqueiriana

10. Ovário oblongo, estigma levemente bilobado P. gnaphaloides

9. Folhas sem nervuras proeminentes

11. Pedúnculos curtos a médios $2,5-5 \mathrm{~cm}$ compr

P. cipoana

11. Pedúnculos longos 7-13,5 cm.compr

P. sericantha

4. Inflorescências em espiga ou em espiga e capituliformes

12. Caules prostrados ou semiprostrados

13. Pedúnculos curtos a médios $2-6 \mathrm{~cm}$ compr P. minarum

13. Pedúnculos longos $7-8 \mathrm{~cm}$ compr P. argyrea

12. Caules eretos

14. Folhas lanceoladas a linear-lanceoladas P. jubata

14. Folhas elípticas, oblongo, orbiculares, ovaladas ou obovaladas

15. Folhas com as faces glabras

P. sarcophylla

15. Folhas com as faces pilosas, lanosas, tomentosas ou velutinas

16. Base da folha rotunda

17. Pedúnculo seríceo, ráquis tomentosa P. elata

17. Pedúnculo lanoso, ráquis lanosa P. townsendii

16. Base da folha não rotunda

18. Pedúnculos médios $4-5 \mathrm{~cm}$ compr P. tuberculosa

18. Pedúnculos longos 7-20 cm compr.

19. Bráctea mediana ovalada, aguda $2,0 \mathrm{~mm}$ compr.

P. tuberosa

19. Bráctea mediana lanceolada, acuminada 3,5-4,0 mm compr.

P. velutina

Secção Pfaffia (Mart.) Endl.

Pfaffia acutifolia (Moq.) Stützer, Feddes Repert. Spec. Nov. Regni Veg. 88. 22. 1935 E Gomphrena tuberosa Spreng. var. acutifolia Moq., in DC.
Prodr. 13. 388. 1849. Tipo: BRASIL. PIAUHY: Gardner 2294, II. 1839. (K, fotografia!). Figura 1

Erva a subarbusto, $0,30-1,20 \mathrm{~m}$ de altura, 


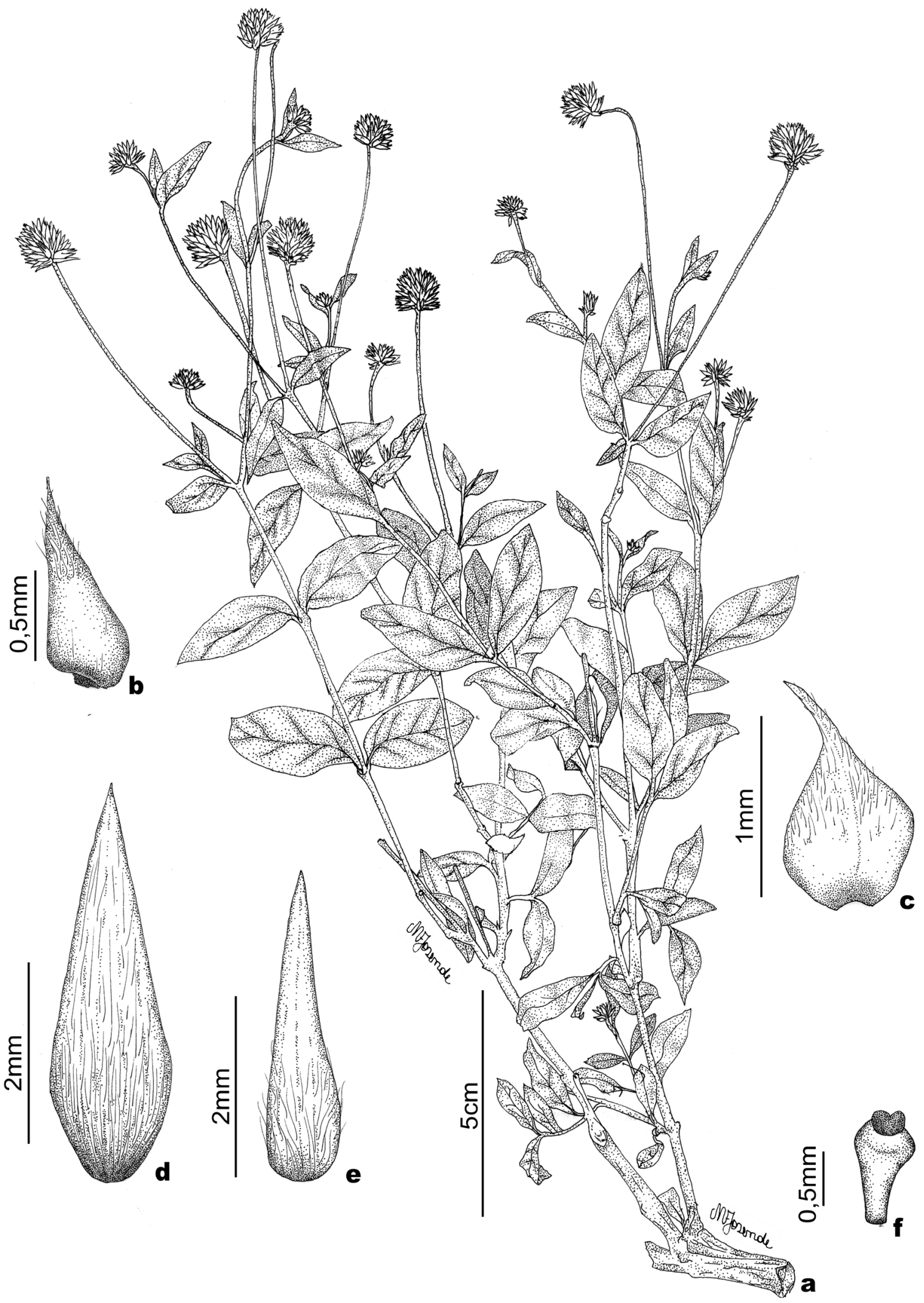

Figura 1. Pfaffia acutifolia (Moq.) Stützer. a. Ramo. b. Bráctea mediana. c. Bráctea lateral. d-e. Sépalas. f. Ovário (Hatschbach et al. $65840, \mathrm{UB})$.

Figure 1. Pfaffia acutifolia (Moq.) Stützer. a. Branch. b. Median bract. c. Lateral bract. d-e. Sepals. f. Ovary (Hatschbach et al. 65840, UB). 
caule semiprostrado a ereto, ramoso, piloso, tricomas híspidos, articulados; entrenós de 3-11 cm; raiz semilenhosa. Folhas ovaladas, ovalado-lanceoladas, ovalado-elípticas a elípticas, 1,2-8,5 × 0,5-3,7 cm., curto-pecioladas, 3-5 mm compr.; ápice mucronado; base aguda; face adaxial pilosa, tricomas estrigosos, articulados, face abaxial pilosa ou vilosa, tricomas estrigosos, articulados. Inflorescência capituliforme, isolada, simples, axilar ou terminal; pedúnculo longo, $7-10 \mathrm{~cm}$, viloso, ráquis velutina. Bráctea mediana ovalado-lanceolada, ápice atenuado, dorso piloso, 2-3 mm de compr., brácteas laterais ovaladas, ápice atenuado, dorso piloso, uninervadas, 2,5-3,5 $\mathrm{mm}$ de compr.. Sépalas lanceoladas, 6-10 mm compr., ápice acuminado, pilosas, tricomas incano-lanados na base, trinervadas. Tubo estaminal menor que o tamanho das sépalas, filamentos laterais fimbriados, filamento anterífero filiforme, anteras oblongas, 1,21,5 mm compr.. Ovário obovalado, 1-1,5 mm compr., estigma capitado.

Distribuição geográfica e hábitat: espécie brasileira encontrada nos estados da Bahia, Goiás, Minas Gerais e Tocantins, em caatingas, carrascos, cerrados, campos rupestres e campos úmidos, em altitudes entre 400-1.500 m.

Material selecionado: BRASIL. BAHIA: Andaraí, $8 \mathrm{Km}$ South of Andaraí on road to Mucugé, 13-II1977, Harley et al. 18600 (CTES, NY); Bom Jesus da Lapa, Juá, na encosta da colina junto a lajedos rochosos, 5-IV-1992, Hatschbach \& Barbosa 56612 (CEPEC,CTES, MBM); Brejinhos das Ametistas, serra geral de Caitité, 11-IV-1980, Harley et al. 21207 (CTES); Brejöes, Estrada, BR 4, 30-III-1967, Krapovickas 12784 (CTES); Brotas de Macaubas, Caminho para o Barreiro, na caatinga, 10-IV-2001, Nunes et al.. 274 (HUEFS, PACA); Caetité, $23 \mathrm{Km}$ al E de Caetité, camino a Brumado, na caatinga al borde del camino, 21-I-1997, Arbor et al. 7637 (CEPEC, NY, PACA); Cafarnaum, Próximo a Várzea do Cerco, 16-III-1984, Lima 51 (HRB); Campo Formoso, Morro do Cruzeiro, no cerrado, 31-I-1993, Thomas et al. 9691 (CEPEC, NY); Cansanção, 18 Km SW de Cansação, na caatinga, 16-I-1997, Arbor et al. 7289 (CEPEC, PACA); Candeal, $8 \mathrm{Km}$ al $\mathrm{N}$ de Tanquinho, camino a Ichu, na caatinga, al borde del camino, 15I-1997, Arbor et al. 7244 (CEPEC, PACA); Cocos, ca. 35-37 Km W de Cocos, proximidades de Jacaré, no cerrado, 17-V-2001, França et al. 3645 (ALCB); Corrrentina, on the road to Goiás, no cerrrado, 26-IV1980, Harley 21802 (SPF); Feira de Santana, Maria Quitéria, Serra de São José, na mata estacional,
6-III-2002, Van Den Berg et al. 908 (HUEFS); Gentio do Ouro, ca. $20 \mathrm{Km}$ de Xique-Xique, em campo rupestre, 16-VI-1994, Queiroz \& Nascimento 3956 (HUEFS); Ibicoara, Chapada Diamantina, Estrada para Abaíra a partir do entroncamento de Cascavel, $43 \mathrm{Km}$ de Abaíra, no campo rupestre, 4-XII-2003, Roque et al. 834 (ALCB); Ibotirama, Estrada Ibotirama-Bom Jesus da Lapa $\mathrm{Km} \mathrm{8,} \mathrm{na}$ caatinga, 1-VII-1983, Coradin et al., 6321 (CEN, CTES); Iraquara, Fazenda Pratinha, $16 \mathrm{Km} \mathrm{SSE} \mathrm{of}$ Iraquara ,margin Rio San Antonio, na caatinga, 14VI-1981, Mori et al. 14417 (NY); Jacobina, Serra da Jaboticaba, 21-VIII-1980, Fonseca 307 (HRB); Jussiape, caminho para Jussiape, 15-I-2003, Senna et al. 64 (HUEFS); Lençóis, Chapada Diamantina, ca. $3 \mathrm{Km} \mathrm{N}$, em restinga, 26-I-2000, Jardim et al. 2495 (CEPEC, PACA); Macaúbas, Pajeú, em área de cultivo abandonado, Hatschbach et al. 77097, 16VI-2004 (CTES); Mirangaba, 23-IV-1981, Fonseca 400 (HRB, MG); Morro do Chapéu, BA-426, 29 Km al NE de Morro do Chapéu, na caatinga, 17-I-1997, Arbor et al. 7449 (CEPEC, CTES, SI); Oliveira dos Brejinhos, Rodovia Oliveira dos Brejinhos a Macaúbas, BR 122, Km 8, na caatinga, 20-IV-1996, Hatschbach et al. 65095 (CEPEC, CTES, MBM); Paramirim, Estrada Paramirim-Caetité, na caatinga, 18-IV-2001, Silva et al. 86 (ALCB); Paratinga, na caatinga, 15-V-1978, Souza Silva 513 (SP, PACA); Piatã, ca. $16 \mathrm{Km}$ de Piatã, 26-IV-1980, Harley et al. 21802 (HUEFS, SPF); Porto Novo, Rodovia BA-349 ca. $1 \mathrm{Km}$ da estrada para Porto Novo, na caatinga, 15V-2001, Groppo Jr. et al. 715 (SPF, PACA); Santana do Riacho, Barauninha, na caatinga, 19-IV-1996, Hatschbach et al. 65050 (CTES); São Desidério, Bairro Estivas, no cerrado, 29-III-2002, Guedes et al. 9463 (ALCB); Serra Sincorá, 13-II-1977, Harley $18600(\mathrm{NY})$; Tanhaçu, 1-2 Km a SE, na caatinga degradada, 22-I-1997, Arbor et al. 7663 (CEPEC, CTES, SI); Tucano, ca $23 \mathrm{Km}$, na Estrada de Tucano para Euclides da Cunha, na borda da caatinga, 22III-1992, Carvalho et al. 3927 (CEPEC, NY). GoIÁs: Alvorada do Norte, Fazenda Estância Paraná, no cerrado, 24-VIII-2003, Sevilha et al. 3053 (CEN, PACA); Flores de Goiás, Km 36 da estrada Flores de Goiás/Alvorada do Norte, no cerrado, 9-IX-1994, Pereira 2618 (RB); São Domingos, Serra Geral, Córrego do Buriti, em campo cerrado, 13-V-2000, Hatschbach et al. 71008 (MBM). Minas Gerais: Formoso, Parque Nacional Grande Sertão Veredas, no cerrado, 30-IV-1999, Rodrigues-da-Silva 293 (IBGE); Grão Mogol, Rio Itacambiruçu, entre rochas, 
21-IV-1978, Hatschbach 41275 (CTES, MBM, NY); idem, Entre BR 251 e Grão Mogol, Cachoeira Véu de Noiva, na trilha para a cascata, 15-III-2007, Marchioretto 359 (PACA); Janaúba, BR- 112, Km 145, 13-I-1997, Hatschbach et al. 65699 (BHCB, CTES, MBM); Januária, Fazenda Raizama, no cerrado 28-III-1990, Mendonça et al. 1614 (IBGE); Rio Pardo de Minas, Distrito Serra Nova, Parque Estadual de Serra Nova, mata beira da cascata, 12-III2007, Marchioretto 328 (PACA); Santana do Riacho, Barauninha, na caatinga, 19-IV-1996, Hatschbach et al. 65050 (CEPEC). TocAntins: Itacajá, Reserva indígena Krahó, aldeia Pedra Branca, em campo úmido, 6-V-2000, Santos et al. 652 (CEN).

Material adicional examinado: BOLÍVIA: DePTo. SANTA CRUz: Andres Ibanez, on W side of city of Santa Cruz, 4-XII-1988, Nee 37017 (SP).

Moquin-Tandon (1849) descreveu a variedade acutifolia, incluída em Gomphrena tuberosa Spreng., comentando que a mesma possuía folhas ovaladoelípticas ou elíptico-agudas, ocorrendo no Piauí e citando como tipo a exsicata Gardner 2294. O autor questionou a possibilidade de ser uma espécie distinta (Moquin-Tandon 1849). Já Stützer (1935), a considerou como espécie distinta, elevando a variedade à categoria de espécie, colocando em sinonímia Gomphrena tuberosa variedade acutifolia. Siqueira \& Grandi (1986) relataram que é uma espécie pouco coletada e que, em Minas Gerais, ocorre em campos rupestres, junto aos riachos.

Pfaffia aphylla Suess., Repert. Spec. Nov. Regni Veg. 44: 40. 1938. Tipo: BRASIL. MinAs Gerais: Conselheiro da Mata, Brade 13464, VI-1934 (holótipo RB!, Isótipo B!). Fotografia do tipo (B!) Figura 2

Subarbusto, caule cilíndrico, ereto, estriado, glabro, engrossado nos nós, entrenós de 7-10 cm; afilo; raiz semilenhosa. Inflorescência em espigas de fascículos, simples ou dicotômica, terminal, pedúnculo médio, 5-6 $\mathrm{cm}$, breve piloso, tricomas setosos articulados, ráquis densamente velutina. Bráctea mediana ovalada a ovalado-lanceolada, hialina, densamente lanosa na extremidade do dorso, ápice acuminado, base glabra, uninervada, nervura proeminente, $2,5 \mathrm{~mm}$ compr., brácteas laterais ovalado-lanceoladas, densamente lanosas na extremidade do dorso, ápice aristado, base glabra, univervada, nervura proeminente, escura e larga na base, 2-2,5 mm compr.. Sépalas oblongo-lanceoladas, densamente lanosas, aspecto coriáceo, ápice agudo,
3-3,5 mm compr.. Tubo estaminal quase do tamanho das sépalas, filamentos laterais fimbriados, filamento anterífero menor, filiforme, anteras oblongas, $1 \mathrm{~mm}$ compr.. Ovário oblongo, 1-1,5 mm compr., estigma capitado.

Distribuição geográfica e hábitat: esta espécie, até o presente, foi encontrada somente no estado de Minas Gerais, em área de cerrado.

Material examinado: BRASIL. MinAs GERAIS: Gouveia, Córrego do Tigre, no cerrado, 5-IX-1971, Hatschbach 27024 (CTES, MBM).

Segundo Suessenguth (1938), a espécie se parece com $P$. denudata (Moq.) Kuntze no hábito e partes vegetativas (falta de folhas, caule ereto e duro), mas as flores se parecem com P. elata R.E. Fr. O autor comenta que as flores de $P$. aphylla, sem pedicelo, são em número de 6-8, localizadas na extremidade dos ramos, diferente das espécies mencionadas que apresentam flores isoladas nas extremidades dos ramos.

Pfaffia argyrea Pedersen, Bonplandia 10(1-4): 108. 2000. Tipo: BRASIL. Minas Gerais: Grão Mogol, 10 Km NW of Grão Mogol, solo arenoso, 21-111978, Hatschbach \& Kasper 41365 (holótipo MBM, isótipo CTES!).

\section{Figura 3}

Erva a subarbusto, caule semiprostrado, densamente folhoso, glabro a piloso, tricomas seríceos, articulados, entrenós de 0,8-2 cm compr.; raiz grossa, semilenhosa. Folhas ovalado-elípticas, 1,2-2 $\times 0,6-1 \mathrm{~cm}$, subsésseis, ápice agudo a acuminado, base obtusa a arredondada, face adaxial tomentosa a velutina, face abaxial velutina; inflorescência em espiga isolada, simples, terminal, pedúnculo longo, 7-8 cm compr., velutino, ráquis densamente velutina. Bráctea mediana ovalado-lanceolada, glabra a pilosa no dorso, escariosa, 1-4 mm compr., ápice atenuado, uninervada, brácteas laterais suborbiculares, ápice acuminado a mucronado, pilosas na extremidade do dorso, escariosas, 2,5-3,5 mm compr., uninervadas. Sépalas oblongas, 3-5 $\mathrm{mm}$ compr., ápice agudo, trinervadas, dorso tomentoso adpresso, na base pilosa, externamente tricomas longos, internamente, tricomas longos, ondulados. Tubo estaminal mais curto que as sépalas, filamentos laterais fimbriados, filamento anterífero agudo, anteras oblongas, $1 \mathrm{~mm}$ compr.. Ovário ovalado, $1 \mathrm{~mm}$ compr., estigma capitado- emarginado.

Distribuição geográfica e hábitat: espécie brasileira, encontrada até o presente somente no estado de Minas Gerais, em campos rupestres, com solo arenoso. 


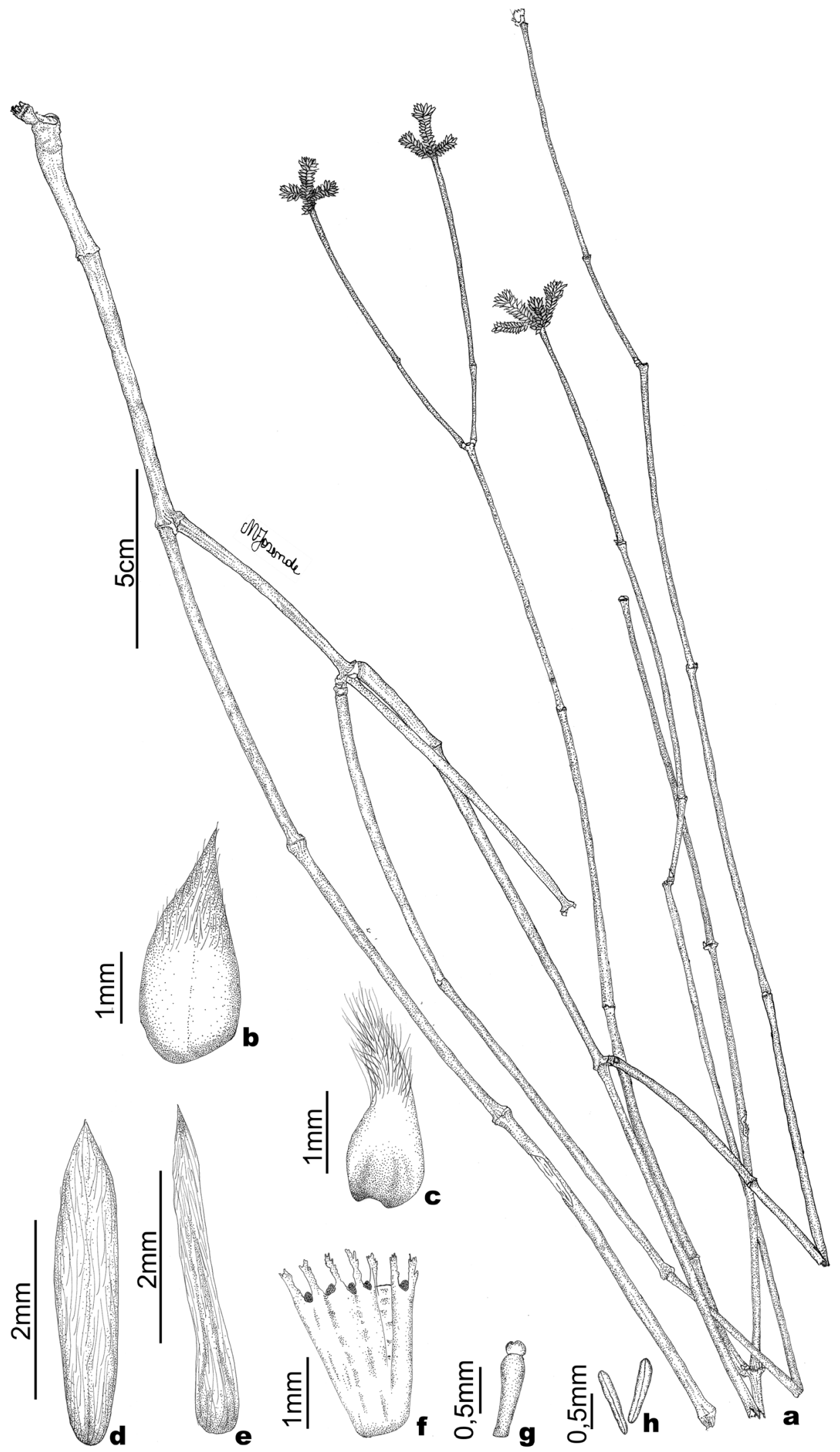

Figura 2. Pfaffia aphylla Suess. a. Ramo. b. Bráctea mediana. c. Bráctea lateral. d-e. Sépalas. f. Tubo estaminal. g. Ovário. h. Anteras (Hatschbach 27024, MBM).

Figure 2. Pfaffia aphylla Suess. a. Branch. b. Median bract. c. Lateral bract. d-e. Sepals. f. Staminal tube. g. Ovary; h. Anthers (Hatschbach 27024, MBM). 


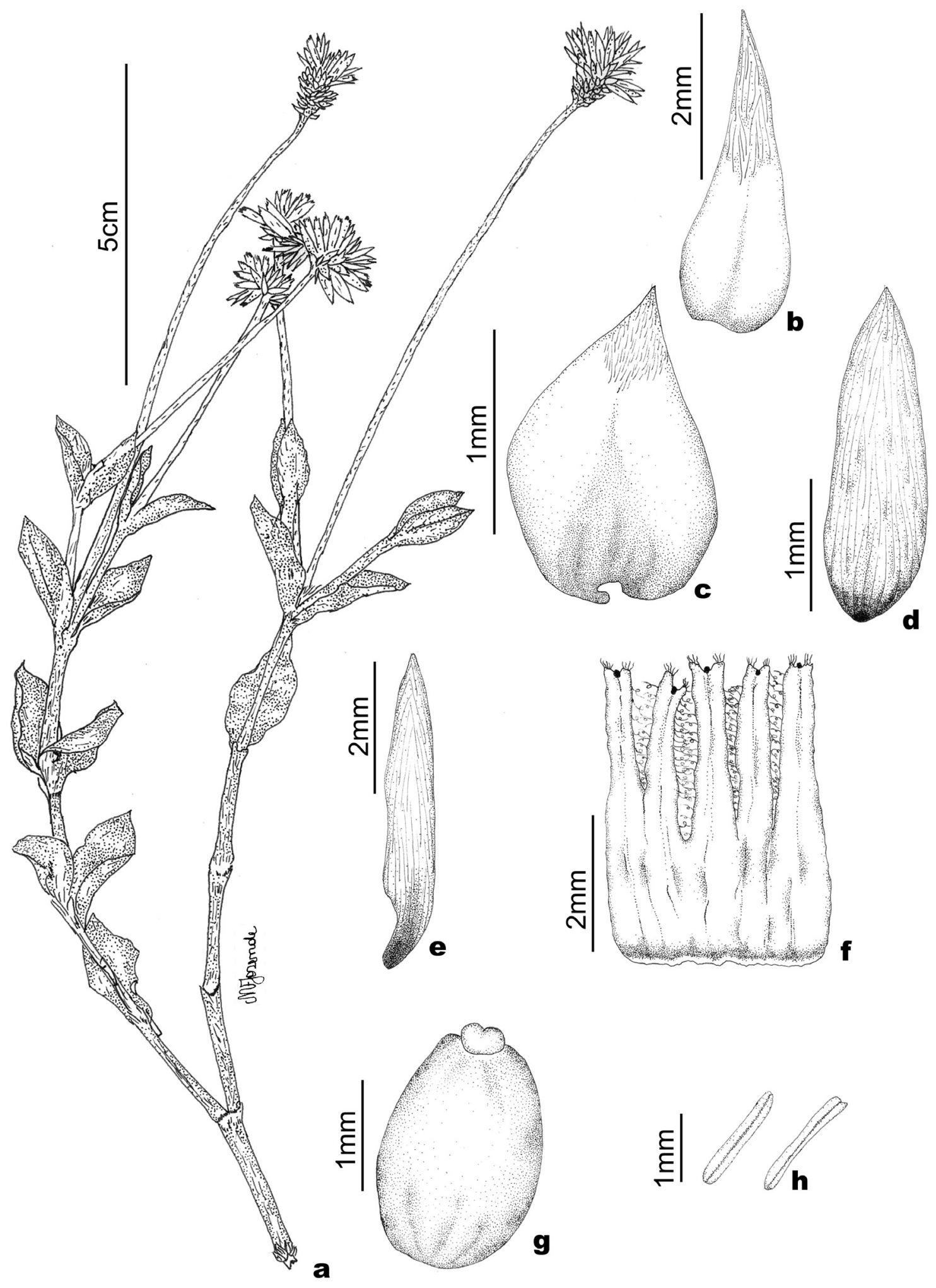

Figura 3. Pfaffia argyrea Pedersen. a. Ramo. b. Bráctea mediana. c. Bráctea lateral. d-e. Sépalas. f. Tubo estaminal. g. Ovário. h. Anteras (Silva et al. 13482, PACA).

Figure 3. Pfaffia argyrea Pedersen. a. Branch. b. Median bract. c. Lateral bract. d-e. Sepals. f. Staminal tube. g. Ovary. h. Anthers (Silva et al. 13482, PACA). 
Material examinado: BRASIL. MINAS GERAIS: Cristália, Sonora, em campo rupestre, 18-VII-1998, Hatschbach et al. 68045 (CTES, MBM); Grão Mogol, Vale do Rio Itacambiruçu, 14-VI-1990, Zappi et al. 12910 (SPF, PACA); idem, alto do Morro do Jambeiro, flanco da descida para o Córrego Escurinha, em campo arenoso, 7-IX-1990, Silva et al. 13482 (SPF, PACA).

Pedersen (2000), apesar de ter examinado somente o material-tipo, comenta que esta espécie assemelha-se à $P$. sericantha (Mart.) Pedersen, diferenciando-se principalmente, pela presença de um longo tufo de tricomas no interior das tépalas, próximo da base, o qual parece impedir alguma afinidade com outras espécies como $P$. acutifolia, $P$. elata e $P$. fruticolosa Suess.

Pfaffia cipoana Marchioretto, Miotto \& Siqueira, Rodriguésia 59(1): 130. 2008. Tipo: BRASIL. Minas Gerais: Itambé do Mato Dentro, Serra do Cipó, Serra das Bandeirinhas, about $18 \mathrm{Km}$ by foot trail WNW of settlement of Serra das Alves, N. Sra. do Carmo, 11-V-1982, N. Hensold 820 (holótipo PACA!, isótipos SPF!, NY!).

Figura 4

Subarbusto, caule ereto, ramos delgados, escuros, brilhantes, estriados, brevemente pilosos, tricomas setosos a híspidos, entrenós de 2,5-4,5 $\mathrm{cm}$; raiz semilenhosa. Folhas lanceoladas a linearlanceoladas, $1,5-3 \times 0,1-0,2 \mathrm{~cm}$, sésseis, ápice agudo, base aguda ou decurrente, faces adaxial e abaxial brevemente pilosas, tricomas híspidos. Inflorescência capituliforme isolada, simples, di ou tricotômica, terminal, pedúnculo curto a médio, 2,5$5 \mathrm{~cm}$, estriado, piloso, tricomas híspidos ferrugíneos, ráquis tomentosa. Bráctea mediana ovalada, bordos hialinos, nervura dorsal larga, escura, ápice apiculado a acuminado, 1,5-1,8 mm compr., brácteas laterais ovaladas a côncavas, quase hialinas, nervura dorsal proeminente, ápice acuminado, 1,5 $\mathrm{mm}$ compr., tricomas no dorso em direção ao ápice. Sépalas desiguais três externas oblongas densamente pilosas no dorso, ápice agudo, $4 \mathrm{~mm}$ compr., as internas um pouco menores, oblongas, densamente pilosas no dorso, ápice agudo. Tubo estaminal menor que as sépalas, filamentos laterais fimbriados, filamento anterífero filiforme, anteras lineares, $1 \mathrm{~mm}$ compr.. Ovário oblongo, $1 \mathrm{~mm}$ de compr., estigma capitado.

Distribuição geográfica e hábitat: até o presente só foi coletada no Brasil, no estado de Minas Gerais, em altitudes entre 1.300-1.500 m.
Material examinado: BRASIL. MINAS GERAIS: Itambé do Mato Dentro, Serra do Cipó, Serra das Bandeirinhas, about $18 \mathrm{Km}$ by foot trail WNW of settlement of Serra das Alves, N. Sra. do Carmo, 11V-1982, N. Hensold 820 (PACA, SPF, NY).

Marchioretto et al. (2008), comentaram que esta espécie é afim de $P$. denudata, diferenciando-se desta por apresentar ramos folhosos, folhas lanceoladas a linear-lanceoladas, com $3 \mathrm{~cm}$ de comprimento por $0,2 \mathrm{~cm}$ de largura, bráctea mediana com bordo hialino e nervura dorsal larga e escura além de sépalas oblongas. Marchioretto et al. (2008) argumentaram que o epíteto cipoana se refere ao local onde a mesma foi coletada: Serra do Cipó, Minas Gerais.

Pfaffia denudata (Moq.) Kuntze, Rev. Gen. 543. $1891 \equiv$ Gomphrena denutata Moq. in DC., Prodr. 13. 388. 1849. Tipo: BRASIL. MinAs Gerais: Serra do Frio, Vauthier 572, 1833 (Herbário Francavillano). Fotografias do Isótipo (P!, NY!). Figura 5

Erva, subarbusto a arbusto, 0,20-2 m de altura, caule ereto, ramoso, subtricotômico, estriado, levemente piloso, tricomas híspidos, articulados, entrenós de 3,5-20 cm compr.; raiz semilenhosa. Folhas raras, quando presentes, lineares a linearlanceoladas, 1,5-1,8 ×0,3-0,6 cm, ápice acuminado, base atenuada, faces adaxial e abaxial pilosas, tricomas híspidos, articulados. Inflorescência capituliforme, isolada, simples, di ou tricotômica, terminal, pedúnculo curto, 1-2,5 cm compr., piloso, tricomas híspidos, articulados, ráquis subinflada tomentosa. Bráctea mediana ovalada, mucronulada, $1,5 \mathrm{~mm}$ compr., brevemente pilosa, tricomas adpressos, brácteas laterais ovaladas, côncavas, dorso piloso, ápice atenuado, 1,5 mm compr.. Sépalas lanceoladas a ovalado-lanceoladas, dorso densamente piloso, tricomas alongados, alvos, ápice agudo, trinervadas, 3-5 mm compr. Tubo estaminal mais curto que as sépalas, filamentos laterais fimbriados, filamento anterífero agudo, anteras oblongas, 1,2 $\mathrm{mm}$ compr. Ovário obovalado, $0,5 \mathrm{~mm}$ compr., estigma capitadobilobado.

Distribuição geográfica e hábitat: ocorre no Brasil nos estados da Bahia, Distrito Federal, Goiás, Minas Gerais e no Paraná, em cerrados e campos rupestres, em locais de altitude entre 1.000-1.350 m, em solos arenosos e pedregosos.

Material examinado: BRASIL. BAHIA: Correntina, Velha da Galinha, Fazenda do Sr. Edgard Von der Bürcher, no cerrado, 24-VIII-1995, Fonseca et al. 

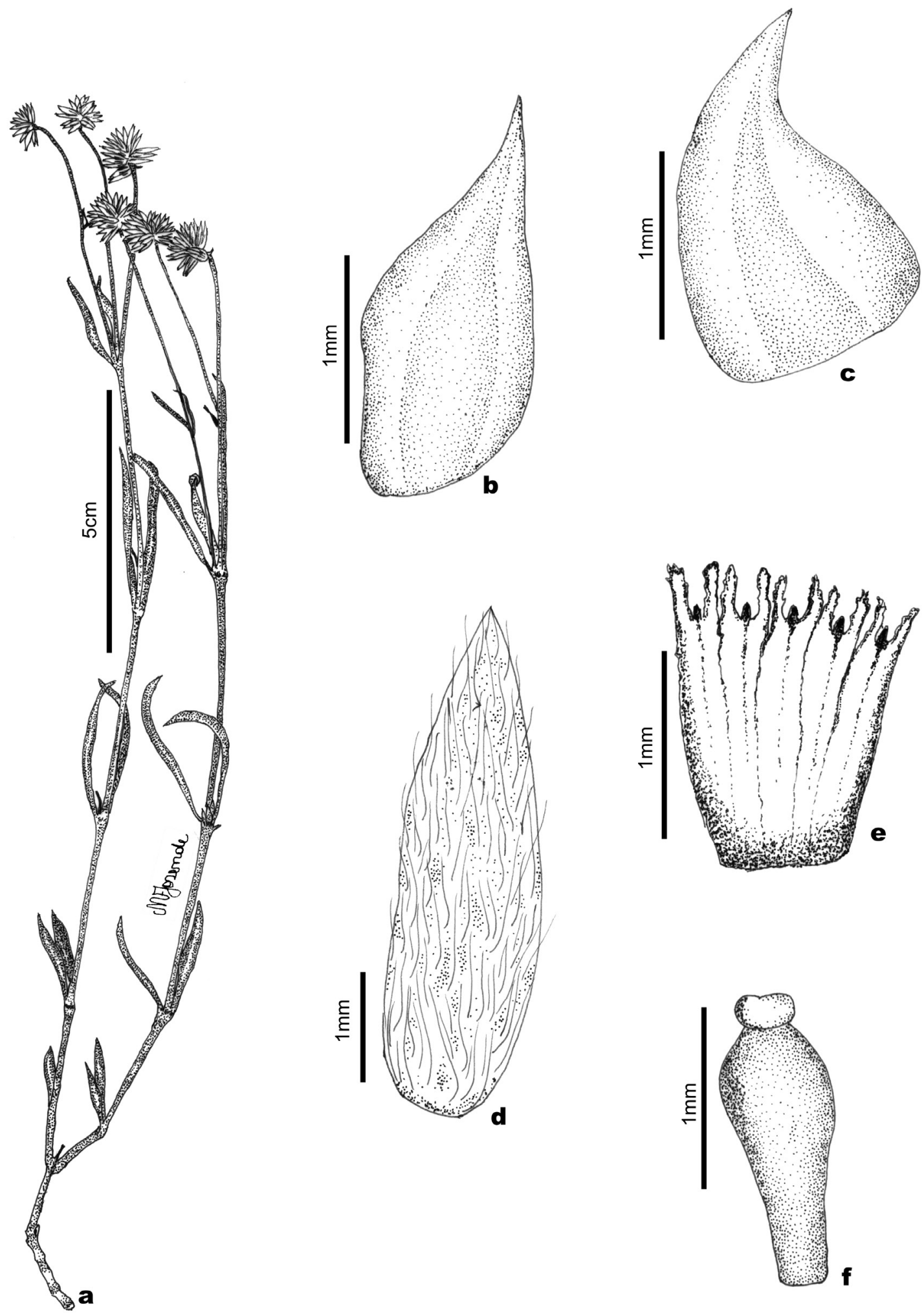

Figura 4. Pfaffia cipoana Marchioretto, Miotto \& Siqueira a. Ramo. b. Bráctea mediana. c. Bráctea lateral. d. Sépala. e. Tubo estaminal. f. Ovário (Hensold 820, PACA).

Figure 4. Pfaffia cipoana Marchioretto, Miotto \& Siqueira a. Branch. b. Median bract. c. Lateral bract. d. Sepal. e. Staminal tube. f. Ovary (Hensold 820, PACA). 


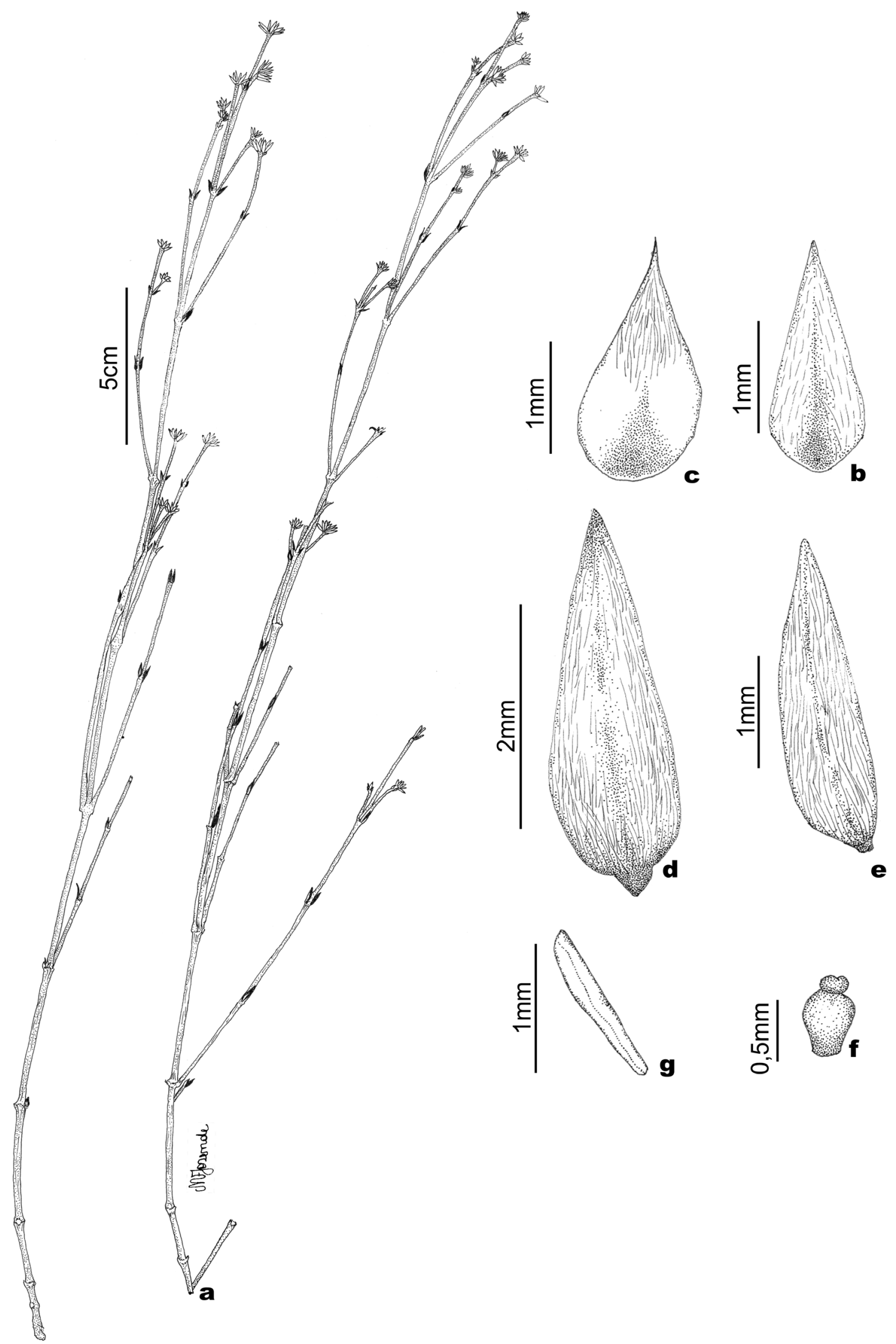

Figura 5. Pfaffia denudata (Moq.) Kuntze. a. Ramo. b. Bráctea mediana. c. Bráctea lateral. d-e. Sépalas. f. Ovário. g. Antera (Souza et al. 8506, ESA).

Figure 5. Pfaffia denudata (Moq.) Kuntze a. Branch. b. Median bract. c. Lateral bract. d-e. Sepals. f. Ovary. g. Anther (Souza et al. 8506, ESA). 
457 (HRCB). Distrito Federal: Cabeça do Veado, Caminho da Papuda, 2-IX-1960, Andrade et al. 340 (R); Chapada da Contagem, no cerrado, 17-II-1975, Hatschbach et al. 36229 (CTES); Jardim Botânico de Brasília, Trilha de entrada de visitação, 6-IX1999, Nóbrega 1006 (MBM); Sobradinho, 23-VII1964, Duarte 8266 \& Mattos 652 (RB); área da UNB, cabeceira de córrego sem nome, no cerrado, 27-VIII-1990, Alvarenga \& Silva 863 (CTES). GoiÁs: Pirenópolis, Cocalzinho, Santuário do Morro Cabeludo, no campo de areia quatzosa, 28-VIII-1993, Spett 62 (UB). Minas Gerais: Alto Congonhas, 12 Km NE de Cardeal Mota, hacia Conceicäo do Mato Dentro, Serra do Cipó, no campo rupestre, s.d, Arbor et al. 4693 (CTES); Congonhas do Norte, próximo à margem do Rio Preto, 23-IV-1982, Furlan et al. s.n (SPF 31140, PACA); Couto Magalhães, Chapada do Couto, 17-VII-1984, Furlan et al. s.n (SPF 33207, PACA); Datas, $2 \mathrm{Km}$ de Datas em direção a Serro, Km 462 da estrada em campo arenoso, 13-III-1995, Souza et al. 8506 (ESA, SPF); Diamantina, estrada de Sá Benta, no campo, 15-VII-1970, Duarte s.n (BHCB 8036); Estrada Diamantina-Conselheiro da Mata 30-X-1981, Giulietti et al. 2401 (RB); Gouveia, Km 66 da Estrada Curvelo-Diamantina, estrada para o Morro do Camilinho, Serra do Brejo Grande, 9-IV-1982, Furlan et al. s.n ( SPF 23450, PACA); Grão Mogol, Córrego das Mortes, 3-IX-1985, Kawasaki et al. s.n (HRCB); Santana do Pirapama, Fazenda Ihame, Serra do Cipó, Estrada Lagoa SantaConceição do Mato Dentro, Km 109, 22-III-1982, Pirani et al. 8053 (SPF, PACA); Santana do Riacho, Serra do Cipó, Estrada Lagoa Santa-Conceição do Mato Dentro, Km 109, no campo rupestre, 1-II-1987, Araújo 7705 (GUA); São Roque de Minas, 16-VII1995, Romero et al. 2445 (HRCB); Serro, Sítio de Manoel Joaquim, entre Capivari e Pico Itambé, em campo arenoso, 6-V-1942 Magalhães 1792 (BHCB); Serra do Cipó, $7 \mathrm{Km}$ NE de Cardeal Mota, camino a Conceição do Mato Dentro 8-II-1991 Arbor et al 4609 (CTES). PARANÁ: Curitiba, no campo 25-II1904 Dusén 3854 (R).

Seubert (1875) comentou que Moquin-Tandon (1849), para descrever Gomphrena denudata, baseouse nas característas do espécimen Vauthier 572, conservado no Herbário Francavillano. Siqueira \& Grandi (1986) destacaram que esta espécie é bastante freqüente em áreas de campos rupestres de Minas Gerais e que, até a data do trabalho, não havia sido coletada em áreas de cerrado. Esta espécie apresenta uma disjunção no estado do Paraná, apesar apesar de ter sido examinada somente uma coleta muito antiga (1904), a mesma não pode ser desprezada, por ser autêntica.

Pfaffia elata R.E. Fr., Ark Bot. 16. 12: 4. 1920. Tipo: BRASIL. Mato Grosso: inter Sta Anna da Chapada et Buriti 6-XI-1903 Malme II: 3489 (S).

Fotografia do tipo (S!, K!).

Figura 6

Subarbusto, 1,5-2 m. de altura, caule ereto, cilíndrico, tomentoso, entrenós de 13,5-14,5 cm compr.; raiz semilenhosa. Folhas orbiculares a elípticas, cartáceas, 4,5-15 × 3-6,5 cm, curto pecioladas, $0,5 \mathrm{~cm}$ compr., ápice mucronulado ou agudo, base rotunda, ambas as faces densamente pilosas, tricomas seríceos, sendo que a face abaxial apresenta nervuras proeminentes. Inflorescência capituliforme ou em espiga, isolada, tricotômica, terminal, pedúnculo médio a longo, $4-7 \mathrm{~cm}$ compr., rígido, seríceo-tomentoso, ráquis densamente tomentosa. Bráctea mediana ovalada, côncava, ápice cuspidado, uninervada, $4 \mathrm{~mm}$ compr., brácteas laterais ovalado-cordadas, ápice cuspidado, uninervadas, 2,5-4 mm compr.. Sépalas lanceoladas, ápice agudo, trinervadas, densamente pilosas, tricomas longos, articulados, 6-9 mm compr., entre as brácteas e sépalas grande quantidade de tricomas longos, alvacentos, articulados. Tubo estaminal longo, quase do tamanho das sépalas, filamentos laterais subulados, filamento anterífero filiforme, anteras oblongas, $2 \mathrm{~mm}$ compr.. Ovário obovalado, 2,5 mm compr., estigma capitado. Distribuição geográfica e hábitat: espécie brasileira, ocorrendo nos estados de Goiás, Mato Grosso e Mato Grosso do Sul, em cerrados.

Material examinado: BRASIL. GoIÁs: Mineiros, Estrada para Chapadão do Céu, a $32 \mathrm{Km}$ de Mineiros, em campo sujo na beira da estrada, 29-V-2002, Magenta et al. 475 (SPF). Mато Grosso: Cuiabá, São José da Serra, no cerrado da borda da serra, 17V-1973, Hatschbach 32038 (CTES, MBM); Santo Antonio do Leveger, BR 364, Serra de São Lourenço, Est. Velha Cuiabá-São Lourenço, próximo à linha de transissão, no cerrrado, 30-IX-1990, Windisch et al. 5731 (SJRP). Mato Grosso do Sul: Terrenos, Pedro Celestino, no cerrado, 18-V-1970 Hatschbach 24361 (CTES, MBM, SI).

Fries (1920) comentou que Pfaffia elata cresce espaçadamente no cerrado arenoso, juntamente com a vegetação arbustiva. $\mathrm{O}$ autor referiu que a espécie chama atenção pelo seu grande porte, podendo diferenciar-se dos seus parentes do gênero e ainda 


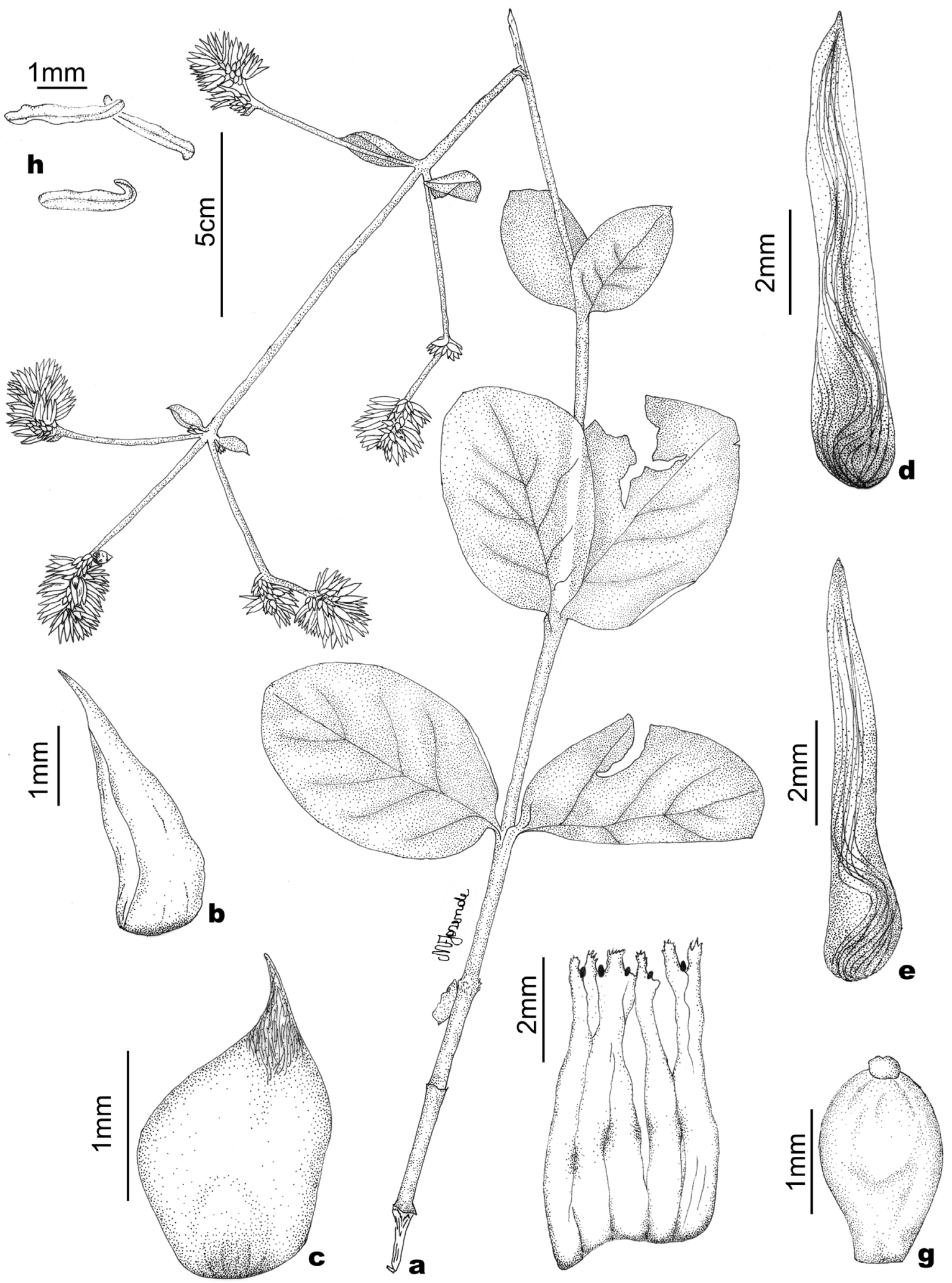

Figura 6. Pfaffia elata R. E. Fr. a. Ramo. b. Bráctea mediana vista lateral. c. Bráctea lateral. d-e. Sépalas. f. Tubo estaminal. g. Ovário. h. Anteras (Magenta et al. 475, SPF).

Figure 6. Pfaffia elata R. E. Fr. a. Branch. b. Median bract side view. c. Lateral bract. d-e. Sepals. f. Staminal tube. g. Ovary. h. Anthers (Magenta et al. 475, SPF). 
destacou que é facilmente reconhecida por suas folhas grandes, arredondadas e inflorescências muito subdivididas (Fries 1920).

Pfaffia glabrata Mart., Nov. Gen. Sp. P1. 2: 21. 1826. Tipo: Criscit in aquaticis umbrosis prope Sabará, oppidum Provinciae Minas Gerais, Martius. s.n, s.d $(\mathrm{M}) \equiv$ Gomphrena glabrata (Mart.) Moq., in DC., Prodr. 13. 388. 1849.

= Gomphrena glabrata (Mart.) Moq. var. angustifolia Seub. in Mart., Fl. Seub. 1: 194. 1875.

$=$ Gomphrena glabrata (Mart.) Moq. var. latifolia Seub. in Mart., Fl. Seub. 1: 194. 1875.

= Pfaffia glabrata Mart. var. rostrata Stützer, Repert. Beih. 88: 24. 1935. Tipo: GUIANA GALLICA: Poiteau s.n, 1826. Fotografia do tipo $(\mathrm{K}$ !).

Figura 7

Erva a subarbusto, 0,50-1 $\mathrm{m}$ de altura, caule ereto, ramoso, estriado, glabro a levemente piloso, entrenós de 3,5-9,5 cm; raiz semilenhosa. Folhas lanceoladas, linear-lanceoladas, 3,5-11 × 0,3-1,5 cm, curto-pecioladas, 0,5-1 cm compr., ápice acuminado, base atenuada, face adaxial glabra, face abaxial glabra a levemente pilosa, tricomas setosos. Inflorescência capituliforme, isolada, simples, terminal, pedúnculo médio, 4-5 cm compr., piloso, tricomas setosos, ráquis semi-inflada, vilosa a tomentosa. Bráctea mediana ovalado-lanceolada, glabra, acuminada, uninervada, 1,5-2 $\mathrm{mm}$ compr., brácteas laterais ovaladas, hialinas, acuminadas, uninervadas, 1,5 mm compr.. Sépalas escuras, oblongo-lanceoladas, glabras, ápice agudo, trinervadas, 3,5-4,5 $\mathrm{mm}$ compr.. Tubo estaminal mais curto que as sépalas, filamentos laterais ciliados, filamento anterífero agudo, anteras oblongo-lineares, $1 \mathrm{~mm}$ compr.. Ovário oblongo-ovalado, 1,5 $\mathrm{mm}$ compr., estigma capitado.

Distribuição geográfica e hábitat: a espécie ocorre desde o norte da América do Sul até o sul do Brasil, nos estados de Goiás, Mato Grosso, Minas Gerais, Paraná e São Paulo, em áreas de cerrados, com solos úmidos, com altitudes de aproximadamente $500 \mathrm{~m}$. Material examinado: BRASIL. GoIÁs: Abadiania, Fazenda Mato Seco, margem direita do Rio Corumbá, em mata de galeria bastante antropizada, 9-V-2003, Pereira-Silva et al. 7607 (CEN, PACA); Silvania, margem direita do Rio das Antas, em mata de galeria, 11-III-2003, Pereira-Silva et al. 7338 (CEN); $4 \mathrm{Km}$ by road $\mathrm{S}$ of Teresina, no cerrado,
18-III-1973, Anderson 7397 (CTES, NY, UB); sem localidade, 1841, Gardner 3965 (K, NY, P). Мато Grosso: Diamantino, Rio Padre Manoel, 13-V1995, Hatschbach 62730 et al. (CTES, MBM). Minas Gerais: à margem do Rio Abaeté, 1862, Lad. Netto 257 (R); Belo Horizonte, Cachoeira do Onça, na margem do brejo, 1-V-1934, Mello Barreto 905 (BHCB); Caldas, 23.II.1885, Regnell III 215 (K, P, R); Carmo do Rio Claro, Fazenda Córrego Bonito, 9-IX-1961, Andrade 1202 \& Emmerich 1163 (R); Fazenda Chichiu, no cerrado, 16-VII-1957, Heringer 5676 (SP); Formoso, Parque Nacional Grande Sertão Veredas, nas margens do Rio Mato Grande, 29-IV-1999, Rodrigues-da-Silva et al. 260 (HRCB, NY); Guaraciaba, UHE Jumerim, Rio Piranga, nas margens do rio, 20-VI-2003, Tameirão Neto 3640 (BHCB); Ibiá, Córrego José Nunes, 5-III-1988, Pedralli et al. s.n (CTES); Perdizes, Rio Capivara, 31-X-1986, Pedrali \& Meyer s.n (BHCB1598); Rib. Brejão, ST 1, marginal, 13-VII1987, Torres \& Mir 37 (BHCB); Rib. Rocinha ST 1, marginal, 14-VII-1987, Torres \& Mir 39 (BHCB); Sem localidade, 1816-1821, Saint-Hilaire 2333 (P). PARANÁ: Jaguariaíva, Rio Jaguariaíva, nas margens rochosas do rio, 13-XI-1974, Hatschbach 35347 (CTES, MBM, SI); Säo José da Boa Vista, Rio Jaguariaiva, Corredeira, junto as corredeiras, 19XI-1970, Hatschbach 25555 (CTES); Tomazina, Salto Cavalcante, Rio das Cinzas, entre rochas às margens do rio, 19-III-1994, Hatschbach et al. 60678 (CTES, MBM). São PAUlo: Amparo, Monte Alegre, 27-III-1943, Kuhlmann 391 (SP); Jeriquara, nas ilhotas do Rio Ponta Nova, Fazenda Estiva, 17III-1964, Mattos \& Bicalho 11621 (SP); Piracicaba, 1914, Souza 212 (ESA); Santa Cruz do Rio Pardo, nas margens do Rio Pardo, 14-VII-1959, Válio 12 (SP).

Material adicional examinados PARAGUAI. Amambay: 12-XII-2003, Múlgura 3710 (CTES, SI); Cordilleras, Areguá, 12-VIII-1974, Arenas 892 (CTES). ARGENTINA. Missiones: Salto Iguazú, 2-IV-1913, Rodrigues 781 (CTES, SI).

O epíteto específico refere-se à escassa pilosidade da espécie (Smith \& Downs 1972). Segundo os autores, a ocorrência da espécie no estado de Santa Catarina parece pouco provável porque o seu limite austral ocorre nos cerrados de Jaguariaíva, no nordeste do Paraná (Smith \& Downs 1972). Siqueira \& Grandi (1986) comentaram que a espécie é pouco frequente em Minas Gerais, tendo sido coletada somente em áreas de cerrado. 




Figura 7. Pfaffia glabrata Mart. a. Hábito. b. Bráctea mediana. c. Bráctea lateral. d-e. Sépalas. f. Tubo estaminal. g. Ovário. h. Anteras (Hatschbach 35437, MBM).

Figure 7. Pfaffia glabrata Mart. a. Habit. b. Median bract. c. Lateral bract. d-e. Sepals. f. Staminal tube. g. Ovary. h. Anthers (Hatschbach 35437 , 
Pfaffia gnaphaloides (L.f.) Mart., Nov. Gen. Sp. Pl. 2: 24. 1826 三 Celosia gnaphaloides L.f., Suppl. Plant.: 161. $1781 \equiv$ Gomphrena gnaphaloides (L.f.) Vahl, R. \& S., Syst. Veg. 5: 542. 1819. Tipo: Montevideo, in Brasília: Commerson s.n (MPU). Fotografias do Holótipo e Isótipo (MPU!).

$=$ Gomphrena gnaphaloides var. planifolia Seub. in DC., Prodr.13(2): 198. 1849.

= Gomphrena gnaphaloides var. floccosa Seub. in DC., Prodr. 13(2): 198. 1849.

= Gomphrena lanata Poir., Encycl. Suppl. 1: 315 . 1810. (non Gomphrena lanata R.Br., Prodr. Fl . N. Holl. 1: 46. 1810) E Pfaffia lanata (Poir.) Gibert., Enum. P1. Montev.: 73. 1873. Tipo: ARGENTINA. Buenos Aires: Commers (Herb. Poiret). Isótipo (P!). Fotografia do Isótipo (P!).

= Gomphrena lanata var. parvifolia Moq. in DC., Prodr.13(2): 390. 1849. Tipo: Sine loco: Poiret (P!). Fotografia do tipo (P!).

$=$ Gomphrena lanata var. oblongifolia Moq. in DC., Prodr.13(2): 390. 1849 三 Pfaffia lanata var. oblongifolia (Moq.) Stützer, Repert. Spec. Nov. Regni Veg. 88: 27. 1935. Tipo: ARGENTINA. Buenos Aires: Hook 837 (P!). Fotografia do tipo (P!).

$=$ Gomphrena lanata var. latifolia Seub. in Mart., Fl. Br. 5(1): 197. 1875 三 Pfaffia lanata var. latifolia (Seub.) Stützer, Repert. Spec. Nov. Regni Veg. 88: 27. 1935.

= Pfaffia lanata var. peretiana Kuntze., Rev. Gen. P1. 2: 544. 1891.

= Pfaffia lanata var. discolor Suess., Repert. Spec. Nov. Regni Veg. 35: 332. 1934.

= Pfaffia lanata f. parvifolia (Moq.) Stützer, Repert. Spec. Nov. Regni Veg. 88: 28.1935.

$=$ Gomphrena poiretiana Schult., in R. \& S., Syst. Veg. 5: 541. $1819 \equiv$ Oplotheca poiretiana (Schult.) Mart., Acta Acad. Caes. Leopold. Carol. Nat. Cur. 13(1): 297. 1826 三 Pfaffia poiretiana (Schult.) Stuchl., Repert. Spec. Nov. Regni Veg. 12: 358. 1913.

$=$ Pfaffia tomentosa Mart., Nov. Gen. Sp. Pl. 2: 24. 1826.

= Gomphrena helichrysoides Moq., l.c. $\equiv$ Pfaffia helichrysoides (Moq.) Kuntze, Rev. Gen. Pl.

544. 1891.Tipo: BRASIL. Minas Gerais: 1811 Clausen 25, (Isótipo P!); Fotografia do Isótipo (P!); BRASIL, Minas Gerais: Clausen 45, abril 1840. Fotografias do tipo (K!, NY!).

= Gomphrena phagnoides Griseb., Abh. Königl.
Ges. Wiss. Göttingen 19: 34. 1874.

= Pfaffia tenuis N.E. Br., Trans. Proc. Bot. Soc. Edinb. 20: 08. 1894. Tipo: URUGUAY. Conception: Quinta de Sagastume, Quinta de Colegrio XI-1876. Lorentz 998. Fotografia do tipo $(\mathrm{K} !)$.

Figura 8

Erva a subarbusto, 0,10-0,70 m compr. de altura, caule ereto, simples ou ramificado, estriado, lanoso, esbranquiçado, entrenós de 2,5-10 cm; raiz lenhosa. Folhas ovaladas, elípticas, lanceoladas, oblongolanceoladas, linear-lanceoladas, cartáceas, 1,7-6,8 $\times$ 0,7-2,3 cm, sésseis; ápice agudo a acuminado; base atenuada, face adaxial verde-acinzentada, denso lanosa, nervuras pouco nítidas, face abaxial brancoacinzentada, denso tomentosa, nervura principal proeminente. Inflorescência capituliforme, isolada, simples, terminal, pedúnculo curto a longo, $2-10 \mathrm{~cm}$ compr., densamente lanoso, ráquis inflada lanosa. Bráctea mediana ovalada a oblonga, ápice atenuado, ciliado, nervura central proeminente, extremidade dorsal superior pilosa, tricomas híspidos, 2,5-3,5 $\mathrm{mm}$ compr., brácteas laterais oblongas a ovaladas, côncavas, extremidade dorsal pilosa, tricomas híspidos, ápice atenuado, ciliado, 3-6 mm compr. Sépalas ovalado-lanceoladas a oblongo-lanceoladas, 4,5-7 mm compr. densamente pilosas a vilosas na base, tricomas longos eretos e brilhantes, ápice agudo a obtuso, trinervadas. Tubo estaminal menor que as sépalas ou quase do mesmo tamanho, margens longociliadas, filamentos laterais crenulados a ciliados, filamento anterífero estreito e subulado, anteras linear-oblongas, $1 \mathrm{~mm}$ compr. Ovário oblongo, 1-2 $\mathrm{mm}$ compr., estigma capitado, levemente bilobado.

Distribuição geográfica e hábitat:Pfaffiagnaphaloides no Brasil, é encontrada nos estados da Bahia, Goiás, Minas Gerais, Mato Grosso, Mato Grosso do Sul, Paraná, Rio Grande do Sul, Santa Catarina, São Paulo e Tocantins, em campos limpos e pedregosos, campos rupestres, em altitudes que variam de 1.005$1.500 \mathrm{~m}$. Ocorre também na Argentina, Bolívia, Paraguai e Uruguai.

Material selecionado: BRASIL. BAHIA: Sine loco, Serra do Chuquê, 1913, Luetzelburg 15211 (NY). GoiÁs: Alto Paraíso, Estrada Alto Paraíso-Teresina, 11-X-1979, Heringer et al. 2502 (IBGE); Alvorada do Norte, $25 \mathrm{Km} \mathrm{S}$, Rod. BR-020, no campo cerrado, 11-X-1976, Hatschbach 39134 (CTES, MBM); Mineiros, Parque Nacional das Emas, no campo sujo, 12-I-1991, Brochado 134 (CTES, IBGE); Niquelândia, Companhia de Níquel Tocantins, 


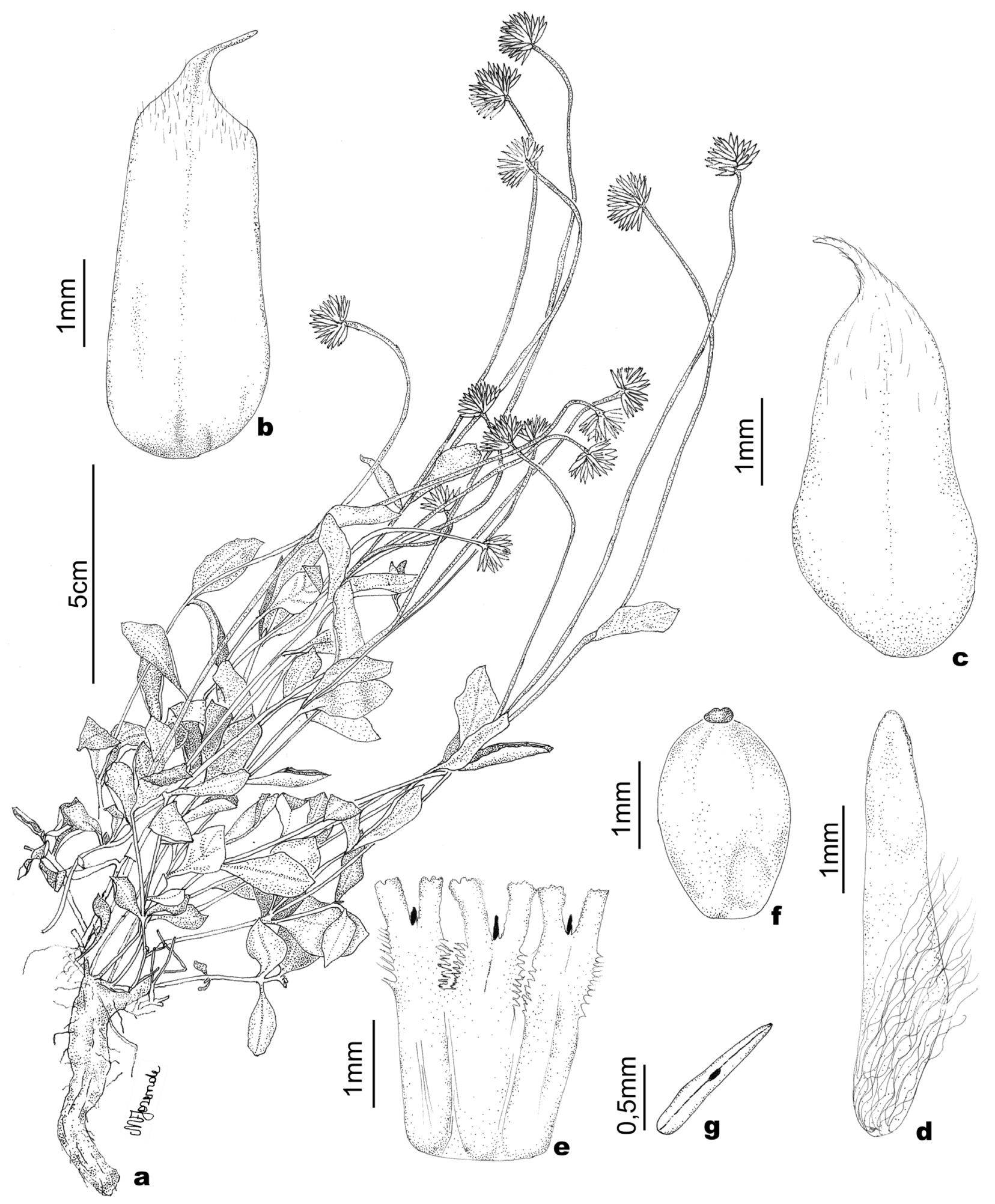

Figura 8. Pfaffia gnaphaloides (L.f.) Mart. a. Hábito. b. Bráctea mediana. c. Bráctea lateral. d. Sépala. e. Tubo estaminal. f. Ovário. g. Antera (Marchioretto 236, PACA).

Figure 8. Pfaffia gnaphaloides (L.f.) Mart. a. Habit. b. Median bract. c. Lateral bract. d. Sepal. e. Staminal tube. f. Ovary. g. Anther (Marchioretto 236, PACA). 
estrada à esquerda da mina de Níquel, ca $2 \mathrm{Km}$ da estrada, no campo, 1-X-1997, Mendonça et al. 3101 (IBGE). Mato Grosso: Brilhante, Rio Brilhante, Rod. BR 267, Entroncamento, em campo cerrado, 22-X-1970, Hatschbach 25047 (CTES, MBM); Cuiabá, 19-XI-1902, Malme 2618 (R). Mato Grosso Do Sul: Campo Grande, Rio Anhanduí, no cerrado, 12-VII-1969, Hatschbach et al. 21826 (CTES, MBM); Selvíria, no cerrado, 5-XI-1985, Barros 1187 (SP). Minas Gerais: Brumadinho, Retiro das Pedras, no campo, 28-X-1997, Barros et al. 180 (BHCB); Conceição, Fazenda Palácio, Serra do Cipó, 22-XII1948, Palacios 3596 (R); Frutal, Arredores, Serra do Cipó, Km 130, margem do Rio, no campo, 10XII-1949, Duarte 2260 (MG); Itabirito, Serra da Moeda, próximo a lanchonete Mirante da serra, na BR 040, 12-VII-2002, Viana 695 (BHCB); Lima, Morro do Chapéu, no cerrado, 22-IX-1982, Andrade et al. 1176 (BHCB); Moeda, Serra da Moeda, em campo rupestre, 4-X-1989, Grandi 2699 (BHCB); Nova Lima, Retiro das Pedras, no campo rupestre sobre canga, 22-X-1999, Lombardi 3327 (BHCB); Ouro Preto, Hargreaves, no campo, 9-I-1942, MelloBarreto 11278 (BHCB); Prata, 5 Km de Prata em direção a Ituiutaba, no cerrado, 13-VII-2000, Souza et al. 23775 (ESA); Santa Luzia, Serra do Cipó, Km 131, Palácio, no campo, 25-XI-1938, MelloBarreto 8523 (BHCB); Santana do Riacho, Km 120 da rodovia Belo Horizonte-Conceição do Mato Dentro, no campo rupestre, 8-XI-1980, Furlan et al. 6724 (RB); São Sebastião do Paraíso, Serrinha, 12-XI-1944, Irmão Teodoro 524 (R); Serra de São José d' El Rei, XI-1896, Silveira 1883 (R); Serra de Ouro Grosso, no Campo de ressurgência, 4-X.1997, Vianna et al. 2399 (GUA); Serra do Cipó, Km 130 margem do rio, no campo, 10-XII-1949, Duarte 2260 (NY); Uberava, 18-I-1948, Regnel lI 268, (R). Paraná: Arapoti, Rio das Cinzas, Barra dos Perdizes, no cerrado, 23-X-1961, Hatschbach s.n (MBM); Campo Mourão, no cerrado, 14-X-1965, Hatschbach 13005 (MBM); Colombo, Capivari, no campo encosta de morro, 4-XI-1971, Hatschbach 27707 (CTES, MBM); Ipiranga, Faxinal de Tanque, em campo graminoso, 20-XII-1970, Hatschbach 25906 (CTES); Jaguaraíva, Parque Estadual do Cerrado, no campo cerrado, 2-XI-1998, Ribas 2779 (MBM); Lapa, Volta Grande, no campo limpo seco, 13-XI-1999, Cordeiro et al. 1572 (CTES, HUEFS); Palmeira, Fazenda Santa Rita, em campo limpo, Dombrowski 14186, 22-XI-1989 (MBM); Ponta Grossa, Passo do Pupo, no campo limpo seco, 12-X-
1995, Poliquesi \& Cruz 457 (BHCB); Serra de Säo Luis, 19-I-1985, Ferrucci et al. 278 (CTES); Volta Grande, no campo limpo, 13-XI-1999, Cordeiro et al. 1572 (HUEFS, MBM). Piauí: Sine loco, 1841, Gardner VII, 2948 (NY). Rio Grande do Sul: Aceguá, BR 153, Km 40, 19-XI-2005, Miotto 2259 (ICN); Alegrete, próximo a Reserva Biológica do Ibirapuitã, em campo sujo, 20-XI-2003, Marchioretto 213 (PACA); Bagé, na beira do Rio Cabuçu, 17-XI2003, Marchioretto 129 (PACA); Caçapava do Sul, $5 \mathrm{~km}$ ao norte de Lavras do Sul, próximo da estrada, 6-XII-1993, Bastos 400 (PACA); Cruz Alta, 10-IV1958, PNC 1128 (ICN5890); Carazinho, Campo da Granja Pinheirinho W de Carazinho, 2-X-1971, Lindeman et al. s.n (CTES, ICN 8203); Dom Pedrito, Fazenda da Toca, no campo, Marchioretto 137, 18XI-2003 (PACA); Montenegro, Estação Azevedo p. Montenegro, in siccis rupestribus graminosis, 17-X-1945, Henz s.n (PACA32701); Palmeira das Missões, na rodovia Sarandi-Palmeira, no campo sujo, 18-III-1980, Mattos et al. 21983 (HAS); Parecí p. Montenegro, in siccis graminosis, 1944, Rambo 26465 (PACA); Quaraí, Cerro do Jarau, no campo, 20-XI-2003, Marchioretto 161 (PACA); Rosário do Sul, BR $290 \mathrm{Km} \mathrm{497,} \mathrm{na} \mathrm{beira} \mathrm{da} \mathrm{estrada,} \mathrm{20-XI-}$ 2003, Marchioretto 236 (PACA); Santa Bárbara do Sul, 24.X.1974, Arzivenco et al. s.n (ICN42279); Santa Rosa, 17-X-1973, Valls et al. s.n (ICN30765); Santana do Livramento, Cerro Palomas, no alto do cerro, 18-XI-2003, Marchioretto 143 (PACA); idem, próximo do Rio Cati, na margem do arroio, 18-XI2003, Marchioretto 149 (PACA); Santo Angelo, Granja Piratini, no campo, 15-XI-1977, Irgang s.n (ICN35627); Säo Francisco de Paula, Fazenda Capão do Ipê, junto a rochedos, 23-X-2004, Wasum 2207 (PACA); Sarandí, $5 \mathrm{Km}$ E, no campo, 30-X1971, Lindmann et al. (CTES, ICN8819); Torres, Três Cachoeiras, Chimarrão, I-1954, Vidal IV-468 (CTES, R); Uruguaiana, Granja Guará, no campo, 19-XI-2003, Marchioretto 168 (PACA); idem, BR 472, Arroio Imbaá, próximo à ponte em beira de estrada, Marchioretto, 19-XI-2003, 190 (PACA); SAnta Catarina: Bom Jardim da Serra, nas encostas do Capivari, acima da Serra Geral, I1891, Ule 1864 (R, SI); Lages, in rupestribus subsiccis, 10I-1951, Sehnem 5484 (B, PACA, SI). São Paulo: Campinas, Jardim Chapadão, 18-IX-1936, Santoro s.n (IAN35427, IAC); Itapetininga, Rodovia Raposo Tavares, Km 150, no cerrado queimado, 17-VII-1962, Labouriau 122 (SP); Itapeva, Estação Ecológica de Itapeva, 12-XI-1994, Souza et al. 7059 
(ESA); Itararé, Córrego da Água do Porco, no campo limpo, 24-IX-1989, Scaramuzza et al. 590 (ESA); Itirapina, no campo arenoso, 25-IX-1940, Toledo et al. s.n (SP); Moji-Guaçu, Martinho Prado, Reserva Biológica da Fazenda Campininha, 17-XI-1981, Mantovani 1271 (SP); Pirassununga, Emas, Km 4 da Estrada Pirassununga-Emas, no cerrado, 4-X-1977, Jung et al. 151 (SP); Prata, 5 Km de Prata em direção a Itaiutaba, no cerrado, 13-VII-2000, Souza et al. 23775 (ESA); São Carlos, Estrada entre Itirapina e Represa do Lobo, próximo ao pedágio municipal, no cerrado, 10-XI-1995, Souza et al. 9346 (ESA). Tocantins: Brejinho de Nazaré, próximo à Fazenda Capivara, no cerrado, 20-X-2000, Soares et al. 1099 (HTO, IBGE); Dianopolis, no campo sujo, 24-IX2003, Scariot et al. 669 (CEN, PACA); Miracema do Tocantins, acesso ao Morro Perdido, no cerrado baixo, aberto queimado, 25-IX-1998, Árbocz 6169 (HTO); Palmas, margem da rod. TO-010 Km, no cerrado aberto, queimado, enfase de rebrota, 29-X1998, Árbocz 6192 (HTO, IBGE,); Paraná, local do futuro eixo da barragem São Salvador, no cerrado, 3-VII-2002, Pereira-Silva et al. 6530 (CEN).

Material adicional examinado ARGENTINA. Buenos Aires, Villarino, Road Bahia Blanca to town of Rio Colorado, 16-XII-1938, Eyerdan et al. 23505 (SI); idem, Sierra de Zapla, Mina 9 de Octubre, 13XI-1980, Cabrera et al. 31968 (SI); idem, Tandil, Alto Lucero, 24-XI-1937, Troncoso 1259 (SI); idem, Gral Pueyrredón, Sierra de los Padres, 16-XII1971, Angel et al. 1864 (SI); Córdoba: Córdoba, 6-XI-1959, Ariza-Espinar 517 (SI); idem, General Roca, 3-XI-1971, Hunziker 21396 (SI); idem, La Redución, 28-XII-1935, Burkart 7170 (SI); idem, General San Martín, 3-IV-1976, Astegiano, 86 (SI); idem, Marcos Juarez, 3-XI-1963, Hunziker 16615 (SI); Córdoba, Río Cuarto, 1-XI-1982, Bernardello 382 (SI); idem, Tercero Arriba, 20-X-1973, Subils 1829 (SI); Corrientes: Corrientes, em campo per la via férrea, II-1918, Fiebrig 12652 (SI); Entre Rios, Villaguay, Sta Martha, 1937, Mück 36 (SI); JusuY: Capital, camino al Cadillal, 17.XI.1978, Cabrera et al. 29953 (SI); Misiones: Candelária, 29-IV-1997, Morrone 2214 (SI); idem, 26-IX-1997, Zuloaga 6548 (SI); Concepción, 29-IX-2004, Romero 4071 (SI); idem, Coronel Pringles, 4-XII-1995, Cerana 1318 (SI); Misiones, 30-X-1968, Anderson 1351 (SI); idem, San Ignácio, 23-IX-1999, Biganzoli 620 (SI); idem, Santana, 17-IV-95, Rodrigues s.n (SI 6395); Salta: Rosário, Los Banos, 26-I-1929, Venturini 1910 (SI); Santa Fé:, Castilhos, Monte Próximo de Lehmnan, 1964, Fossatti 601 (SI); Tucuman:, Catriló, Lonquinay; idem, 15-XII-1944, Fortuna 38 (SI); idem, San Luis, Libertador General San Martín, 15-I-1960, Hunziker 14634, (SI). BOLIVIA. SANTA Cruz: Lara, Campo seco C. Buena Vista, 22-IX-1916, Steinbach 2834 (SI). PARAGUAI. Amambay: 23-X1994, Krapovickas 45937 (CTES, SI); CAaguazÚ: 1905, Hassler 111 (SI); idem, Pedro Juan Cabellero, $10 \mathrm{Km}$ divisa com Brasil, Km 15, no cerrado, 18-XI1963, Gomes Jr 1455 (SP). URUGUAI. Cerro Aguiar, S. Animas, XII-1938, Chebataroff 2806 (BHCB); Juan Jackson p Soriano, in siccis graminosis, 6-XII1935, Rosengurt 243 (PACA); La Colonia, Colonia Luiza, I-1910, Rua s.n (SI); Maldonado, 6-XII-1997, Neffa 405 (CTES, SI); Montevideu, Barra do Rio Santa Luzia, no campo limpo, 1951, Mattos 1748 (HAS); San Carlos, Maldonado, en la arena, s.d, Felippone 4952 (SI); Tacuarembó, 11-XII-1997, Neffa 422 (CTES, SI).

O epíteto provém da semelhança com espécies de Gnaphallium L. Segundo Smith \& Downs (1972) Pfaffia gnaphaloides é vulgarmente conhecida como corango-de-seda.ParaHandro(1967), P.gnaphaloides apresenta epiderme adaxial com poucos tricomas e estômatos, além de células muito grandes. A epiderme abaxial, ao contrário, tem enorme quantidade de tricomas e estômatos. Os tricomas sempre são pluricelulares, às vezes, parcialmente lignificados, sendo que estes se situam sobre uma única célula epidérmica. As células dos tricomas são unidas por dentes que se encaixam perfeitamente, e a superfície é sempre lisa. Quanto ao comprimento e espessura, os tricomas são extremamente delgados e finos. Os estômatos são geralmente do tipo anomocítico, ocasionalmente, paracítico, situam-se geralmente no plano superior às demais células epidérmicas, sendo elevados na face abaxial, enquanto na face adaxial situam-se em depressões.

De acordo com Pedersen (1967), Pfaffia gnaphaloides e $P$. helichrysoides foram motivo de grandes confusões nomenclaturais desde Linnaeus (1781). Moquin-Tandon (1849) designou-as de Gomphrena gnaphaloides e $G$. helichrysoides, como espécies distintas. Seubert (1875) considerou somente a espécie Gomphrena gnaphaloides (L.f.) Vahl., possivelmente, por ser o nome mais antigo e, portanto, prioritário. Suessenguth (1934) citou Pfaffia helichrysoides para o Brasil e disse que esta deveria ser incluída em Pfaffia gnaphaloides. Stützer (1935) comentou que existem semelhanças entre as duas espécies, não sendo constantes os caracteres 
diferenciais e existindo muitas formas intermediárias. Stützer (1935) sugeriu reuní-las sob o nome de Pfaffia helichrysoides (Moq.) O. K. Pedersen (1967) demonstrou que o conceito de prioridade estava errado, mas manteve as duas espécies separadas. Vasconcellos (1986) comentou que, após examinar material de vários Estados brasileiros e também da Argentina, não encontrou características constantes para a diferenciação entre as duas espécies. Vasconcellos (1986) salientou que seguiu a interpretação de Seubert (1875), Suessenguth (1934) e Stützer (1935) e considerou uma única espécie usando o nome mais antigo e prioritário, como fora indicado por Pedersen (1967.), designando-a de Pfaffia gnaphaloides (L.f) Mart. Neste trabalho, segue-se a interpretação de Vasconcellos (1986) por concordar-se plenamente com suas considerações.

Pfaffia hirtula Mart., Nov. Gen. Sp. Pl. 2: 24. 1826. $\equiv$ Gomphrena hirtula (Mart.) Moq., in DC. Prodr. 13. 388. 1849. Tipo: BRASIL. Minas Gerais: in editis campis Serro Frio, Martius s.n (M).

Figura 9

Erva a subarbusto, caule ereto, ramoso, estriado, glabro a piloso, tricomas hírtulos, articulados, entrenós de 3-6 cm compr.; raiz semilenhosa. Folhas lineares, oblongo-lineares a oblongas, 1-2 × 0,2-0,5 $\mathrm{cm}$, sésseis a curto-pecioladas, $0,3 \mathrm{~cm}$ de compr.; ápice acuminado, base atenuada; faces adaxial e abaxial levemente pilosas, tricomas hírtulos, articulados. Inflorescência capituliforme, isolada, simples ou tricotômica, terminal, pedúnculo médio, 4-6 cm compr., levemente piloso, tricomas hírtulos, ráquis levemente inflada, vilosa. Bráctea mediana ovalada, mais ou menos côncava, ápice acuminado, extremidade do dorso piloso, uninervada, $2 \mathrm{~mm}$ compr., brácteas laterais ovaladas, ápice acuminado, extremidade do dorso piloso, uninervadas, nervura proeminente, $2 \mathrm{~mm}$ compr. Sépalas lanceoladas a oblongo-lanceoladas, 3-4 mm compr., densamente vilosas no dorso, trinervadas. Tubo estaminal menor que as sépalas, margem ciliada, filamentos laterais fimbriados, filamento anterífero agudo, anteras lineares, $1 \mathrm{~mm}$ compr. Ovário oblongo, 1,5 mm compr., estigma capitado.

Distribuição geográfica e hábitat: espécie brasileira, encontrada somente no estado de Minas Gerais, em campos rupestres.

Materiais examinados: BRASIL. MINAS GERAIS: Conceiçäo do Mato Dentro, Serra do Cipó, Alto Congonhas, $12 \mathrm{Km}$ NE de Cardeal Mota, em campo rupestre, 9-II-1991, Arbo et al. 4693 (CTES); Diamantina, $5 \mathrm{~km} \mathrm{~W}$ de Diamantina, camino a Gouveia, em campo rupestre, 16-II-1991, Arbor et al. 5221 (CTES, SPF); idem, Guinda, em campo arenoso, 7-IX-1971, Hatschbach 27367 (CTES); idem, Camino a Gouveia, em campo rupestre, 16-II1991, Arbo et al. 5221 (CTES); Jaboticabas, Serra do cipó, em campo pedregoso, 17-I-1972, Hatschbach et al. 28760 (CTES, MBM).

A planta recebeu tal denominação por apresentar tricomas hítulos no caule e folhas. Martius (1826) comentou que a espécie cresce em campos, com altitudes de até $3.000 \mathrm{~m}$, florescendo em maio. Siqueira \& Grandi (1986) destacaram que a espécie somente havia sido coletada no estado de Minas Gerais, em regiões de campos rupestres.

Pfaffia jubata Mart., Nov. Gen. Sp. Pl. 2: 24. 1826.

Tipo: BRASIL. Crescit in campis editis deserti in Provincis Minas Gerais, prope montem Serra S. Antonio (M?) E Gomphrena jubata (Mart.) Moq. in DC. Prodr. 13: 389. 1849. Tipo: BRASIL. BAHIA: s.d: Blanchet 3335, 1841 (NY!, P!). Fotografia do tipo (NY!).

Figura 10

Erva a subarbusto, 0,10-0,20 m de altura, caule ereto, ramoso, estriado, densamente viloso; raiz lenhosa. Folhas lanceoladas a linear-lanceoladas, 1,5-5 $\times$ 0,4-1,6 $\mathrm{cm}$, sésseis, ápice acuminado a cuspidado, base decurrente ou aguda, face adaxial densamente vilosa, flavescente a ferrugínea, face abaxial densamente tomentosa. Inflorescência em espiga, isolada, simples, terminal, pedúnculo longo, 6,5-15 cm compr., piloso, tricomas patentes, ferrugíneos, articulados, ráquis, subinflada, vilosa. Bráctea mediana ovalado a ovalado-lanceolada, ápice acuminado, uninervada, nervura proeminente, escura, vilosa, 3,5-4 mm compr., brácteas laterais ovaladas, ápice agudo a acuminado, uninervadas, nervura proeminente, escura, vilosa no ápice , 4-5 $\mathrm{mm}$ compr. Sépalas lanceoladas, trinervadas, sendo a principal proeminente, vilosas, 6-7,5 $\mathrm{mm}$ compr. Tubo estaminal bem menor que as sépalas, margem ciliada, filamentos laterais ciliados ou fimbriados, filamento anterífero filiforme, anteras oblongas, 1,5$2 \mathrm{~mm}$ compr. Ovário oblongo, 1,5-2 mm compr., estigma capitado.

Distribuição geográfica e hábitat: espécie brasileira, ocorrendo nos estados da Bahia, Ceará, Distrito Federal, Goiás, Minas Gerais, Mato Grosso, Paraná, São Paulo, Rondônia e Tocantins, em campos rupestres 

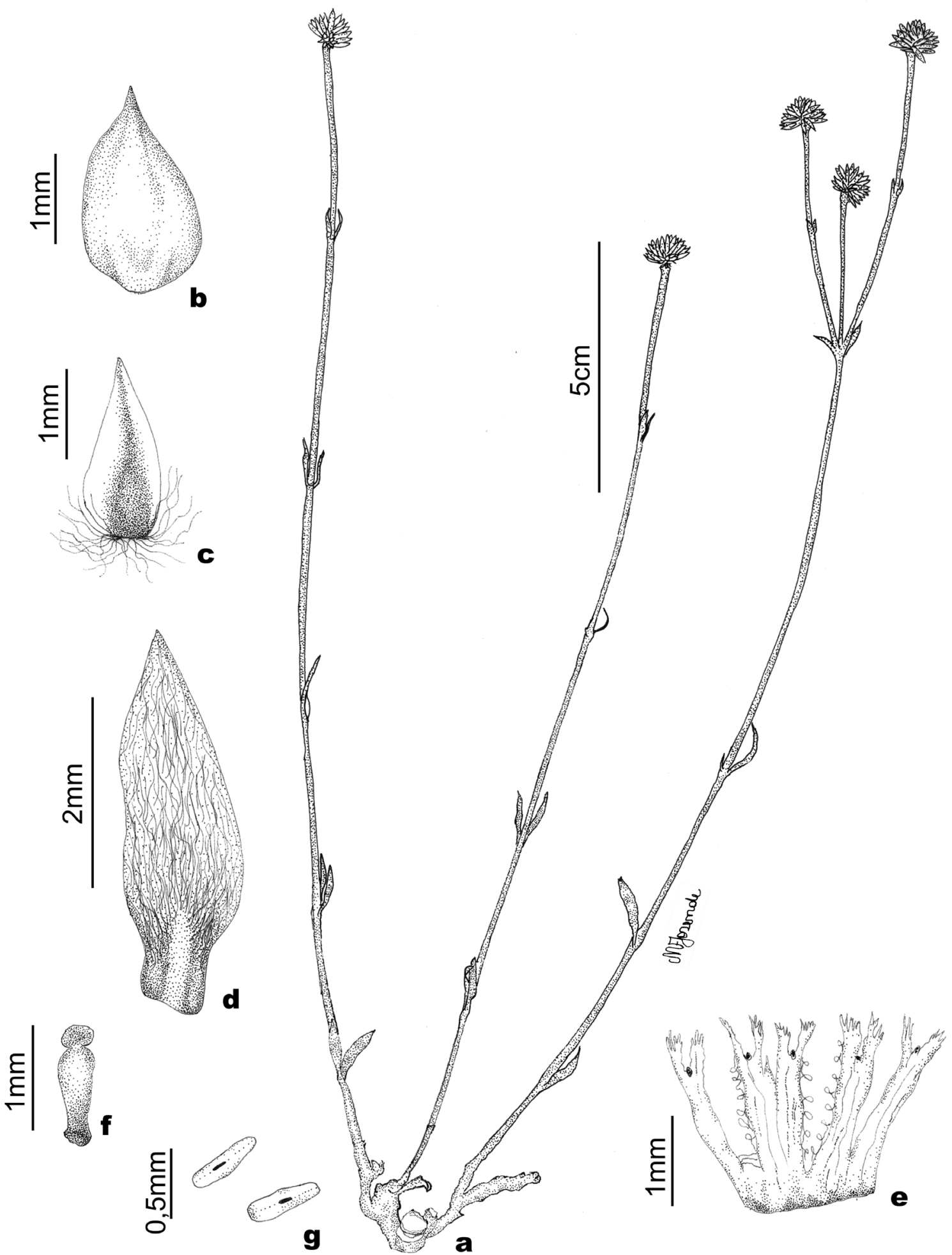

Figura 9. Pfaffia hirtula Mart. a. Hábito. b. Bráctea mediana. c. Bráctea lateral. d. Sépala. e. Tubo estaminal. f. Ovário. g. Anteras (Hatschbach et al. 28760, MBM).

Figure 9. Pfaffia hirtula Mart. a. Habit. b. Median bract. c. Lateral bract. d. Sepal. e. Staminal tube. f. Ovary. g. Anthers (Hatschbach et al. 28760, MBM). 


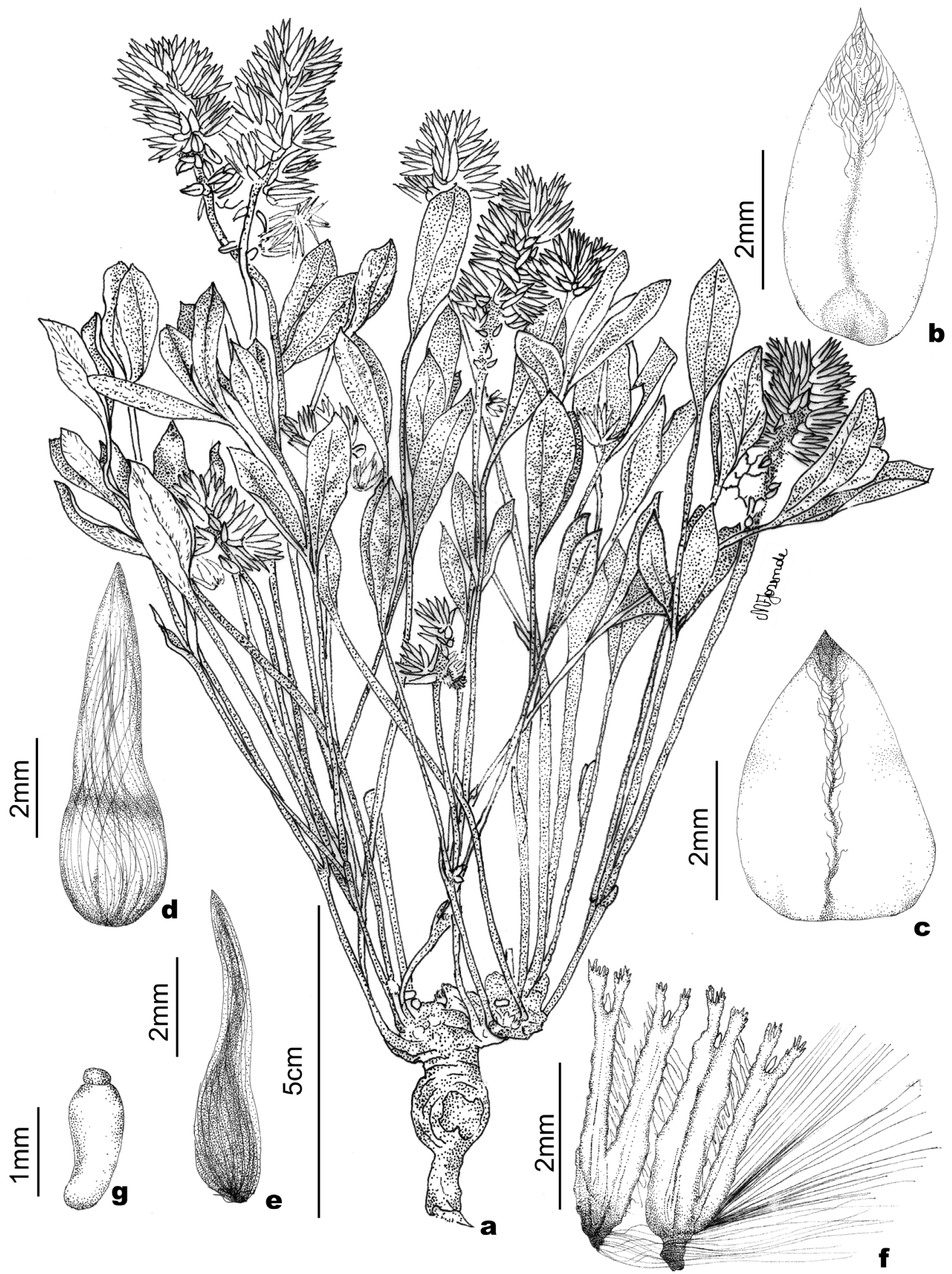

Figura 10. Pfaffia jubata Mart. a. Hábito. b. Bráctea mediana. c. Bráctea lateral. d-e. Sépalas. f. Tubo estaminal. g. Ovário (Hatschbach et al. 53625, MBM).

Figure 10. Pfaffia jubata Mart. a. Habit. b. Median bract. c. Lateral bract. d-e. Sepals. f. Staminal tube. g. Ovary (Hatschbach et al. 53625 , MBM). 
e cerrados, em altitudes que variam de 500-1.700 m. Material selecionado: BRASIL. BAHIA: Abaíra, Campo de Ouro Fino, em campo arenoso, 25-I1992, Stannard et al. s.n (HUEFS71799, SPF90105); Lençóis, 25-IV-1979, Noblick 1219 (ALCB); Rio de Contas, ca. 5-6 Km em direção ao Pico das Almas, no cerrado, 5-XI-1988, Wanderley \& Kral 1522 (SP, PACA). CeArá: Sine loco, 1839, Gardner 1824 (K). Distrito Federal: Área Córrego Cabeça Veado, 3-VIII-1971, Ratter et al. 3350 (K); ca. 23 Km SW of Brasília on road to Anápolis, 4-IX1964, Irwin et al. 5985 (NY); idem, Lago Norte, em cerrrado queimado, 30-VII-1983, Carvalho 125 (BHCB); idem, Samambaia, no campo, 15-IX-1995, Rezende 169 (CEN); idem, ca. $20 \mathrm{Km}$ E of Brasília at Sobradinho, burned over cerrado, 14-IX-1964, Irwin et al. $6222(\mathrm{NY})$; idem, Chapada da Contagem, ca 10 $\mathrm{Km} \mathrm{E}$ of Brasília, in gallery forest and adjacent burned over cerrado, 14-IX-1965, Irwin et al. 8302 (NY); idem, Reserva Ecológica do IBGE, no campo sujo próximo a guarita, 13-IX-2000, Silva 4495 (IBGE); idem, Área de campo sujo próximo ao Córrego Taquara, local queimado, 1-IX-1999, Fonseca et al. 2048, (CTES). GOIÁS: Alto Paraíso, Chapada dos Veadeiros, no campo limpo, 28-IX-1975, Hatschbach 37242 (CTES, MBM); Campo Alegre de Goiás, cerca de $20 \mathrm{Km}$ de Cristalina em direção a Campo Alegre de Goiás, no cerrado recentemente queimado, 8-IX1998, Souza et al. 21333 (ESA); Campinaçu, Região da Fazenda Praia Grande, cruzando o córrego Praia Grande, cerca de $6 \mathrm{Km}$ após o Córrego, em pastagem recém queimada em região de mata seca, 6-X-1995, Walter et al. 2672 (CEN); Campos Belos, Fazenda Mundo Novo, no cerrado queimado recentemente, 1-XI-2000, Oliveira et al. 1180 (IBGE); Cristalina, ca $15 \mathrm{Km}$ de Cristalina em direção a Campo Alegre de Goiás, no cerrado, 8-IX-1998, Souza et al. 21345 (ESA); Goiânia, Serra Dourada, 1969, Rizzo 4390 (RB); Niquelândia, Segunda Bica do asfalto ca $8 \mathrm{~km}$ de Niquelândia, Companhia de Níquel Tocantins, no cerrado queimado, 17-IX-1996, Fonseca et al. 1163 (IBGE); Sine loco, 1816-1821, Saint-Hilaire 287 (P); Sine loco, 1896, Glaziou 21967 (K). Mato Grosso: Chapada dos Guimarães, East of town of Chapada dos Guimarães, no cerrado, 22-X-1973, Prance et al. 19261 (CH, MG, K, NY, R); Marimbondo, IV-1911, Hoehne 23973 (NY); Rio Brilhante, Rod. BR 269, no campo cerrado, 25-VIII-1973, Hatschbach 32328 (CTES); Rio Verde, Serra da Pimenteira, cerrado recém queimado, 28-VIII-1973, Hatschbach 32430 (CTES, MBM); Vila Bela da Santíssima Trindade,
Serra Ricardo Franco, no cerrado, 23-IX-1978, Windisch 2103 (SJRP). Mato Grosso do Sul: Campo Grande, s.d, Kuhlmann s.n (RB110506); Estação Campo Grande, 10-IX-1936, Archer \& Gehert 165 (NY, P). Minas Gerais: Andrelandia, Cruz das Almas, no campo queimado, 23-VIII-1936, MelloBarreto 5246 (BHCB); Belo Horizonte, Morro das Pedras, in campo, 4-IX-1945, Williams et al. 7455 (R); Brumadinho, Retiro das Pedras, em área de sucessão, 27-VIII-1997, Barros et al. 54 (BHCB); Carmo do Rio Claro, na Serra da Tormenta, 3-XI1990, Campos s.n (HRCB); Diamantina, Estrada para Conselheiro Mata, Km 180, 18-II-1980, Furlan et al. s.n (SPF21668, PACA); Divisas de Betim e Brumadinho, Serra da Piedade, no campo queimado, 11-VIII-1945, Mello-Barreto 11618 (BHCB); Gouveia, Serra do Espinhaço, no campo arenoso, 6-IX-1971, Hatschbach 27326 (CTES, MBM); Itabirito, Pico do Itabirito, em campo rupestre, 29VII-1993, Antunes Teixeira s.n (BHCB); Lagoa Santa, s.d, Warming s.n (NY); Lima Duarte, Serra Ibitipoca, no campo pedregoso, 16-IX-1940, Magalhães 446, 16-IX-1940 (BHCB, RB); Moeda, Serra da Moeda, no campo rupestre, 5-X-1985, Carneiro et al. 2082 (BHCB); Ouro Branco, Serra de Ouro Branco, no campo rupestre, 29-VII-1988, Brina et al. s.n (BHCB13685); Paraopeba, Faz. da Vargem Alegre, no cerrado, 6-X-1956, Kunfa s.n (UB14712); Prata, 5 Km de Prata em direção a Ituiutuba, no cerrado, 13VII-2000, Souza et al. 23777 (ESA), São Roque de Minas, $50 \mathrm{Km}$ da sede administrativa, Estrada para Sacramenteo, PARNA, Serra da Canastra, no campo limpo, 21-VIII-1994, Nakajima et al. 435 (HRCB); São Sebastião do Paraíso, Baú: Irmão Teodoro 214, 9-IX-1994 (R); Tiradentes, Serra S. José, plateau principal da Igreja Santíssima, Viana 2437, 6-X-1997 (GUA); Uberaba, estrada de Uberaba a Uberlândia, no campo queimado, 11-VIII-1945, Mello-Barreto 11618 (BHCB, UB); Sine loco, 1816-1821, SaintHilaire 287 (NY, P); Sine loco, 1816-1821, SaintHilaire 649 (P). PARANÁ: Balsa Nova, Barra do Rio Papagaios, no campo pedregoso, 12-IX-1968, Hatschbach 19699 (MBM); Campo Largo, 25-IX1960, Hatschbach, 7306 (SI); Jaguariaíva, Parque Estadual do Cerrado, em campo cerrado, 15-X-1994, Uhlmann et al. 88 (NY); Palmeira, Rodovia do Café, Rio Tibagi, no campo, 29-IX-1965, Hatschbach 12838 (MBM); Ponta Grossa, Parque Vila Velha, no campo limpo, 23-IX-1962, Hatschbach 9829 (HBR, MBM); Sengés, Rod. PR-11, próximo ao Km 252, no campo seco limpo, 18-XI-1989, Hatschbach et 
al. 53625 (MBM). RONDÔNIA: Vilhena, Fazenda Casa Branca, cerrado recém queimado, 1-VI-1997, Miranda \& Silva 1405 (MG). SÃo PAUlo: Itararé, Fazenda Espinho, em campo queimado, 6-IV-1993, Souza et al. 4254 (BHCB, ESA); Itirapina, no campo cerrado, 25-IX-1940, Toledo \& Gehr s.n (K, SP43214); Pirassununga, cerrado de Emas, Reserva da USP, 17-VII-1976, Wanderley 04 (SP, PACA); São Carlos, $7 \mathrm{Km}$ depois de São Carlos- Ibaté, em campo cerrado, 17-IX-1938, Rombouts s.n (IAC 2678); São João da Boa Vista, no cerrado, 20-IX1968, Leitão Filho 534 (IAC); São José dos Campos, no cerrado, 30-VIII-1949, Kuhlmann 1992 (HAS, SP, UB). Tocantins: Miracema do Tocantins, estrada do Córrego Santa Luzia, no campo úmido depois da queimada, 24-IX-1998, Árbocz 6088 (HTO, IBGE); Sine loco, na borda do Rio Tocantins, IX-1844, Weddell s.n (NY).

O epíteto provém de jubatus, semelhante a uma crina, com referência a inflorescência muito vilosa. A espécie é conhecida entre populares dos cerrados como marcela-branca, marcela-do-campo. Para os índios Karajás é denominada kytertenim. As raízes lenhosas, consideradas xilopódios, são empregadas no combate à cólicas e enterites. Entre os índios Karajás, as raízes são utilizadas maceradas como antifebrífugas e antidiarréicas (Silva 1983 apud Siqueira 1987).

Handro (1965), ao analisar os grãos de pólen das plantas do cerrado da família Amaranthaceae, destacou que Pfaffia jubata possuia pólen do tipo esferoidal, pantoporado, com grãos reticulados. Handro (1967), em seu trabalho sobre venação e anatomia foliar, comentou que P. jubata possuia um padrão geral de venação do tipo broquidódromo, entretanto, não típico, pois algumas vezes uma nervura secundária deixava de formar o arco característico que se reuniria à nervura secundária seguinte, como deveria ocorrer neste tipo de venação. Além disso, as nervuras eram extremamente variáveis e a epiderme apresentava tricomas e estômatos em ambas as faces. Os tricomas eram sempre pluricelulares, às vezes, lignificados, a superfície apresentava espículas. Monteiro-Scanavacca (1969) discutiu a anatomia floral de Paffia jubata e afirmou que a anatomia apresentada pelas peças florais do único verticilo do perianto, deixava dúvidas quanto à natureza de sépala ou de pétala. Argumentou, porém, que a tendência é para o caráter de sépala, principalmente, pelo plano geral de venação semelhante à folha e pela presença de um evidente tecido de sustentação, representado por células esclerificadas em relação às nervuras. A presença de muitos tricomas longos na parte dorsal e basal das sépalas poderia substituir, em função, a corola ausente.

Ao comentar a vascularização floral desta espécie, Monteiro-Scanavacca (1971), disse que o tecido vascular do pedicelo da flor apresentava-se na forma de feixes e que o tecido vascular central tinha aspecto fragmentado, com parênquima central em grande extensão, da base para o ápice, tomando após a saída dos traços que constituiam os feixes estaminais. $\mathrm{O}$ aspecto era compacto e continuava através do funículo, do único óvulo terminando na chalaza. Monteiro-Scavanacca (1971) ressaltou que em $P$. jubata havia coesão parcial das sépalas, afetando a parte vascular, pois cinco dos dez traços sepalares, alternadamente, representavam fusões de dois traços que originariam feixes marginais (laterais), cada um de uma sépala vizinha. Havia coesão de estames, constituindo-se dessa forma, o tubo estaminal, até o nível elevado. Não ocorreu adnação de sépala com estame.

Segundo Smith \& Downs (1972) P. jubata não possuia registros para o estado de Santa Catarina, tratando-se de espécie muito rara no sul do Brasil. Smith \& Downs (1972) supuseram sua provável ocorrência nos campos secos de Mafra (sic), os quais representam o limite austral dos Campos Gerais, de onde procedem as coleções paranaenses. Segundo Siqueira (1981), esta espécie é bastante frequente em áreas de cerrados e campos rupestres do Brasil, principalmente na região Centro-Oeste.

Pfaffia minarum Pedersen, Adansonia sér. 3. 19(2): 237. 1997. Tipo: BRASIL. Minas Gerais: Conceição, $8 \mathrm{Km} \mathrm{SW}$ de Conceição do Mato Dentro, camino a Cardeal Mota, borde de selva marginal com afloramientos rocosos: Arbor, Mello-Silva, Schinini \& Souza 4291, 17-V-1990. (Holótipo CTES!, Isótipos C, CTES!, SPF!).

Figura 11

Subarbusto, 0,30-1 m de altura, caule prostrado, acinzentado, tomentoso, entrenós de $2-5 \mathrm{~cm}$ compr.; raiz semilenhosa. Folhas ovaladas, elípticas, 2,5-5 × 1,5-2,2 cm, cartáceas, subsésseis, ápice mucronado, base subcordada, face adaxial pilosa, tricomas hirsutos, face abaxial denso tomentosa. Inflorescência em espiga, isolada, simples, axilar ou terminal, pedúnculos curtos a médios, 2-6 cm compr., tomentosos, ráquis subinflada, tomentosa. Bráctea mediana ovalada, ápice acuminado, uninervada, 

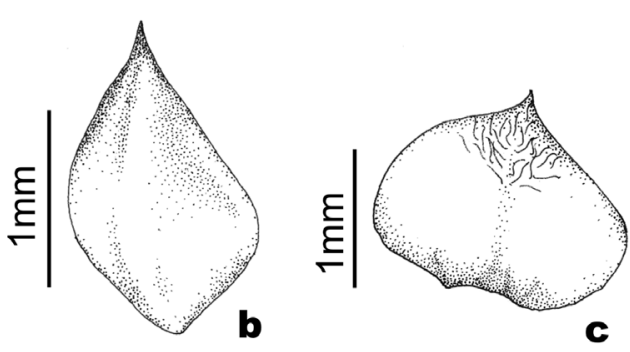

$\frac{\varepsilon}{\varepsilon}$
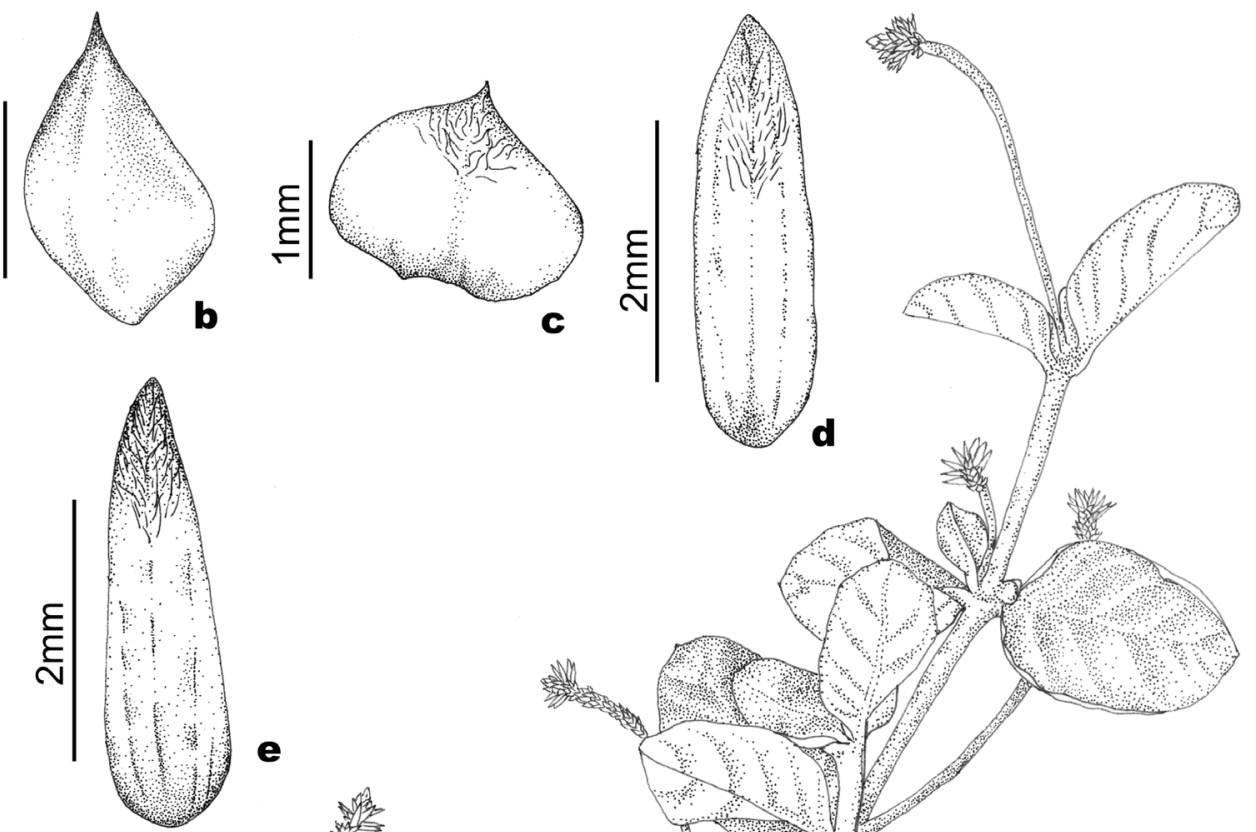
tricomas esparsos, 1,5-2 $\mathrm{mm}$ compr.; brácteas laterais orbicular-cordadas, ápice acuminado, pilosas no ápice, uninervadas, 1,2-1,5 mm compr. Sépalas oblongo-estreitas, trinervadas, dorso piloso, ápice agudo, três externas, $3 \mathrm{~mm}$ compr., duas internas, 2,5 $\mathrm{mm}$ compr. Tubo estaminal menor que as sépalas, margem fimbriada, filamentos laterais longos, fimbriados, filamento anterífero curto, agudo, anteras elípticas, $1 \mathrm{~mm}$ compr. Ovário obovalado, $0,5 \mathrm{~mm}$ compr., estigma capitado-subilobado.

Distribuição geográfica e hábitat: espécie tipicamente brasileira, ocorrendo somente nos estados de Goiás e Minas Gerais, nos cerrados.

Material examinado: BRASIL. GoIÁs: Cristalina, 15 Km W of Cristalina, no campo, 6-III-1966, Irwin et al. 13623 (NY). Minas Gerais: Conceição do Mato Dentro, Rio Santo Antônio, junto ao rio, Hatschbach et al 28884, 18-I-1972. (Parátipos BHCB, CTES, MBM!); idem, Estrada Santana do Riacho-Serro, $\mathrm{Km}$ 155, Próximo à Ponte do Rio Santo Antônio, 5-VII-1996, Souza et al. 11768 (ESA, HUEFS SPF, BHCB); idem, Parque Natural Municipal do Ribeirão do campo, em barranca, próximo ao rio, 31-V2003, Mota et al. 2201 (BHCB); Gouveia, Fazenda Contagem, $13 \mathrm{Km}$ à direita no $\mathrm{Km} 65$ da rodovia Curvelo-Diamantina, 29-VIII-1981, Giulietti et al. s.n (SPF21508, PACA); Paracatu, BR 040, Km 6 from Goiás border, no cerradão, 24-VII-1984, Mori et al. 16957 (CEN); Santana do Riacho, Km 146 ao longo da rodovia Belo Horizonte-Conceição do Mato Dentro, na beira do rio Santo Antonio, 19-IV-1981, Rossi \& Amaral s.n (SPF19953, PACA).

Segundo Pedersen (1997), P. minarum está muito próxima de $P$. townsendii, diferenciando-se principalmente pela forma das folhas e pelas flores menores.

Pfaffia rupestris Marchioretto, Miotto \& Siqueira, Rodriguésia 59(1): 130. 2008. Tipo: BRASIL. Minas Gerais: Rio Pardo de Minas, estrada Serranópolis-Rio Pardo, Serra de Poções, entre rochas, 13-V-1998, J.R. Pirani, A.C. Marcato, R.C. Forzza, M.C. Assis \& P.E. Labiak 4300. (Holótipo PACA!, Isótipos HRCB!, SPF!).

Figura 12

Subarbusto, com caule ereto, inicialmente escuro e glabro, tornando-se densamente lanoso ou tomentoso, verde-acinzentado até canescente, em direção ao ápice, entrenós de 0,5-2 cm compr.; raiz semilenhosa. Folhas opostas ou verticiladas, estreito oblongas, $0,5-1 \times 0,1-0,2 \mathrm{~cm}$, sésseis, ápice agudo, base truncada, faces adaxial e abaxial densamente lanoso-tomentosas, cinza-esverdeadas. Inflorescência capituliforme, isolada, simples, di ou tricotômica, terminal, pedúnculo curto, 2-2,5 $\mathrm{cm}$ compr., lanoso-tomentoso, ráquis tomentosa. Bráctea mediana oblonga, hialina, ápice acuminado, uninervada, tricomas na extremidade do dorso, 3,5 mm compr., brácteas laterais oblongas, hialinas, ápice acuminado, uninervadas, tricomas na extremidade do dorso, $3 \mathrm{~mm}$ compr.; entre as brácteas e sépalas tricomas alvacentos, articulados, com comprimento um pouco maior que a metade do comprimento das sépalas. Sépalas oblongas a oblongo-lanceoladas desiguais, trinervadas, ápice agudo, pilosas no dorso do meio para o ápice, quase hialinas, 3,5-4 mm compr. Tubo estaminal quase do tamanho das sépalas, filamentos laterais subulado-lanceolados, filamento anterífero agudo, anteras oblongas, $1 \mathrm{~mm}$ compr. Ovário oblongo, $1 \mathrm{~mm}$ compr., estigma capitado, pulverulento.

Distribuição geográfica e hábitat: até o presente, encontrada somente no estado de Minas Gerais, em campos rupestres.

Material examinado: BRASIL. Minas Gerais: Rio Pardo de Minas, estrada Serranópolis-Rio Pardo, Serra de Poções, entre rochas, 13-V-1998, Pirani, Marcato, Forzza, Assis \& Labiak 4300 (HRCB, SPF, PACA).

Marchioretto et al. (2008), relataram que Pfaffia rupestris diferencia-se das demais espécies de Pfaffia por ser extremamente folhosa, com folhas muito pequenas, $0,5-1 \mathrm{~cm}$ de comprimento por 1-2 $\mathrm{mm}$ de largura, opostas e verticiladas. A espécie recebeu tal denominação por ter sido encontrada entre rochas.

Pfaffia sarcophylla Pedersen, Adansonia sér. 3. 19(2): 239. 1997. Tipo: BRASIL. GoIÁs: Niquelândia, southernmost ultranafic hill of Tocantins complex, $800 \mathrm{~m}$, herb filld in gully and lower part fullslope, rocky serpentine slope, Reeves, Baker \& Dias Ferreira Braspex 234, 29-IV-1988 (Holótipo C!). Figura 13

Subarbusto, 0,60-1,20 m de altura, caule ereto, lenhoso, estriado, glabro, engrossado nos nós, entrenós de 3,5-19 cm compr.; raiz semilenhosa. Folhas oblongas, coriáceas, 4-10,5 × 1,2-2,4 cm, sésseis, ápice agudo a mucronado, base aguda, faces adaxial e abaxial glabras. Inflorescência em espiga, isolada, di ou tricotômica, terminal, pedúnculo longo, 10-20 cm compr., glabro a levemente piloso, ráquis lanosa. Bráctea mediana ovalado-côncava, escariosa, 


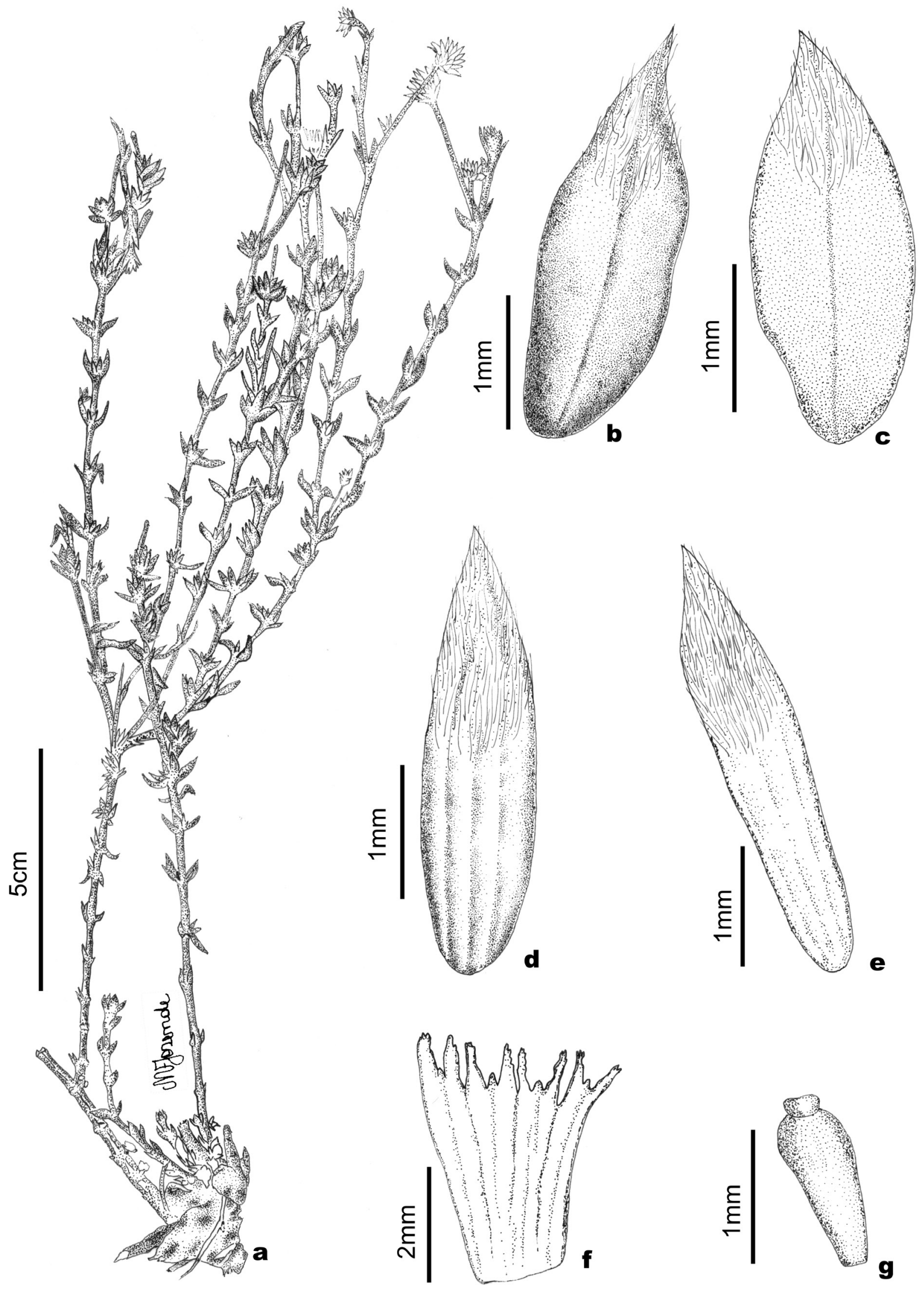

Figura 12. Pfaffia rupestris Marchioretto, Miotto \& Siqueira. a. Hábito. b. Bráctea mediana. c. Bráctea lateral. d-e. Sépalas. f. Tubo estaminal. g. Ovário (Pirani et al. 4300).

Figure 12. Pfaffia rupestris Marchioretto, Miotto \& Siqueira. a. Habit. b. Median bract. c. Lateral bract. d-e. Sepals. f. Staminal tube. g. Ovary (Pirani et al. 4300). 

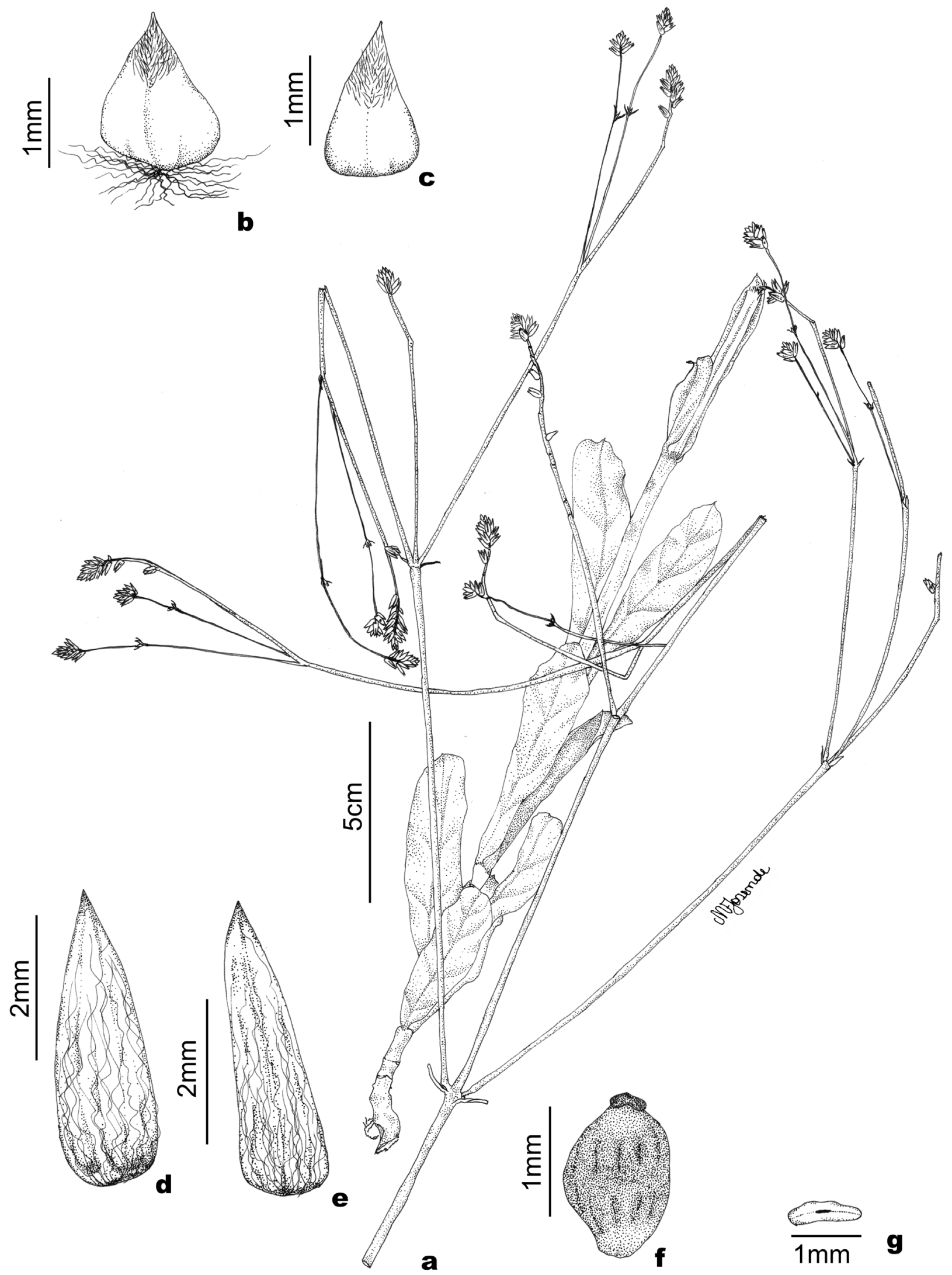

Figura 13. Pfaffia sarcophylla Pedersen. a. Ramo. b. Bráctea mediana. c. Bráctea lateral. d-e. Sépalas. f. Ovário. g. Antera (Mendonça et al. 2445, IBGE).

Figure 13. Pfaffia sarcophylla Pedersen. a. Habit. b. Median bract. c. Lateral bract. d-e. Sepals. f. Ovary. g. Anther (Mendonça et al. 2445, IBGE). 
ápice mucronado, uninervada, lanosa, decídua, $2 \mathrm{~mm}$ compr., brácteas laterais ovaladas, ápice acuminado, base aguda, uninervadas, vilosas no dorso, 1,5-2 mm compr. Sépalas oblongas, ápice agudo, trinervadas, vilosas, 3,5-4 $\mathrm{mm}$ compr. Tubo estaminal curto, na parte inferior soldado, filamentos laterais longo ciliados, filamento anterífero, breve agudo, anteras oblongas, 1-1,2 mm compr. Ovário obovalado, 0,7-1 mm compr., estigma capitado, levemente emarginado. Distribuição geográfica e hábitat: espécie brasileira, encontrada até o presente no estado de Goiás, no cerrado, com solo serpentina, pedregoso, em altitude de $965 \mathrm{~m}$.

Material examinado: BRASIL. GoIÁs: Macedo, ca 15 $\mathrm{Km} \mathrm{N}$ of Niquelândia; $14^{\circ} 18^{\prime} \mathrm{S}, 48^{\circ} 23^{\prime} \mathrm{W}$. S. facing hill slope, stable peridotite/dunite-based scree \& flat area below, ca. 500-800 m east of nickel workings. ca.1.000 m alt, campo, on hillside, Brook et al, 21IV-1988. (Parátipos C, K); Niquelândia, ca. 210 Km, 9-XI-1994, Filgueiras 3087 (HRCB, IBGE); idem, Macedo, ca. $18 \mathrm{Km}$ de Niquelândia, 24-VIII1994, Filgueiras et al. 2951 (IBGE); idem, estrada de terra à direita da Mina de Níquel, no cerrado, 29II-1996, Fonseca et al. 819 (CTES, IBGE); idem, Macedo Velho, Perto do local de movimentação das máquinas, no cerrado, 1-VI-1999, Filgueiras et al. 3540 (IBGE); idem, morro pedregoso com entrada na Av. Brasil, Fazenda Água, no campo sujo perto do brejo, 14-VIII-1996, Fonseca et al. 1094 (IBGE); idem, Km 30 ao 40 da estrada de Terra à direita da Mina de Níquel, 24-III-1995, Oliveira et al. 273 (IBGE); idem, $5 \mathrm{Km}$ após a Mina de Níquel da Companhia de Níquel Tocantins CNT, no campo sujo sobre morro, 12-IV-1996, Mendonça et al. 2445 (IBGE); idem, Companhia de Níquel Tocantins (CNT), ca. $1 \mathrm{Km}$ abaixo da Mina de Níquel, 7-V1998, Alvarenga 1186 (IBGE, NY); idem, Macedo, ca. $1 \mathrm{Km}$ abaixo da Mina de Níquel, no cerrado, 29V-1996, Silva et al. 2967 (HRCB, IBGE); idem, 26VII-1952, Macedo s.n (RB78763); Niquelândia, 26II-1956, Macedo 4458 (RB).

Pedersen (1997) comenta que esta espécie é próxima de $P$. tuberosa (Spreng.) Hicken, da qual se diferencia pela maior largura das folhas carnosas, inflorescências profundamente ramificadas e ramos quase completamente glabros.

Pfaffia sericantha (Mart.) Pedersen, Bull. Mus. Natn. Hist. Nat. 4. 12. B. Adansonia 4: 12(1): 90. $1990 \equiv$ Gomphrena sericantha Mart., Nov. Gen. Sp. Pl. 2(1): 8,tab. CVIII. 1826. Tipo: BRASIL.
Minas Gerais: ad montium tractum Serra de S. Antonio.(M).= Xeraea sericantha (Mart.) Kuntze, Rev. Gen. Pl. 2: 545. 1891.

= Gomphrena cinerea Moq., in DC., Prodr. 13(2): 390. 1849 三 Pfaffia cinerea (Moq.) Kuntze, Rev. Gen. Pl. 2: 543. 1891.

Figura 14

Erva a subarbusto, $15-50 \mathrm{~cm}$ de altura, caule ereto tomentoso, acinzentado, entrenós de 6,0$10,5 \mathrm{~cm}$ compr. raiz semilenhosa. Folhas oblongas, elípticas, $1,4-3,7 \times 0,8-1,5 \mathrm{~cm}$, sésseis ou curtopecioladas, 0,3-0,5 cm de compr., ápice acuminado a cuspidado, base decurrente, face adaxial esverdeada, densamente pilosa, tricomas estrigosos, face abaxial esbranquiçada ou acinzentada, lanosa ou tomentosa. Inflorescência capituliforme, isolada, simples, terminal, pedúnculo longo, 7-13,5 cm, tomentoso, esbranquiçado, ráquis subinflada, tomentosa. Bráctea mediana oblongo-lanceolada, hialina, ápice acuminado, uninervada, tricomas esparsos no dorso, 3-3,5 mm compr., brácteas laterais ovaladas, côncavas, hialinas, ápice agudo, uninervadas, 3,5-4 mm compr. Sépalas ovalado-lanceoladas a lanceoladas, coriáceas, lanosas a tomentosas, esbranquiçadas, trinervadas, nervuras escuras, 6-8 mm compr. Tubo estaminal curto, margens ciliadas, filamentos laterais fimbriados, filamento anterífero filiforme, anteras oblongas, 1,2 $\mathrm{mm}$ compr. Ovário ovalado, $2 \mathrm{~mm}$ compr., estigma capitado, às vezes bilobado.

Distribuição geográfica e hábitat: espécie brasileira, ocorrendo nos estados da Bahia, Distrito Federal, Goiás e Minas Gerais, em cerrados ou entre cerrado e carrasco, em solos arenosos, com altitudes que variam de 820-1.200 m.

Material examinado: BRASIL. BAHIA: Barreiras, Rod. BR 020, Km 30 O, no cerrado, 11-III-1979, Hatschbach 42081 (CTES, MBM); Correntina, Fazenda Jabotá, na margem da estrada, 5-VI-1992, Silva et al. 1274 (IBGE); Rio de Contas, 22-VII-1981, Furlan et al. 18562 (K); Distrito Federal: Cafuringa, APA de Cafurinaga, nas cabeceiras do córrego Monjolo e Ribeirão, próximo à rodovia DF-170, no campo queimado, 21-IX-1993, Pereira et al. 2576 (CTES, HRCB); Região da Palma, no cerrado, 19X-1982, Palagi 20 (GUA); ca 20 Km NE de Brasília, estrada Brasília- Fortaleza, no campo cerrado, 20-IX1967, De Haac 65 (CTES); ca. $20 \mathrm{Km}$ E of Brasília, burned over cerrado, 14-IX-1964, Irwin et al. 6225 (NY); ca. 15 Km E of Brasília, 30-VIII-1964, Irwin et al. 5749 (NY); EEJBB, no cerrado queimado, 14- 


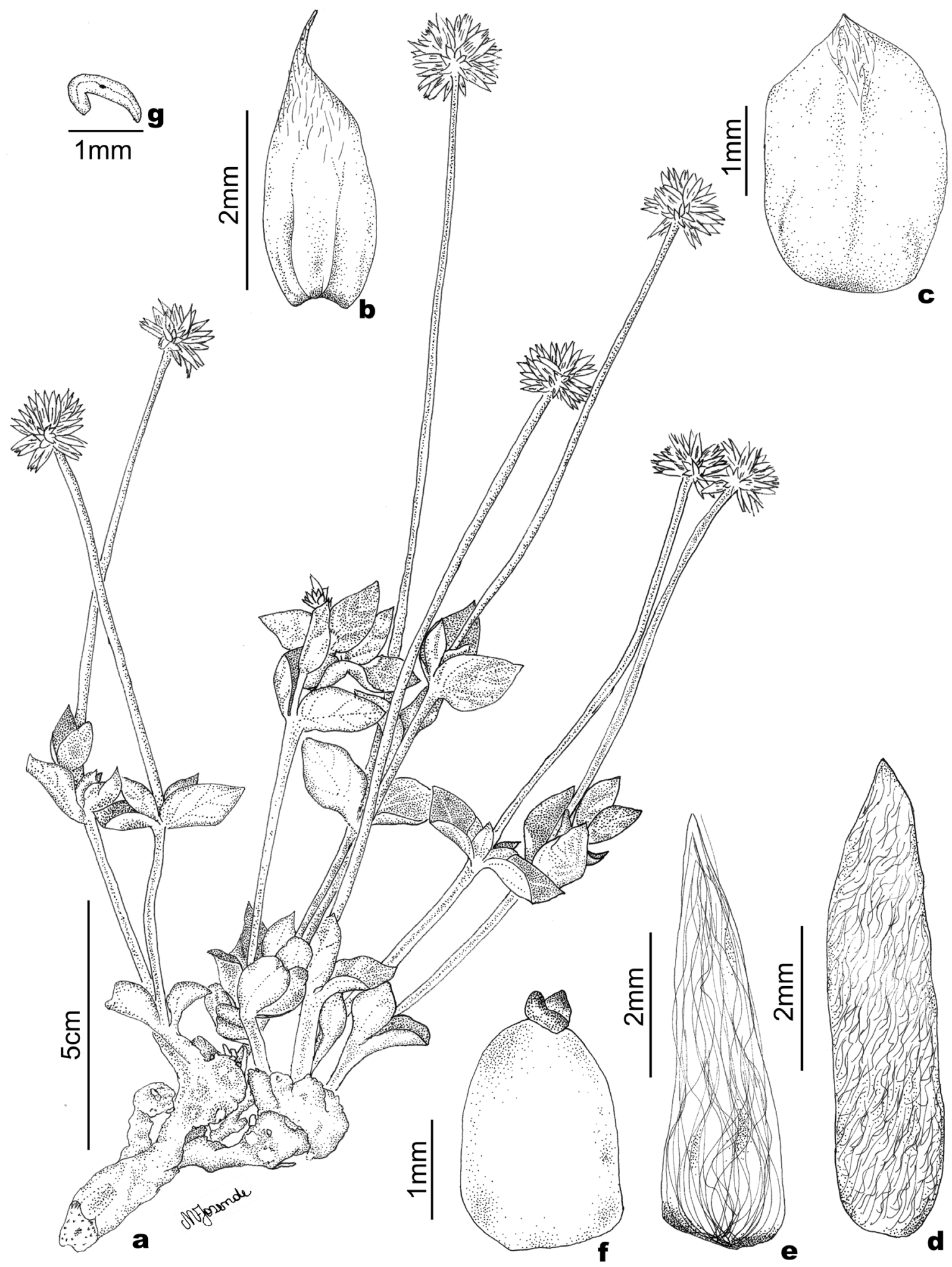

Figura 14. Pfaffia sericantha (Mart.) Pedersen. a. Hábito. b. Bráctea mediana. c. Bráctea lateral. d-e. Sépalas. f. Ovário. g. Antera (Irwin et al. 8019, MBM).

Figure 14. Pfaffia sericantha (Mart.) Pedersen. a. Habit. b. Median bract. c. d. Lateral bract. d-e. Sepals. f. Ovary. g. Anther (Irwin et al. 8019, MBM). 
X-1994, Ramos 927 (MBM); DF-170 a 7 Km do entroncamento com DF 001- Chapada da Contagem, no cerrado, 12-VII-1990, Cavalcanti et al. 529 (CEN); Chapada da Contagem, ca $25 \mathrm{Km}$ N.W. of Brasília, burned over cerrado, 6-IX-1965, Irwin et al. 8019 (NY), Chapada da Contagem, 1.200 m, Rodovia DF. 5 , no campo cerrado, recentemente queimado, 5-VII1980, Barros et al., 64 (NY); Chapada da Contagem, ca. $10 \mathrm{Km}$ E of Brasília, burned-over cerrado, 13-IX1965, Irwin et al. 8270 (NY); GOIÁS: Corumbá de Goiás, Estrada para Corumbá-Goiás a mais ou menos $2 \mathrm{Km}$ no desvio a direita, rumo a cidade eclética, no cerrado, 11-IX-1990, Vieira et al. 455 (CEN). Planatina, Rod. GO-12, no campo cerrado, 29-IX1975, Hatschbach 37277 (CTES); Posse, estrada de Chão próximo ao Aeroporto, cerrado queimado recentemente, 16-X-2001, Mendonça et al. 4454 (IBGE); Sine loco, 9-X-1896, Glaziou 21969 (K, P). Minas Gerais: Formoso, Parque Nacional Grande Sertão Veredas, $6 \mathrm{Km}$ da sede Funatura em direção ao povoado Chapada Gaúcha, em carrasco queimado recentemene, 2-XII-1997, Silva et al. 3672 (CTES, IBGE); Parque Nacional Grande Sertão Veredas, Serra Limoeiro, $11 \mathrm{Km}$ da Sede da Funatura, no cerrado, 17-X-1997, Silva et al. 3433 (IBGE); Unaí, Fazenda São Miguel, Grupo Votorantin, no cerrado próximo a cabeceira do Veado Branco, 7-XI-1993, Silva et al. 1787 (CTES, IBGE); Vila dos Gaúchos, 15-XI-1980, Silva 103 (HRB).

Pedersen (1990) transferiu Gomphrena sericantha para Pfaffia sericantha e argumentou que Martius (1826) a considerou uma espécie do gênero Gomphrena por apresentar estigma profundamente lobado e que esse ponto de vista foi aceito, posteriormente, por muitos outros pesquisadores. Pedersen (1990) salientou que após o exame do espécime-tipo e de um maior número de exsicatas, concluiu que existe uma variação na forma do estigma, de profundamente lobado para meramente emarginado e que o androceu é típico de Pfaffia, com filamentos fimbriados. Este último caráter não foi observado por Martius (1826) quando da descrição da espécie.

Pfaffia siqueiriana Marchioretto \& Miotto, PesquisasBotânica. 58: 383. 2007. Tipo: BRASIL. Minas Gerais: Rio Pardo de Minas, Parque Estadual da Serra Nova, em beira de trilha: Marchioretto 324, 12-III-2007, 15'39'10.4”S, 4244'17'”, $932 \mathrm{~m} \mathrm{de}$ altitude (Holótipo PACA!, Isótipo BHCB!).

Figura 15

Subarbusto, $0,50 \mathrm{~cm}$ de altura, caule ereto, inicialmente estriado, glabro, escuro, tornando-se densamente lanoso acinzentado, entrenós de 1,5-5,5 cm compr., raiz semilenhosa. Folhas oblongas, 1,5-3,5 $\times 0,4-0,8 \mathrm{~cm}$, sésseis, ápice agudo, base aguda, face adaxial verde-acinzentada densamente lanosa, face abaxial verde-amarelada densamente lanosa, nervuras proeminentes. Inflorescência capituliforme, isolada, simples, terminal, pedúnculo longo, 7-13 cm compr., acinzentado, lanoso, ráquis tomentosa. Bráctea mediana obovalada, ápice atenuado, univervada, densamente pilosa a tomentosa no dorso, tricomas seríceos, 2 $\mathrm{mm}$ compr., brácteas laterais ovaladas, hialinas, uninervadas, ápice acuminado, pequena quantidade de tricomas, na extremidade do dorso, 2-2,5 mm compr., entre as brácteas e sépalas com grande quantidade de tricomas longos alvos. Sépalas desiguais, oblongas quase hialinas, trinervadas, ápice agudo, 3-3,5 mm compr.Tubo estaminal menor que as sépalas, filamentos laterais crenulados, filamento anterífero curto, agudo, anteras elípticas, $0,7 \mathrm{~mm}$ compr. Ovário ovalado, $1 \mathrm{~mm}$ compr., estigma capitado, pulverulento.

Distribuição geográfica e hábitat: a espécie é restrita até o momento aos estados da Bahia e Minas Gerais, em campos rupestres e caatingas, em altitudes entre 770 $832 \mathrm{~m}$.

Material examinado: BRASIL. BAHIA: Urandi, Rod. Licício de Almeida/Urandi 15,4 Km, em campo rupestre intercalada por cerrado, 31-III-2001, Jardim, Juchum, Santana, Santos \& Querino 3326 (ALCB). Minas Gerais. Janaúba, Campus Avançado de Janaúba, Unimontes, na caatinga arbórea, em afloramento herbáceo, ca. $15^{\circ} 48^{`} \mathrm{~S}$ e $43^{\circ} 18^{`} \mathrm{O}$ 8-XI2001, Vasconcelos 67 (BHCB); Rio Pardo de Minas, Parque Estadual da Serra Nova, em beira de trilha, 12III-2007 Marchioretto 323 15'39'10.4'S, 4244'17'O, $932 \mathrm{~m}$ de altitude (PACA, BHCB); Serranópolis, Serra do Talhado, na subida da serra, $15^{\circ} 49^{\prime} 07,9^{\prime \prime} \mathrm{S}$ e 42\%49'22"O Marchioretto 347, 14-III-2007, $770 \mathrm{~m}$ de altitude (PACA, BHCB, ICN).

Marchioretto \& Miotto (2007), destacaram que Pfaffia siqueiriana é próxima de $P$. gnaphaloides, mas se diferencia desta por ser um subarbusto, com folhas sempre oblongas, com a face abaxial apresentando nervuras proeminentes, capítulos menores, flores menores, bráctea mediana obovalada, brácteas laterais ovaladas, com ápice acuminado, sépalas menores, oblongas, hialinas, tricomas entre as sépalas e brácteas, alvos, de menor tamanho e não ondulados. De acordo com as autoras o epíteto foi dado em homenagem ao Dr. Josafá Carlos de Siqueira, especialista em Amaranthaceae no Brasil. 


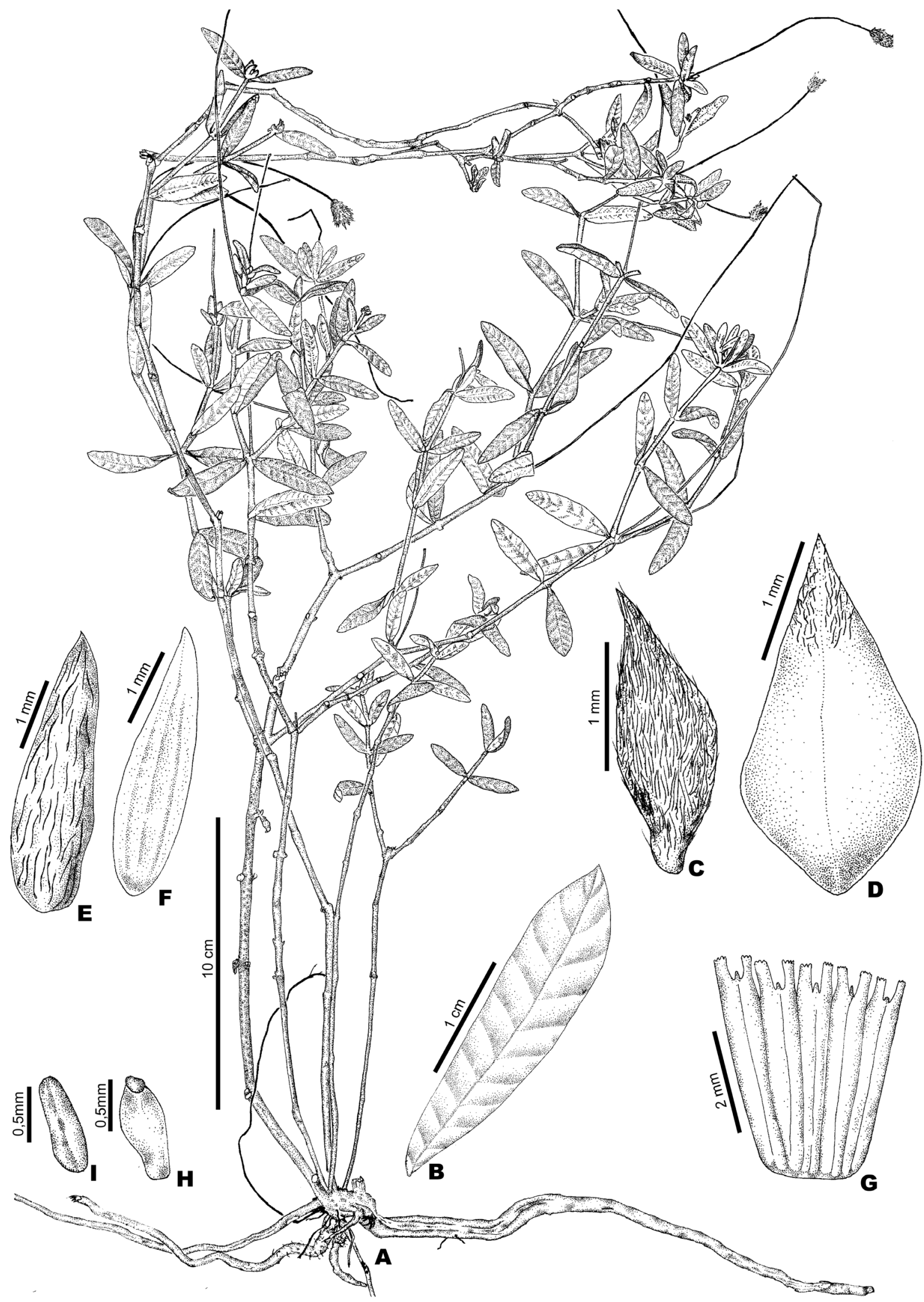

Figura 15. Pfaffia siqueiriana Marchioretto \& Miotto a. Hábito. b. Detalhe da folha. c. Bráctea mediana (vista lateral). d. Bráctea lateral. e. Sépala, aspecto externo. f. Sépala, aspecto interno. g. Tubo estaminal. h. Ovário. i. Antera (Marchioretto 324, PACA).

Figure 15. Pfaffia siqueiriana Marchioretto \& Miotto a. Habit. b. Detail leaf. c. Median bract (side view). d. Lateral bract. e. Sepal outer aspect. f. Sepal inner aspect. g. Staminal tube. h. Ovary. i. Anther (Marchioretto 324, PACA). 
Pfaffia townsendii Pedersen, Bull. Mus. Natl. Hist. Nat. 4. 122. B. Adansonia 4: 12(1): 92. 1990. Tipo: BRASIL. GoiÁs: Chapada dos Veadeiros, ca 20 $\mathrm{Km}$ of Veadeiros, Rocky slopes and wet campo. Elevation 1000 m, H.S. Irwin, J.W. Grear Jr., R. Souza, R. Reis-dos-Santos 12611, 11-II-1966. (Holótipo K, Isótipos NY!, RB!, UB! e CTES!). Fotografias: Holótipo (K!), Isótipo (NY!).

\section{Figura 16}

Subarbusto, 0,30-1,0 $\mathrm{m}$ de altura, caule ereto, lenhoso, tomentoso, acinzentado, entrenós de 1-6 cm compr.; raiz semilenhosa. Folhas oblongas, oblongo-ovaladas a ovaladas cartáceas, 3-8,5 × 1,5$5,2 \mathrm{~cm}$, sésseis a curto-pecioladas, pecíolo, $0,3 \mathrm{~cm}$ compr., ápice agudo ou acuminado, base rotunda, face adaxial tomentosa, verde-acinzentada, face abaxial lanoso-tomentosa, nervuras destacadas, sendo a principal proeminente, branco-acinzentada. Inflorescência capituliforme ou em espiga, isolada, simples, terminal, pedúnculo longo, 7-12 cm compr., lanoso, acinzentado a esbranquiçado, ráquis inflada, densamente lanosa. Bráctea mediana ovalada a ovalado-lanceolada, uninervada, escura, ápice acuminado, glabra, 4-4,5 $\mathrm{mm}$ compr., brácteas laterais ovaladas, uninervadas, ápice acuminado, pilosas na extremidade do dorso, 3-3,5 mm compr. Sépalas oblongas, oblongo-ovaladas ou oblongolanceoladas, escariosas, ápice agudo, trinervadas, pilosas, tricomas adpressos no ápice, 5-7 $\mathrm{mm}$ compr. Tubo estaminal unido na base e mais da metade estreitado, filamentos laterais lineares, fimbriados, filamento anterífero breve, agudo, anteras oblongas, $1,5 \mathrm{~mm}$ compr. Ovário oblongo, $1 \mathrm{~mm}$ compr., estigma capitado-emarginado.

Distribuição geográfica e hábitat: espécie tipicamente brasileira, com ocorrência nos estados da Bahia, Goiás e Minas Gerais, em campos rupestres e cerrados, em solos arenosos entre rochas, em altitudes que variam de 1.100-2.000 metros.

Material examinado: BRASIL. BAHIA: Abaíra, Campo da Pedra Grande, 30-I-1992, Lughadha et al. 51115 (CTES, MBM, UB); Água Quente, Pico das Almas, Vale NW do Pico, no campo rupestre, 29.XI.1988, Harley et al. 26696 (CEPEC, CTES, HRCB, HUEFS); Mucugê, Fazenda Pedra Grande, estrada para Boninal, 17-II-1997, Atkins et al. 5819 (ALCB, HUEFS, PACA); Piatã, Estrada Piatã-Ribeirão, no cerrado, 1-XI-1996, Bautista 3884 (CEPEC); Pico das Almas, em campo arenoso com afloramentos, 14-XII-1984, Stannard et al. s.n (HUEFS71798); Rio de Contas, arredores, em campo rupestre, 15-
V-1983, Hatschbach 46420 (CEPEC, CTES, ESA, MBM, UB); GoiÁs: Água Fria de Goiás, Rod. GO118, subida para a Torre repetidora de Roncador, no campo cerrado, entre rochas, 8-V-2000, Hatschbach et al. 70666 (BHCB, CTES, HUEFS); Alto Paraíso, Parque Nacional Chapada dos Veadeiros, trilha para as Cachoeiras de 80 a $120 \mathrm{~m}$, no cerrado, 10IX-1996, Mendonça et al. 2649 (IBGE); Chapada dos Veadeiros, Rod GO-118 Km 200, no campo rupestre, 9-V-2000, Hatschbach et al. 70733 (MBM); Cavalcante, ca. 7 Km South of Cavalcante, no cerrado, 8-III-1969, Irwin et al. 24025 (MG, NY, UB). Minas Gerais: Chapada da Contagem, ca. 25 Km NW of Brasília, no cerrado, 6-IX-1965, Irwin 8019 (MBM).

Pedersen (1990) dedicou esta espécie ao seu ilustre amigo Charles. C. Townsend, do Royal Botanic Gardens, Kew, Inglaterra, que também considerava esta espécie como nova para a ciência.

Pfaffia tuberculosa Pedersen, Adansonia sér. 3 19(2): 241. 1997. Tipo: BRASIL. BAHIA: Paramirirm, na caatinga/campo rupestre: Harley et al. 27180, 14XII-1988 (Holótipo K, Isótipos CTES!; HUEFS !, SPF !). Fotografia do Holótipo (K!).

Figura 17

Erva a subarbusto, caule ereto, cilíndrico, estriado, quando jovem densamente piloso a viloso, tricomas híspidos, quando adulto glabro, entrenós de 0,5-4 cm compr.; raiz tuberculosa semilenhosa. Folhas elípticas a largo-lanceoladas, 1,5-2,5 × 0,5$1 \mathrm{~cm}$, curto-pecioladas, pecíolos $0,3 \mathrm{~cm}$ de compr., ápice mucronado, base aguda, face adaxial pilosa, tricomas estrigosos, articulados, face abaxial densamente pilosa, tricomas estrigosos, articulados. Inflorescência capituliforme ou em espiga, isolada, simples, terminal, pedúnculo médio, $4-5 \mathrm{~cm}$ compr., densamente tomentoso, ráquis tomentosa. Bráctea mediana ovalada, ápice acuminado, pilosa no dorso, escariosa, uninervada, 2,5 $\mathrm{mm}$ compr., brácteas laterais ovalado-cordadas, ápice mucronado, dorsalmente piloso, univervadas, $3 \mathrm{~mm}$ compr. Sépalas oblongas, oblongo-ovaladas, 3-5 mm compr., escariosas, trinervadas, ápice agudo, densamente pilosas no dorso. Tubo estaminal mais curto que as sépalas, margens ciliadas, filamentos laterais ciliados, filamento anterífero linear. Ovário oblongo, $1 \mathrm{~mm}$ compr., anteras lineares a oblongas, 1,5 mm compr., estigma capitado-emarginado.

Distribuição geográfica e hábitat: até o presente, somente encontrada no estado da Bahia, em zonas 


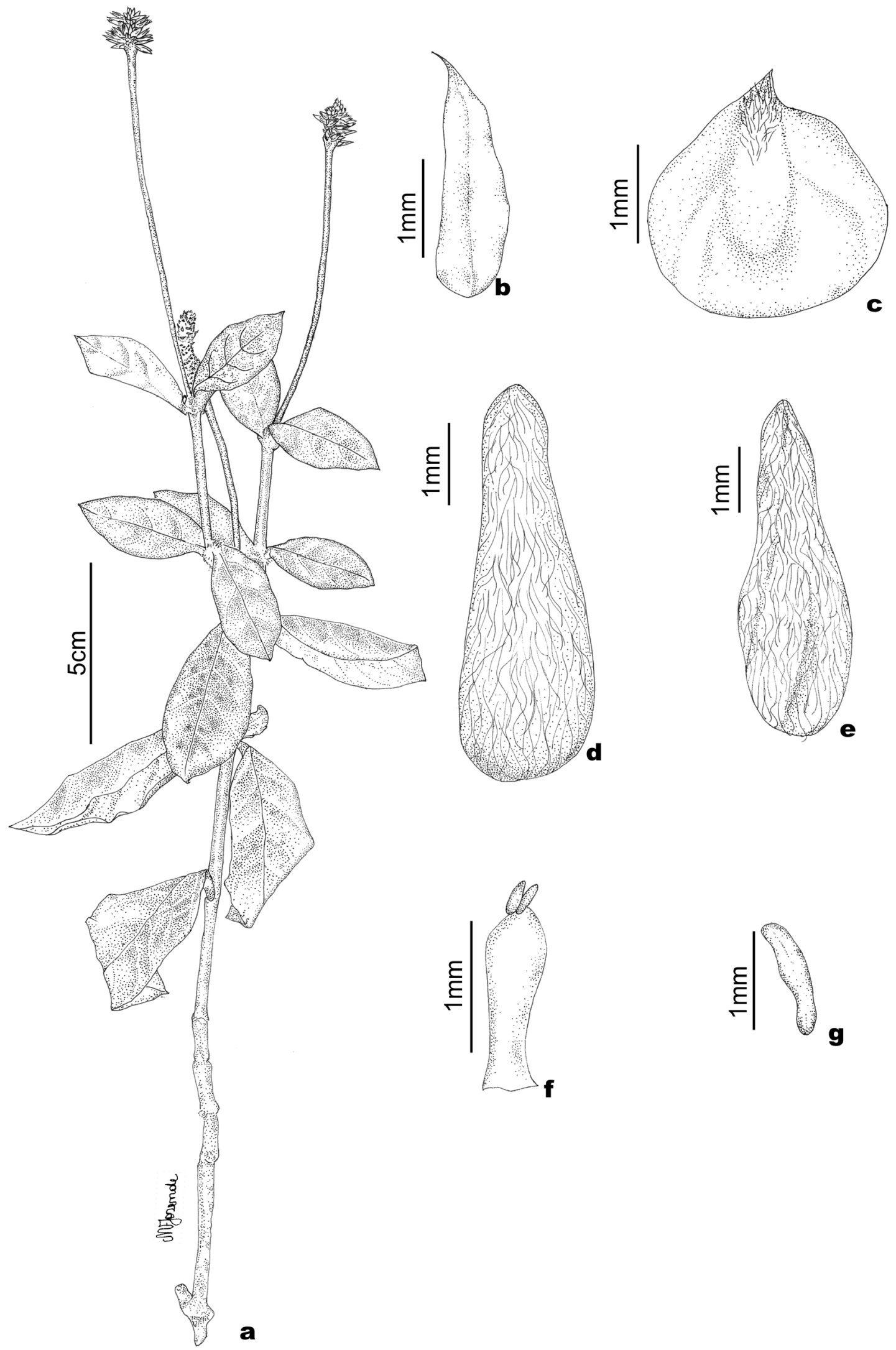

Figura 16. Pfaffia townsendii Pedersen. a. Ramo. b. Bráctea mediana. c. Bráctea lateral. d-e. Sépalas. f. Ovário. g. Antera (Lughadha et al. s.n., MBM).

Figure 16. Pfaffia townsendii Pedersen. a. Habit. b. Median bract. c. d. Lateral bract. d-e. Sepals. f. Ovary. g. Anther (Lughadha et al. s.n., MBM). 


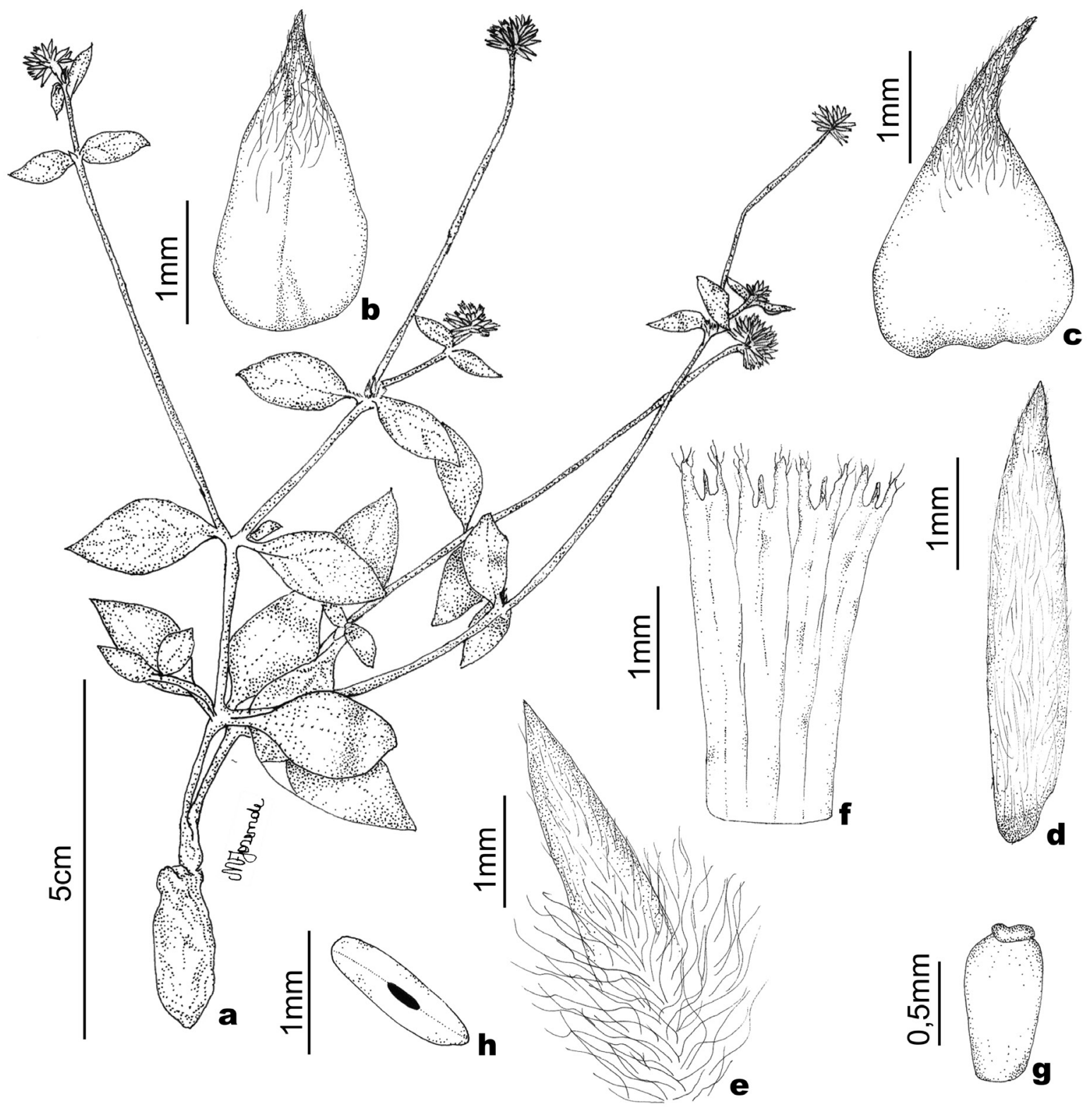

Figura 17. Pfaffia tuberculosa Pedersen. a. Hábito. b. Bráctea mediana. c. Bráctea lateral. d-e. Sépalas. f. Tubo estaminal. g. Ovário. h. Antera (Harley et al. 27180, HUEFS).

Figure 17. Pfaffia tuberculosa Pedersen. a. Habit. b. Median bract. c. d. Lateral bract. d-e. Sepals. f. Ovary. g. Anther (Harley et al. 27180 , HUEFS). 
de transição, entre caatinga e campo rupestre, em elevações de 640m, com solo arenoso e pedregoso. Material examinado: BRASIL. BAHIA: Paramirirm, na caatinga/campo rupestre, Harley et al. 27180, 14XII-1988. (K, CTES, HUEFS, SPF).

O epíteto provém da raiz semelhante a um tubérculo.

Pedersen (1997) relata que viu somente um exemplar desta espécie e comenta que o tufo de pêlos na superfície interna das tépalas é um caráter compartilhado com Pfaffia acutifolia (Moq.) Stützer, P. elata R.E. Fr., P. fruticulosa Suess., e P. rotundifolia Pedersen, espécies encontradas no oeste do Brasil Central, Paraguai e Bolívia. Pedersen (1997) pondera que este caráter não é taxonomicamente significativo.

Pfaffia tuberosa (Spreng.) Hicken, Apunt. Hist. Nat. 2: $93.1910 \equiv$ Gomphrena tuberosa Spreng., Syst. Veg. ed. 16. 1: 823. 1825. Tipo: Uruguai Montevideo: Sellow s.n. (Herbário não mencionado).

$=$ Gomphrena tuberosa Spreng var. vestita Moq. in DC; Prodr. 13(2): 388. 1849.

= Gomphrena tuberosa Spreng. var. glabrescens Moq. in DC., Prodr. 13 (2): 388. 1849.

= Gomphrena tuberosa Spreng. var. sericea (Spreng.) Seub. in Mart., Fl. Bras. 5(1): 195. 1875.

= Pfaffia tuberosa (Spreng.) Hicken subsp. goiana Pedersen, Adansonia, ser. 3, 19(2): 243. 1997. Tipo. BRASIL. Distrito Federal: Brasília, University Campus, cerrado, red. Dusty latosoil, 23-IX-1975: Oldenburger \& Mecenas 1531 (Holótipo U). syn nov.

= Gomphrena sericea Spreng., Syst. Veg. Ed. 16. 1. 823. 1825. Tipo: Uruguai Montevideo, Sellow s.n. (Herbário não mencionado) $\equiv$ Pfaffia sericea (Spreng.) Mart., Nov. Gen. Sp. P1. Br. 2: 387. 1826.

= Pfaffia sericea (Spreng.) Mart. f. vestita (Moq.) Stützer, Repert. Spec. Nov. Regni Veg. 88: 29. 1935.

Figura 18

Erva a subarbusto, 0,35-1 m de altura, caule ereto, delgado, lignificado na base, simples, ou ramificado, engrossado nas articulações, avermelhado, glabro a piloso, tricomas seríceos, articulados; entrenós de 3-9,5 cm compr.; raiz tuberosa, lenhosa. Folhas oblongas, ovaladas ou obovaladas, 3,3-11 × 0,8$3,5 \mathrm{~cm}$, curto-pecioladas a semi-amplexicaules, 0,5-1 cm compr., ápice agudo a mucrunolado, base decurrente, face adaxial pilosa, tricomas seríceos, articulados, face abaxial glabra a levemente pilosa, tricomas seríceos articulados, nervura principal proeminente. Inflorescência capituliforme ou em espiga, isolada, simples, di, ou tricotômica, terminal, pedúnculo longo, $10-20 \mathrm{~cm}$ compr., tomentoso, ráquis inflada, lanosa. Bráctea mediana ovalada, ápice agudo, glabra, $2 \mathrm{~mm}$ compr., brácteas laterais ovaladas, côncavas, ápice mucronulado, levemente cristado, piloso no ápice, 2-2,5 $\mathrm{mm}$ compr. Sépalas lanceoladas, trinervadas, densamente pilosas na base, ápice agudo, 3,5-4 mm compr. Tubo estaminal curto, com margens fimbriadas, filamentos laterais fimbriados, filamento anterífero subulado, diminuto, anteras linear-oblongas, $1,5 \mathrm{~cm}$ compr. Ovário ovalado ou obovalado, 0,5-1 $\mathrm{mm}$ compr., estigma capitado-emarginado, papiloso.

Distribuição geográfica e hábitat: espécie com distribuição na América do Sul, ocorrendo na Argentina, Paraguai, Uruguai e Brasil (Distrito Federal, Goiás, Minas Gerais, Mato Grosso, Mato Grosso do Sul, Paraná, Rio de Janeiro, Rio Grande do Sul, Santa Catarina e São Paulo), em cerrados, campos rupestres e campos secos, com solos arenosos, em altitudes que variam de 30-1.600 m.

Material selecionado: BRASIL. Distrito Federal: Brasília, Plano Piloto, cerrado, 5-V-1962, Heringer 8956 (Parátipos CTES!, NY!). Fazenda Água Limpa, University of Brasília field station, near Vargem Bonita, no cerrado, 6-XI-1966, Ratter et al. 4279 (NY); Chapada da Contagem, no cerrado, 19-VIII1964, Irwin \& Soderstrom 5149 (NY); Plano Piloto, 5-V-1975, Heringer, 8956 (CTES, NY). GOIÁS: Alto Paraíso, Serra dos Pirineus, 5-I-1972, Irwin et al. 34221 (NY); Alto Paraíso, Chapada dos Veadeiros, 3-II-1979, Gates \& Estabrook 107 (CTES, SP, UB). Mato Grosso do Sul: Brilhante, Rio Brilhante, próximo a Dourador, no cerrado, 25-I-1979, Irgang s.n (ICN43571). Minas Gerais: Caldas, 1846, Regnel II-226 (K, R); Diamantina, Rio Jequití, 13-III-1970, Irwin et al. 27447 (NY); Joaquim Felício, Serra do Cabral, no campo rupestre, 15-IV-1996 Hatschbach 64822 (CTES, MBM); Ituiutuba, BR 365, Córrego Fundo, no cerrado sencudário, 4-I-1989, Krapovickas \& Cristóbal 42776 (CTES); Parreiras, Fazenda da Serra, em fenda de rochas em campo queimado com elementos de capoeira, 7-XII-1940, Mello-Barreto 11060 (ESA, SPF); Rio Pardo de Minas, Serra Nova, Parque Estadual Serra Nova, em beira de trilha, 12III-2007, Marchioretto 318 (PACA); São Roque de Minas, PARNA Serra da Canastra, 12-I-1995, 

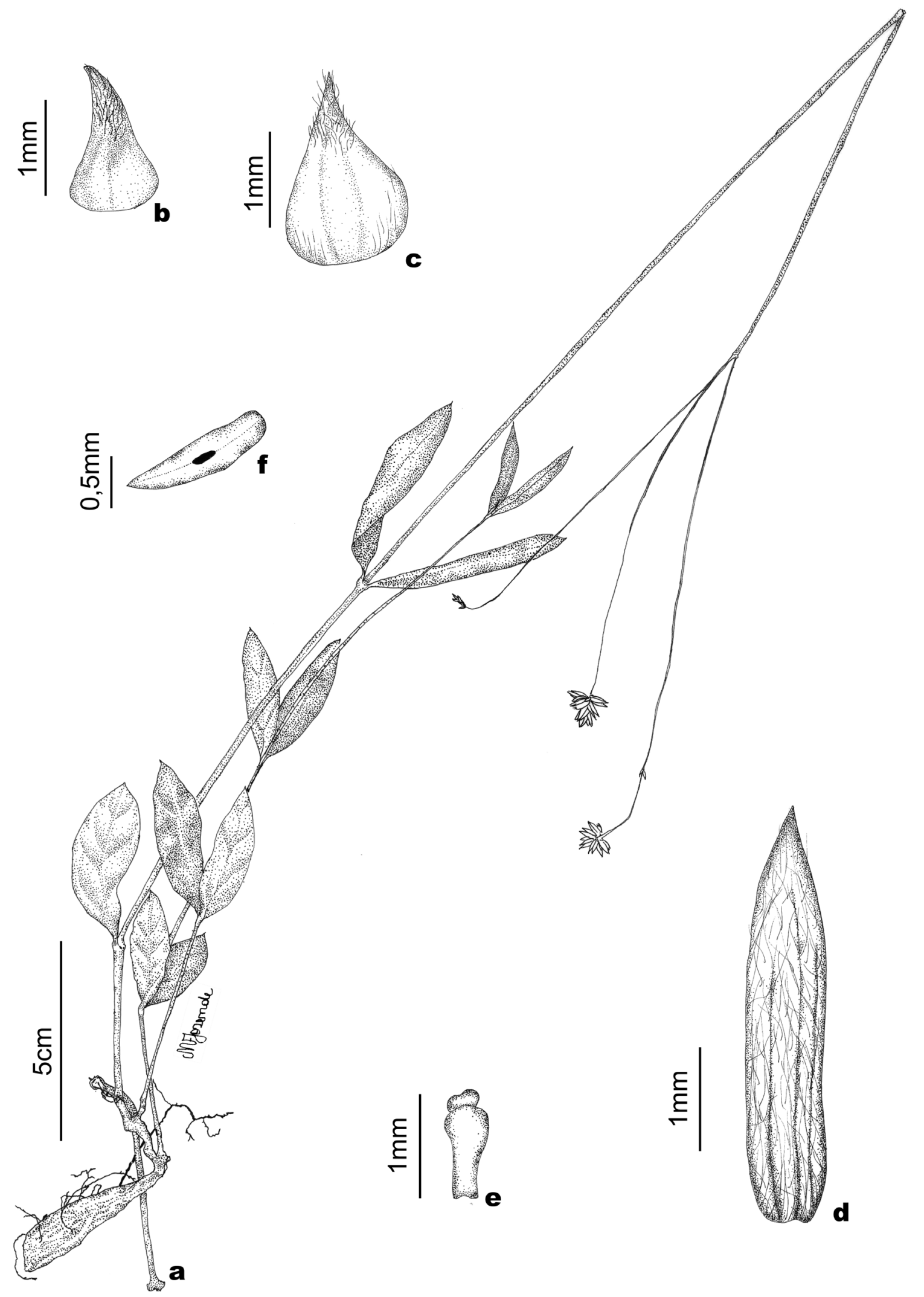

Figura 18. Pfaffia tuberosa (Spreng.) Hicken. a. Hábito. b. Bráctea mediana. c. Bráctea lateral. d. Sépala. e. Ovário. f. Antera (Marchioretto 182, PACA).

Figure 18. Pfaffia tuberosa (Spreng.) Hicken. a. Habit. b. Median bract. c. d. Lateral bract. d-. Sepal. e. Ovary. f. Anther (Marchioretto 182, PACA). 
Romero et al. 1742 (HRCB). PARANÁ: Araucária: na beira da estrada de ferro, X-1955, Moreira Filho 53 (SPF); Balsa Nova, Serra de Säo Luis, no campo, 14I-1965, Smith \& Klein 14433 (HBR); Castro, no campo recém revolvido, 20-III-1968, Hatschbach 18778 (CTES, HBR, NY); Eng. Bley p. Lapa, in siccis graminosis, 28-XI-1948, Hatschbach, 1106 (PACA, SI); Guarapuava, BR 373, Km 389, na mata, 14-I-1983, Pirani et al. 426 (SP, PACA, SPF); Ipiranga, $29 \mathrm{Km}$ de Ipiranga, no campo, 30-XI-1984, Mattos et al. 26560 (HAS); Jaguariaiva, em campo cerrado, 26-X-1977, Dombrowski, 8963 (CTES); Lapa, Assentamento Contestado, campo limpo seco, 7-III-2002, Ribas et al. 4509 (MBM); Mandirituba, Rio Mauricio, no campo seco, 23-II-1978, Hatschbach 41434 (CTES, NY); Palmeira, Rod. BR-277, no campo limpo seco, 4-II-1999, Hatschbach et al. 68968 (MBM); Ponta Grossa, 11-I-2007, Miotto 2494 (ICN); Quatro Barras, Rio Taquari, em campo ácido, 7-XII-1979, Hatschbach 41992 (CTES, MBM); Senges, Rio Velame, no cerrado recém queimado, 17-VI-1971, Hatschbach 26793 (CTES, MBM); Smith et al. 14433 (R); Tibagi, in fields and waste places, 17-XI-1935, Reiss 170 (NY); Vila Velha, Rodovia do Café, 24-V-1978, Ochioni 8428 (ICN). Rio DE JANEIRO: Sine loco, s.d, s.col. (R57803); Sine loco, s.d, s.col. (R173872); Sine loco, s.d, s.col. (R173871). Rio Grande do Sul: Aceguá, BR 153, Km 40, Miotto 2260, 19-XI-2005 (ICN); Alegrete, Cerro do Tigre, na subida do cerro, 20-XI-2003, Marchioretto 219 (PACA); idem, próximo ao Arroio Maleva, na beira da estrada, 20-XI-2003, Marchioretto 228 (PACA); idem, próximo da Reserva Biológica do Ibirapuitã, em campo sujo, 20-XI-2003, Marchioretto 192 (PACA); Bagé, Estrada para Bagé, Km 535, em beira de estrada, Marchioretto 124, 17-XI-2003 (PACA); idem, na beira do Rio Cabuçú, Marchioretto 131, 17-XI-2003 (PACA); Barra do Ribeiro, Sertão Santana, Hiltl 1213, 1-V-1982 (HAS); Bom Jesus, Faz. da Ronda, in siccis graminosis subdumetosis, Rambo 35003, 10-I-1947 (PACA, NY); Butiá, BR 290, Km 78, Mondin et al. 2141, 3-I-2001 (PACA); Caçapava do Sul, BR 13, Km 476, em beira de estrada, Marchioretto 120, 17-XI-2003 (PACA); Cachoeira do Sul, Irapuá, em beira de estrada perto do rio, 6-III-2006, Marchioretto 293 (PACA); Cambará do Sul, in graminosis siccis, II-1948, Rambo 36562 (PACA); Candiota, perto da Vila Operária de Candiota, no campo, Mattos et al. 25249, 30-XI1983 (HAS); Canela, caminho para São Francisco de Paula, 29-I-1994, Krapovickas \& Cristóbal 44687
(CTES); Carazinho, 28-I-1975, Pereira \& Pabst 8677 (CTES); Caxias do Sul, Vila Oliva, in siccis graminosis, 4-I-1946, Rambo 31037 (PACA); Cerro largo, p. São Luiz, in campestribus alte graminosis, 20-XI-1952, Rambo 53084 (PACA); Chiapeta, no campo sujo, 28-IV-1981, Mattos et al. 23925 (HAS); Cruz Alta, no Km 226, no campo, 28-IV-1988, Mattos et al. 31595 (HAS); Dom Pedrito, Estrada para Santana do Livramento, na beira de estrada, 18-XI2003, Marchioretto 139 (PACA); Esmeralda, na estrada Esmeralda-Barracão, na beira da estrada, 23$\mathrm{X}-1985$, Vascocellos et al. 221 (HAS); General Câmara, no campo sujo, 20-XI-1977, Mattos et al. 17644 (HAS); Gravataí, Banhado dos Pachecos, 28I-1976, Soares et al. s.n (HAS3484); Guaíba, 30-X1961, Pabst et al. 6402 (CTES, HAS, R); Itaquí, Fazenda 3 de outubro, 12-V-1985, Mentz \& Stehmann s.n (ICN88884); Júlio de Castilhos, a $20 \mathrm{Km} \mathrm{N}$ de Santa Maria, em campo com terreno pedregoso, 21-I1978, Mattos et al. 18151 (HAS); Lagoa Vermelha, in siccis graminosis, I-1943, Friderichs s.n (PACA10921); Maquiné, na Estação Experimental Fitotécnica, no campo sujo, 26-IV-1979, Mattos et al. 22080 (HAS); Montenegro, Pólo Petroquímico, 18VIII-1977, Bueno 390 (HAS); Mostardas, Lagoa do Peixe, em campo arenoso, 21-II-1970, Baptista et al. s.n (ICN7530); Novo Hamburgo, Parque Municipal Henrique Roessler, em campo degradado, 3-VII1994, Mauhs 386 (PACA); Pântano Grande, BR 290, $\mathrm{Km}$ 108, em campo úmido na beira da estrada, 30-I1984, Neves 356 (HAS); Passo Fundo, no campo, 22V-1977, Mattos et al. 1770 (HAS); Pinheiro Machado, no campo, 15-III-1978, Mattos et al. 18600 (HAS); Planalto, Entre Planalto e Alegrete, 5-XII-1973, Valls et al. s.n (ICN 30753); Porto Alegre, Morro da Polícia, 13-III-1992, Longhi-Wagner et al. 2538 (ICN); Quarai, Cerro do Jarau, no campo, 19-XI2003, Marchioretto 153 (PACA); Rosário do Sul, BR $290 \mathrm{Km} \mathrm{497,} \mathrm{na} \mathrm{beira} \mathrm{da} \mathrm{estrada,} \mathrm{20-XI-2003,}$ Marchioretto 231 (PACA); Santa Bárbara do Sul, no Campo, 10-XII-1974, Arzivenco s.n (ICN); Santa Maria, Estação Experimental de Silvicultura, num vassoural, 31-III-1977, Mattos et al. 17001 (HAS); Santa Vitória do Palmar, Estação Ecológica do Taim, na margem da estrada, 13-XII-1986, Jarenkow 555 (PACA); Santana do Livramento, em beira de estrada, 18-XI-2003, Marchioretto 151 (PACA); idem, Cerro Armour, 16-XI-1975, Porto et al. 1818 (ICN); idem, Cerro Palomas, no alto do cerro, 18-XI-2003, Marchioretto 140 (PACA); Santiago, Estrada entre Santiago e Bossoroca, Km 08, em beira de estrada, 
5-X-2004, Marchioretto 246 (PACA); Santo Antônio das Missões, BR 285, junto da ponte do Rio Pessegueiro, 5-X-2004, Marchioretto 252 (PACA); São Borja, Fazenda Nhamandu, junto ao canavial, 5-II-2006, Bastos-Záchia s.n (PACA82006); São Francisco de Assis, a $7 \mathrm{Km}$ de Manoel Viana, no campo, 17-X-1979, Mattos et al. 19361 (HAS); São Francisco de Paula, Floresta Nacional, na borda da estrada, 8-I-2003, Marchioretto s.n (PACA); São Francisco do Sul, Estrada para Santiago, RS 377, Km 316, na encosta em beira de estrada, 4-X-2004, Marchioretto 243 (PACA); São Gabriel, BR 290, na beira de estrada, 20-XI-2003, Marchioretto 239 (PACA); São Jerônimo, Pólo Carboquímico, no campo, 18-X-1982, Dutra 85, (HAS); São José dos Ausentes, no campo: Silveira 5218, 8-II-1988 (HAS); São Lourenço, na encruzilhada, 17-I-1979, Mattos et al. 19166 (HAS); São Miguel das Missões, em beira de estrada, 7-X-2004, Marchioretto 258 (PACA); São Pedro do Sul, BR 287, Km 290, em beira de estrada, 4-X-2004, Marchioretto 264 (PACA); São Vicernte do Sul, BR 241, Km 46, em local a pouco tempo queimado, 4-X-2004, Marchioretto 241 (PACA); Soledade, BR 386, Km 190, após Vila Assis, 12-XI-1977, Miotto 609 (ICN); Tapes, BR 116, 10 $\mathrm{Km}$ após Tapes, Km 93, na beira da estrada, 8-X1977, Miotto 520 (ICN); Tupanciretan, in siccis graminosis, 29-I-1942, Rambo 9797 (PACA); Triunfo, 6-IX-1977, Ungaretti 602 (HAS); Uruguaiana, Granja Guará, na beira da estrada, 19XI-2003, Marchioretto 167 (PACA); idem, Arroio Imbaá II, BR 472, próximo à ponte em beira de estrada, 19-XI-2003, Marchioretto 181 (PACA); Vacaria, ca. de $8 \mathrm{Km}$ do Passo do Socorro, no campo sujo, 2-XI-1983, Mattos et al. 25396 (HAS); Viamão, no campo, 3-I-2003, Marchioretto s.n (PACA). SANTA Catarina: Água Doce, BR 153, 12-I-2007, Miotto 2504 (ICN); Campo Erê, 17 Km O de Campo Erê, no campo, 7-XII-1964, Smith \& Klein 13800a (HBR,

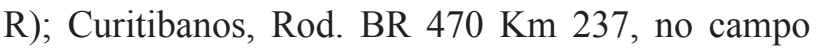
limpo seco, 11-II-1996, Ribas et al. 1236 (BHCB, MBM, UB); Florianópolis, Ressacada, 20-XI-1969, Klein \& Bresolin 8490 (HBR, ICN, PACA); Irani, no campo, 28-XII-1963, Reitz \& Klein 16473 (HBR); Lajes, BR $282 \mathrm{Km} \mathrm{199,} \mathrm{em} \mathrm{beira} \mathrm{de} \mathrm{estrada,} \mathrm{10-I-}$ 2006, Marchioretto 267 (PACA); Lebon Regis, BR

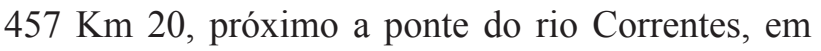
beira de estrada, 11-I-2006, Marchioretto 275 (PACA); Mafra, in campestribus, 26-I-1962, Reitz 5265 (HBR, NY, PACA); Orleães, serra do Rio do Rastro, na estrada, 29-I-1950, Reitz 3335 (HBR); São
Joaquim, near Encruzilhada de Boava, $8 \mathrm{~km}$ south of São Joaquim, no campo, 5-I-1965, Smith \& Reitz 14270 (R); Videira, na Encruzilhada do Caçador, no campo, 25-III-1960, Mattos 7614 (HAS); São PaUlo: Botucatu, no cerrado, 22-XI-1968, Sendulsky 884 (SP, PACA); Cabreúva, Jacaré, no cerrado, 8-III1994, Barreto et al. 2107 (ESA); Ipiranga, 27-II1886, Glaziou 16309 (P); Itararé, Rodovia ItapevaItararé, próximo à ponte do Rio Verde, em área de banhado com transição para o cerrado, 30-X-1993, Souza 4414 (ESA); Itapeva, Estação Ecológica de Itapeva, 12-XI-1994, Souza et al. 7026 (BHCB); Itatinga, $26 \mathrm{Km}$ de Itatinga em direção a Angatuba, no posto em área originalmente ocupada por cerrado, 27-IV-1996, Souza 605 (ESA); Mogi, 1833, Riedl 1680 (K); Mogi-Guaçu, Pádua Sales, na Reserva Florestal, Fazenda Campininha, no cerrado, 17-XI1960, Mattos et al. s.n (HAS51143); Moji-Mirim, Cia Luz e Força, 2-VI-1939, Viégas \& Zagatto s.n (IAC4518); São Roque, Caeté , $50 \mathrm{Km}$ W from São Paulo, on grasse gentle slope, 2-XII-1987, Tsugaru et al. 2225 (NY); Tatuí, no cerrado degradado, 3-XII1974, Mattos \& Mattos 16300 (SP); Sine loco, 18161821, Saint-Hilaire 1152 (P); Sine loco, s.d, Riedel 1780 (NY).

Material adicional examinado: ARGENTINA. Córdoba: Pocho, 28-XI-1967, Luti 4317 (SI); Corrientes: Concepción, Carambola, 12-V-1986, Pedersen 14559 (HUEFS); Mercedes, Ayo. Medina, camino desde Ruta 3 a San Roquito, em terrenos modificados, 5-I-1975, Irigoyen et al. 185 (ESA); San Martín, La Cruz, Tres Cerros, 22-X-1976, Cabrera 28123 (SI); San Miguel, 01-III-1990, Vanni 1547 (CTES, SI, UB); San Roque, 22-X-1996, Arbo 6708 (CTES, SI); Santo Tomé, 30-I-1982, Troncoso 3389 (SI); 20-I-2000, Arbo 8655 (CTES, SI); Misiones: Candelaria, 29-IV-1997, Morrone 2215 (SI); idem, 09.XII.1991, Rodríguez 304 (SI); Capital, 8-XII1900, Gallardo, s.n (SI5530); Entre Rios: Colón, Parque Nacional El Palmar, 3-XII-1982, Troncoso et al. 3498 (SI); Santiago, Estancia La Soledad, 23-XII1965, Pedersen 7649 (CTES); San Ignácio, 22-VIII1978, Cabrera 29359 (SI); idem, Santa Ana, 24-III1910 Rodriguez 228 (SI). PARAGUAI. AmAMBAY: 23 X-1994, Krapovickas 45936 (CTES, SI); Caballero, Fazenda Cerro-Cora, no cerrado, 15-II-1964, Gomes Júnior 1585 (SP, PACA); Canindeyú, s.d, Jiménez 1425 (CTES, SI); Itapúa, 7-X-1993, Krapovickas 44461 (CTES, SI); Carrendiyú, Lagunita, 23-IX1988, Pedersen 15096 (CTES); Hernandarias 6 Km, Reserve Tajipuji, 7-I-1985, Ortega 2142 (NY); 
San Pedro, Lima, Estancia Carumbé, 10-X-1967, Pedersen 8609 (CTES). URUGUAI: Cerro de Montevideo, Costa del Swift, II-1938, Chebataroff 33 (BHCB); Juan Jackson Soriano, II-1945, Rosengurtt s.n (PACA30176); Lavalleja, Minas, 8-V-1935, Legrand 6622 (BHCB); MaldonAdo: Cavalleja, em Águas Lancas, no campo, 1951, Mattos 225 (HAS); idem, 6-XII-1997, Neffa, 406 (CTES); Montevideu, Atahualpa, XI-1925, Herter 222 (SI); Tacuarembó, 11-XII-1997, Neffa, 419 (CTES, SI).

O nome da espécie é relativo à raiz tuberosa que segundo Smith \& Downs (1972), provém da base inchada e lenhosa da planta. Em Santa Catarina é vulgarmente conhecida como corango-de-batata.

Lindman (1906) denominou de campos Amarantáceos, os campos dos morros de Porto Alegre, Rio Grande do Sul, devido à ocorrência constante de P. tuberosa, fato este observado até os dias de hoje. Smith \& Downs (1972) comentaram ser a espécie xerófita e heliófita, muito freqüente em campos limpos, secos, pedregosos, apresentando distribuição bastante uniforme, sem formar agrupamentos. Smith \& Downs (1972) ainda ressaltaram que a planta é muito comum e característica entre as gramíneas dos campos secos, chamando a atenção sua inflorescência cimosa, paleácea a branca, em forma de glomérulos. Vasconcellos (1986) comentou ser esta espécie muito freqüente em todas as regiões do Rio Grande do Sul, principalmente, em campos secos e arenosos. Para Siqueira \& Grandi (1986) esta espécie foi pouco coletada em Minas Gerais, mas parece ocorrer tanto no cerrado como em campos rupestres. Pedersen (1987) citou que a espécie é muito difundida no sul do Brasil, Paraguai, sendo muito comum em areais da Mesopotâmia, no nordeste argentino e também em cultivos. Pedersen (1987) ainda comentou que provavelmente a espécie possa ser um relicto da vegetação primitiva.

Handro (1965), também tratou P. tuberosa como $P$. sericea e destacou que o pólen da espécie é similar ao de $P$. jubata pelo murus simplificado baculado. Cuadrado (1988) examinou os grãos de pólen de espécies de Pfaffia ocorrentes no nordeste argentino e destacou que $P$. tuberosa apresenta grãos com 3334 poros, o diâmetro dos grãos é de 11-12 $\mu \mathrm{m}$ e o diâmetro dos poros é $2 \mu \mathrm{m}$.

Seubert (1875) incluiu a espécie na secção Pfaffia, fez uma breve descrição apresentando três variedades: sericea, vestita e glabrescens. Stützer (1935) designou a espécie de $P$. sericea, atualmente sinônimo de $P$. tuberosa, com a variedade foliosa e as formas eusericea, vestita e glabrescens.

Neste trabalho, Pfaffia tuberosa subsp. goiana está sendo considerada sinônimo novo de $P$. tuberosa. Após o exame dos parátipos e de outros exemplares, inclusive o citado por Pedersen (1997) como holótipo, concluíu-se que apesar de apresentarem inflorescências maiores, e menor quantidade de tricomas no caule, não se justifica manter esta subespécie. Pfaffia tuberosa tem uma ampla distribuição em praticamente todo território brasileiro e também na Argentina, Paraguai e Uruguai em distintos ecossistemas, sob condições edáficas e climáticas diferentes. A diversificação de ambientes muitas vezes condiciona o número, tamanho e forma de algumas estruturas vegetativas e/ou reprodutivas. O próprio autor da subespécie argumentou, quando da sua descrição, que era um tratamento provisório.

Pfaffia velutina Mart., Nov. Gen. Sp. P1. 2: 23.1826 $\equiv$ Gomphrena velutina (Mart.) Moq. in DC., Prodr. 13: 389. 1849. Tipo: BRASIL. s.d.: Riedel 2710 (NY!). Fotografia do tipo (NY!).

Figura 19

Subarbusto 0,20-0,90 m de altura, caule ereto, ramoso, piloso ou velutino, tricomas patentes, rufescentes, articulados; entrenós de 7,5-12 cm compr.; raiz semilenhosa. Folhas ovalado-elípticas, oblongo-ovaladas ou oblongas, 3-8,2 $\times 1,5-5 \mathrm{~cm}$, curto-pecioladas, $0,5-1 \mathrm{~cm}$ compr., densamente pilosos ou velutinos, tricomas, rufescentes, articulados; ápice mucrunolado ou aristado, base aguda, face adaxial e face abaxial densamente pilosas ou velutinas, tricomas, rufescentes, articulados. Inflorescência em espiga, isolada, simples ou tricotômica, terminal pedúnculo longo $7-12 \mathrm{~cm}$ compr., densamente piloso ou velutino, tricomas rufescentes, articulados, ráquis densamente vilosa. Bráctea mediana lanceolada, ápice acuminado, uninervada pilosa, mais densamente vilosa no ápice 3,5-4 mm compr., brácteas laterais ovaladas, ápice agudo, uninervadas, pilosas, mais densamente vilosas no ápice, 3,5-4,5 $\mathrm{mm}$ compr. Sépalas lanceoladas, ápice agudo, trinervadas, densamente vilosas no dorso, 6-7 mm compr. Tubo estaminal com margem ciliada, filamentos laterais fimbriados, filamento anterífero agudo, anteras oblongas, sagitadas, 1,51,7mm compr. Ovário oblongo, 1,5-2 mm compr., estigma capitado.

Distribuição geográfica e hábitat: espécie brasileira, ocorrendo somente no estado de Minas Gerais, em cerrados e campos rupestres, freqüentemente 


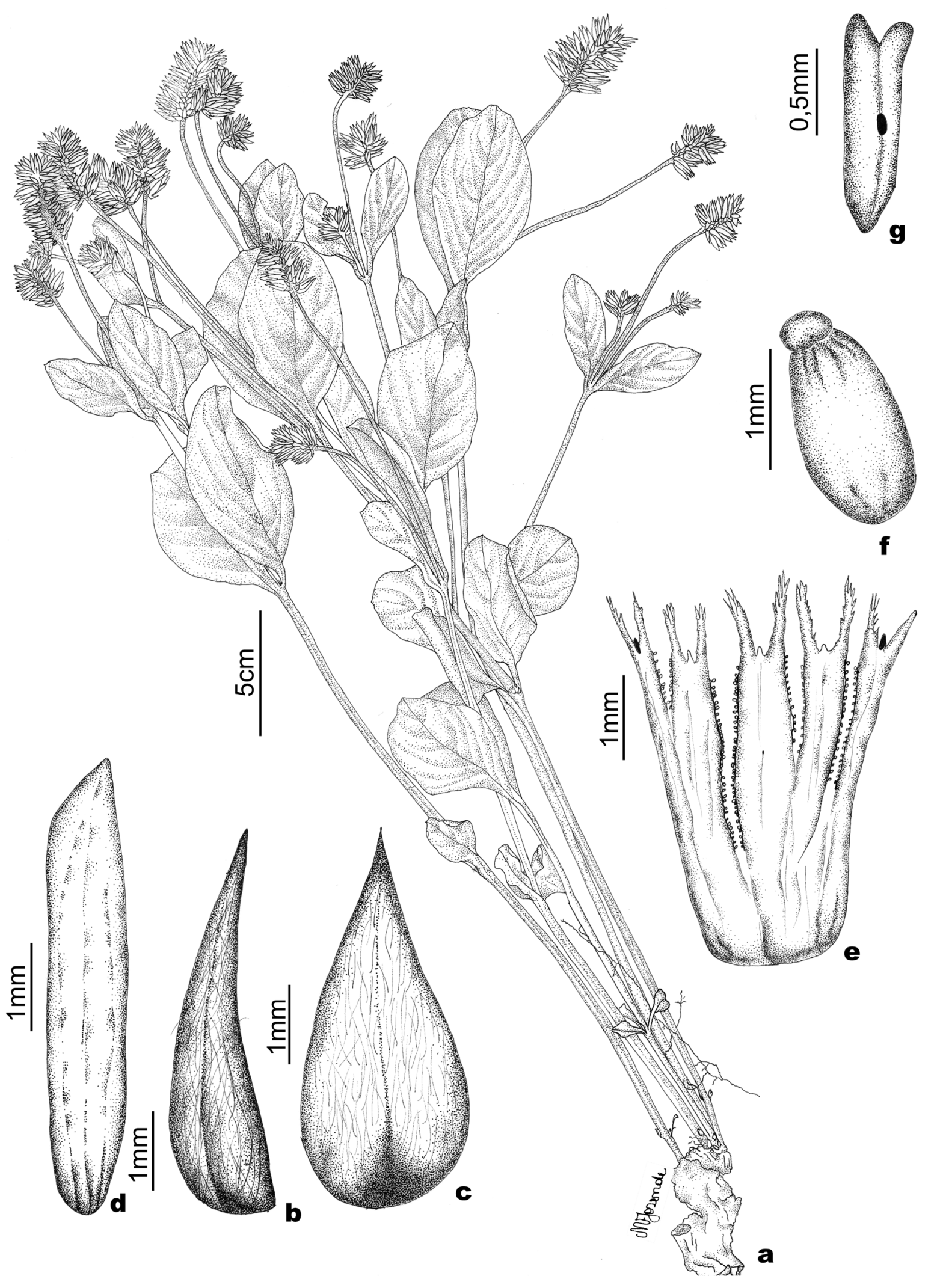

Figura 19. Pfaffia velutina Mart. a. Hábito. b. Bráctea mediana. c. Bráctea lateral. d. Sépala. e. Tubo estaminal. f. Ovário. g. Antera (Hatschbach et al. 41674, MBM).Figure 19. Pfaffia velutina Mart. a. Habit. b. Median bract. c. d. Lateral bract. d-. Sepal. e. Staminal tube. f. Ovary. g. Anther (Hatschbach et al. 41674, MBM). 
encontrada após as queimadas, em solos arenosos, com altitudes que variam de $600-1.410 \mathrm{~m}$.

Material examinado: BRASIL. Minas GeraIs: Arcos, Fazenda do Engenho, Calciolândia, no cerrado, 12X-1940, Oliveira 211 (BHCB, UB); Belo Horizonte, Parque das Mangabeiras, no cerrado, X-1984, Siqueira s.n (BHCB5553); Brumadinho, Retiro das Pedras, Serra da Calçada, VIII-2002, Viana 264 (BHCB); Couto-Magalhães, VII-1984, Furlan s.n (HRCB); Diamantina, Natureza, no campo queimado, 10-XI1937, Mello-Barreto 9723 (BHCB); Entre Pirapora e Montes Claros, 18-IX-1963, Castellanos 24372 (GUA, NY); Gouveia, Serra do Espinhaço, rodovia para Barão do Guaçui, no campo rupestre, 24-X-1999, Hatschbach et al. 69654 (MBM); Lagoa Santa, s.d, Warming s.n (NY); Nova Lima, em campo cerrado, 27-X-1982, Andrade et al. 1218 (BHCB); idem, Retiro das Pedras, no campo rupestre, 22-X-1999, Lombardi 3305 (BHCB); Ouro Preto, Rodrigo Silva, no campo, 18-IX-1977, Badini s.n (CTES378167, VIC); Paracatu, Córrego Rico, em campo cerrado, 24-X-1978, Hatschbach et al. 41674 (CTES, MBM); Paraepeba, VIII-1930, Rodrigues-de-Souza s.n (R); Pedro Leopoldo, Lapa Vermelha, no cerrado, 17-X1977, Prous \& Pedersoli s.n (BHCB1913); Pouso Alto, 29-III-1964, Trinta \& Fromm 693 (CTES); Santa Luzia, Lagoa Santa, no cerrado queimado, 28-IX-1939, Mello-Barreto 9210 (R); Santana do Riacho, Km 87 ao longo da rodovia Belo HorizonteConceição do Mato Dentro, próximo do Rio Cipó, no cerrado, Cordeiro et al. s.n (SPF20481, PACA); Serra de São José Del Rei, in campis, XI-1895, Silveira 1918 (R); Sete Lagoas, 1-XI-1971, Cardoso 87 (CTES, R); $13 \mathrm{Km}$ by road SW of Rio Jequetí et Mendanha, on road to Diamantina, no cerrado, 15IV-1973, Anderson 8983 (UB).

Handro (1965) destacou que os grãos de pólen de Pfaffia velutina são similares aos de $P$. jubata com murus simplificado ou duplificado, baculado. Handro (1967) comentou que a venação de $P$. velutina apresenta terminações de xilema com muitas células e que as nervuras apresentam maior espessura em virtude do maior número de elementos do xilema. Os tricomas apresentam superfície lisa variando, consideravelmente, na mesma espécie, o seu comprimento e espessura.

Siqueira \& Grandi (1986) comentaram que $P$. velutina apresenta uma distribuição geográfica bastante reduzida, porém, é uma das espécies mais freqüentes nos cerrados e campos rupestres de Minas Gerais, sendo fácilmente encontrada após as queimadas.

Secção Serturnera (Mart.) Endl.

Pfaffia glomerata (Spreng.) Pedersen, Darwiniana 14(2-3): 450. 1967 IIresine glomerata Spreng., Neue Entdeck. 2: 110. 1821. Tipo: In Brasilia, s.col., s.d.(M).

= Gomphrena stenophylla Spreng., Syst. Veg. Ed. 16. 1: 823. 1825. 三 Pfaffia stenophylla (Spreng.) Stuchl., in Feddes Repert. Spec. Nov. Regni.Veg. 12: 357. 1913.

= Sertürnera glauca Mart., Nov. Gen. Sp. P1. 2:37. 1826 三 Pfaffia glauca (Mart.) Spreng., Curae Post. In Syst. Veg: 107. $1827 \equiv$ Gomphrena glauca (Mart.) Moq. in DC., Prodr. 13(2): 384. $1849 \equiv$ Mogiphanes glauca (Mart.), Grisb., Abh. Königl. Ges. Wiss. Göttengen 24: 35. 1879 E Alternanthera glauca (Mart.) Hossens, Bol. Acad. Nac. Ci. 26: 60. 1921. Tipo: BRASIL. Minas Gerais: Lagoa Santa, Warming s.n, s.d (NY!).

= Sertürnera luzulaeflora Mart., Nov. Gen. Sp. P1. 2: 39. 1826 三 Pfaffia luzulaeflora (Mart.) D. Dietr., Syn. Pl. 1: 868. 1839 E Gomphrena luzulaeflora (Mart.) Moq. in DC. Prodr. 13(2): 384. 1849.

= Paffia luzulaeflora var. microcephala Stützer ex Suess. in Repert. Sp. Nov. Regni. Veg. 35: 332. 1934.

= Pfaffia luzulaeflora f. gracilis Stützer, Repert. Sp. Nov. Regni. Veg, 35: 332. 1934.

= Pfaffia luzulaeflora var. paniculata Stützer, Repert. Sp. Nov. Regni. Vegni, 35: 332. 1934.

= Pfaffia luzulaeflora var. virgata Stützer, Repert. Sp. Nov. Regni. Vegni, 35: 332. 1934.

$=$ Gomphrena dunalina Moq., Nov. Gen. Sp. Pl. 2: $37.1826 \equiv$ Mogiphanes dunalina (Mart.) Grisb., Abh. Königl. Ges. Wiss. Göttengen 24: 35. 1879 三 Pfaffia dunalina (Moq.) Schinz, in Engler \& Plantl., Pflanzenfamilien, 2. Aufl, 16c: 68. 1934.

= Pfaffia iresinoides var. angustifolia Stützer, Repert. Sp. Nov. Regni. Veg. Beih. 88: 34. 1935. Tipo: PARAGUAI. Sudl. Von Villa Ocidental, II-1879, Lorentz 16 (B).

= Pfaffia vana S. Moore, Trans. Linn. Soc. London. Bot. Ser. II Bd. 4S. 443. 1895. Tipo: BRASIL. Mato Grosso: Crescit ad Santa Cruz, ubi mens. Oct. Floret, Spencer 654, 7-XI-1893. (B!), Fotografia do tipo (B!), syn. nov.

Figura 20 


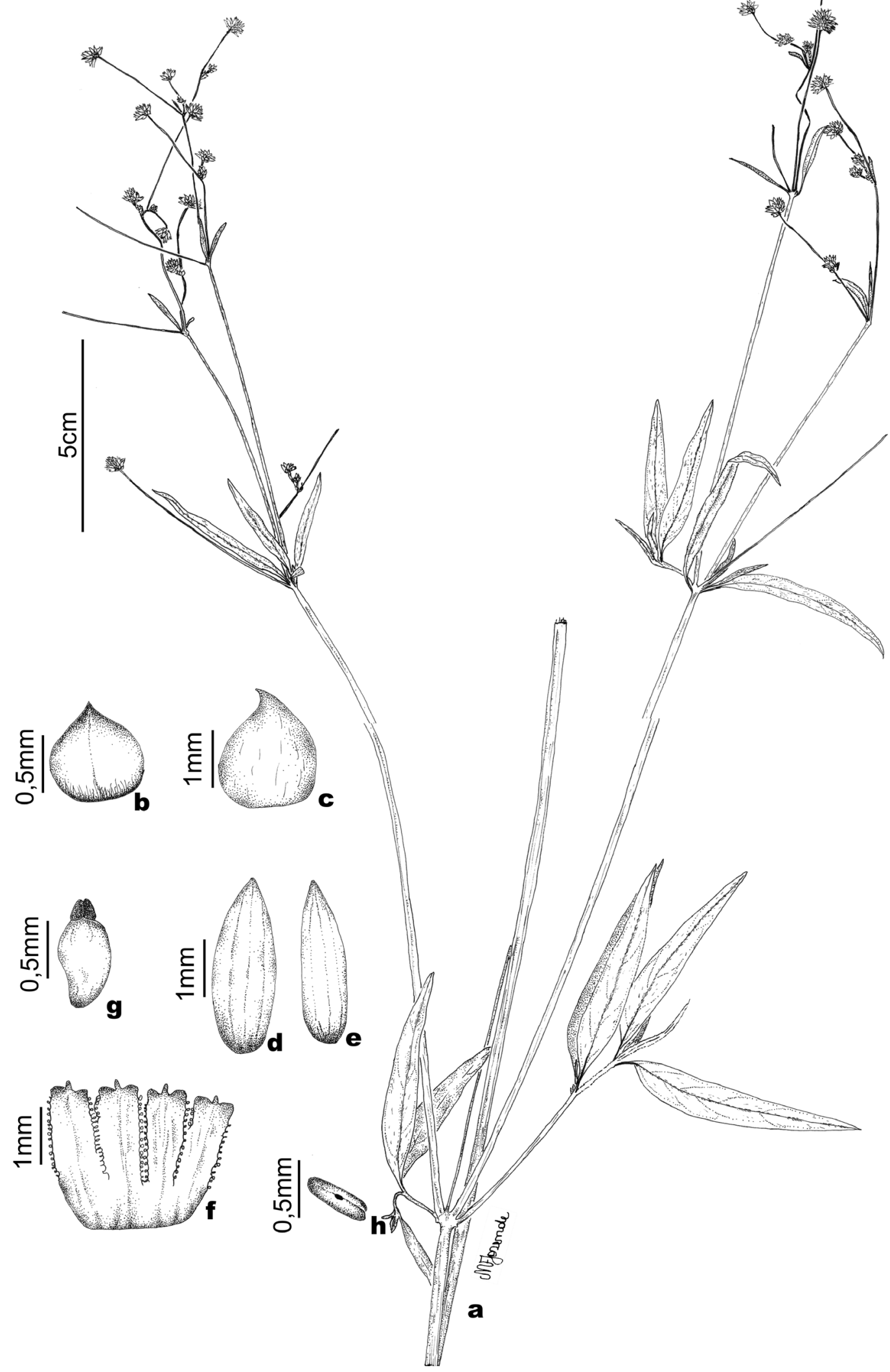

Figura 20. Pfaffia glomerata (Spreng.) Pedersen. a. Ramo. b. Bráctea mediana. c. Bráctea lateral. d-e. Sépalas. f. Tubo estaminal. g. Ovário. h. Antera (Jörssen s.n., NY).Figure 20. Pfaffia glomerata (Spreng.) Pedersen. a. Habit. b. Median bract. c. d. Lateral bract. d-e. Sepals. f. Staminal tube. g. Ovary. h. Anther (Jörssen s.n., NY). 
Erva a subarbusto, 0,40-3 m de altura, caule semiprostrado, lenhoso na base, fistuloso, engrossado nos nós, estriado, glabro a piloso, tricomas setosos a estrigosos articulados, densamente ramificados dicotômica ou tricotômicamente; entrenós de 3,0-27 cm compr.; raiz suculenta. Folhas linear-oblongas, linear-laceoladas, lanceoladas, ovalado-lanceoladas, 3,0-15,0 × 0,2-3,5 cm, pecíolos 0,5-2 cm compr., brevemente pilosos, ápice agudo a acuminado, base decurrente, face adaxial glabra a levemente pilosa, tricomas estrigosos, articulados, face abaxial com nervuras mais proeminentes, pilosas, tricomas estrigosos a híspidos. Inflorescência capituliforme ou em espiga, reunidas em dicásios, simples, di ou tricotômica, terminal, pedúculo curto ou longo, 2-20 cm compr., breve a densamente piloso, tricomas estrigosos ou híspidos, ráquis densamente lanosa. Bráctea mediana ovalada, ápice agudo, acuminado ou mucronado, univervada, hialina, pilosa na base, 1-1,5 $\mathrm{mm}$ compr., brácteas laterais ovaladas, côncavas, ápice apiculado, hialinas, glabras a levemente pilosas no dorso, $1 \mathrm{~mm}$ compr., pequena quantidade de tricomas alvos entre as brácteas e sépalas. Sépalas oblongas, oblongo-lanceoladas, ápice agudo, trinervadas, glabras, 2-3,5 mm compr. Tubo estaminal mais curto que as sépalas, margens fimbriadas, filamentos laterais subtriangulares ou quadrangulares fimbriados, filamento anterífero subulado, inteiro e maior que os laterais, anteras oblongas, $0,5-0,8 \mathrm{~mm}$ compr. Ovário ovalado-globoso, 1,2-1,5 mm compr., estigma capitado-bilobado, papiloso.

Distribuição geográfica e hábitat: espécie bastante difundida no sul da América tropical e subtropical chegando até a beira austral do Rio da Prata (Pedersen 1987). Para Stützer (1935), a espécie encontra-se distribuída no México, Guianas, Bolívia, Peru, Colômbia, Paraguai, Argentina, Uruguai e Brasil. No Brasil é encontrada em todas as regiões e praticamente em todos os Estados, em borda de rios, orla de matas, com solos arenosos, úmidos, em altitudes que variam de $80-800 \mathrm{~m}$.

Material selecionado: BRASIL. AMAPÁ: Macapá, Canteiro do Museu, em área de vegetação invasora, 9-IV-1980, Rabelo 403 (MG); On north bank of Amazon, ca. $1 \mathrm{Km}$ east of Arumanduba W Pará, $27-$ VII-1961, Egler \& Irwin 46017 (MG); Rio Araguarí, no campo aberto, 22-VII-1951, Froes \& Black 27577 (IAN). Amazonas: Maués Airport Road, between Maués and Airport, 27-IV-1974, Campbell et al. s.n (CTES, MG 49432, R); Parque Nacional do Jau, 2-X1995, Rodrigues s.n (SP); Rio Negro between Iha
Uabetuba \& Ilha da Silva, 14-X-1971, Prance et al. 15238 (NY, R); Manaus, BR 17, Km 9, 17-I-1955, Chagas s.n (MG21628); Falls of Madeira, X-1886 Rusby 1517 (NY). BAHIA: Casa Nova, Rio São Francisco, 4-VIII-1939, Mendes s.n (IAC4942); Cruz das Almas, 10-II-1993, Pinto 18 (CTES, HRB, RB); Feira de Santana, 1983, Nepanuceno s.n (HUEFS73191); Ilhéus, Vila do Rio do Engenho, barragem do Rio Santana, 27-II-1998, Costa 12 (CEPEC); Jequié, banks of Rio de Contas, 31-III1976, Davidse \& D'Arcy 11654 (SP); Lençóis, BR 472, ca. $70 \mathrm{Km}$ de Ibotirama, 6-VI-1996, Franca et al. 1662 (HUEFS); Rodelas, Itacoatiara, 21-I-1987, Mattos-e-Silva et al. 12 (ALCB, CEPEC, HUEFS, HRB); Mucurí, BR 101, Vale do Rio Mucurí, na margem do rio, 1-IV-1971, Santos 1525 (CEPEC); Paraguaçu, Amélia Rodrigues, Comunidade de Campos, 27-XI-1999 Santana et al. 32 (ALCB); Simões Filho, ca. 4 Km da Av. Urbana, 24-II-1992, Fonseca s.n (ALCB); Salvador, 10-XI-1998, Pinto s.n (HRB39960); Xique-Xique, na caatinga, 22-VI1996, Harley et al. 2943 (ALCB, HUEFS, PACA, SPF). Espírito SANTo: Colatina, Rio Pancas, 6-10 Km $\mathrm{N}$ de Colatina, camino de tierra sobre la margen izquierda, 28-I-1997, Arbor et al. 7756 (CEPEC, CTES); Rod. Linhares para Povoação, na plantação de Cacau, 26-XI-1973, Pinheiro et al. 2289 (CEPEC, SPF). GoIÁs: Niquelândia, ca. $17 \mathrm{Km}$ S of Niquelândia, in gallery forest and adjacent cerrado, 23-I-1972, Irwin et al. 34889 (NY). MARANHão: São Luís, Herbarium Atiço Seabra, 10-VIII-2001, Dominici s.n (MG165367); idem, Vila de Embratel, in garden of University, 25-XI-1985, Prance 29878 (CTES, NY). Mato Grosso: Cuiabá, Baía do Burro, $2^{\circ}$ Ponto, 22III-2001, Cunha et al. 1448 (CH); Poconé, 23-X1988, Boock s.n (IAC); Porto Esperança, Rio Araguai, IX-1914, Kuhlmann 207 (R); Rio Brilhante, no brejo, 27-I-1971, Hatschbach 26158 (MBM); Santo Antonio do Leverger, Baía Porto de Fora, 10-I-1986, Silva 750 (CH); Sine loco, Fazenda Miranda, no pantanal, 5-V-1979, Schaller 299 (NY). Mato Grosso Do SuL: Anaurilândia, Rio Paraná, Ilha a montante da Barragem de Porto Primavera, 17-X-1998, Amaral Jr. 250 (NY); Aquiduana, Fazenda Santa Cruz, no pantanal, 17-VII-1969, Hatschbach 21963 (CTES, MBM); Brilhante, Rio Brilhante, 27-I-1971, Hatschbach 26158 (CTES); Corumbá, no campo cerrado, II-1911, Standley 4870 (R); idem, Piuval, 120 Km W-NW de Guaicurus, 5-VI-1973, Silva 100 (SP); Estrada Transpantaneira, 28-I-1979 Heringer et al. 851 (IBGE, NY); Guia Lopes da Laguna, Estância 
Uchoa, na orla do brejo, Hatschbach et al. 76032, 8-X-2003 (CTES); Iguatemi, $16 \mathrm{Km} \mathrm{O,} \mathrm{Rod.} \mathrm{MS-}$ 295, no brejo, 8-II-1993, Hatschbach et al. 58643 (MBM); Miranda, Passo da Lontra, Conceição 2447, 4-II-1989 (UB); Porto Muritinho, na orla do brejo, 19-III-1985, Hatschbach et al. 49282 (MBM); Três Lagoas, debaixo do leito do Rio Paraná, 23-V-1964, Gomes Júnior 1815 (MBM). Minas Gerais: Belo Horizonte, próximo a Pampulha, no cerrrado, 17VIII-1958, Pabst 4526 (HBR); Carandái, Km 418, 20-II-1946, Duarte 584 (HBR); Governador Valadares, 19-IV-1964, Trinta 730 \& Fromm 1806 (CTES, NY, R); Juiz de Fora, Campus da UFJF, IV1992, Verardo s.n (HRCB 16280); Lagoa Santa, s.d, Warming s.n (NY); São Roque de Minas, Cachoeira da Casca D' Anta, PARNA Serra da Canastra, 17VII-1995, Romero et al. 2555 (HRCB); Vale do Rio Verde, até Três Corações pela Serra da Mantiqueira, I-1885, Saldanha 8674 (R); Viçosa, Vila Gianeti, 23VII-1996, Carvalho s.n (VIC16379). PARÁ:Almeirim, Monte Dourado, próximo à marina da balsa da SION em Munguba, 16-I-1986, Pires Silva et al. s.n (MG125324); Amaranduba, on north bank of Amazon, ca. $1 \mathrm{Km}$ east of Arumanduba W Pará, 27VII-1961, Engler \& Irwin 46017 (MG, NY); Belém, 28-I-1962, Pires 7854 (UB); Garotire, Reserva Florestal de Garotine, surrounfings of Garotire Village at Rio Fresco, 22-I-1988, Gottsberger \& Posey 126-21183 (MG); La Pedreza, rio Caquetá, rochedos acima da cachoeira, 25-XI-1916, Ducke s.n (MG12308); Lageira, on Rio Maicuru, on riverbanks of Maicuru up to $1 \mathrm{~km}$ upstream of airstrip, 20-VII1981, Sobel et al. 3293 (MG, NY, CTES); Monte Alegre, Cateia, Rio Maicurú, na várzea, 15-VII-1957, Black 57-20119 (IAN); Óbidos, Mamaui, 1-III-1915, Ducke s.n (MG2615712); Santarém, Cacaual Grande, Canal Novais Filho, 3-VII-1952, Black 52-15362 (IAN). PARAíba: Caaporã, 18-X-1989, Miranda \& Zoraida s.n (JPB15845); Lagoa Seca, 23-XI-2000, T. Grise 122 (JPB); Massaranduba, 7-I-1978, Agra 1 (JPB). ParanÁ: Balsa Nova, Rio Iguaçu, em mata de galeria, 10-VI-1969, Hatschbach 10969 (B); Campo Mourão, Rio Mourão, Represa da Copel, na orla da mata de galeria, 28-XI-2001, Ribas \& Costa 3929 (CTES, MBM); Foz do Iguacú, 27-IX-1967, Pedersen 8416 (CTES); Guaíra, Parque Nacional Sete Quedas, nas margens do Rio Paraná, 24-III1997, Hatschbach 39809 (CTES, MBM); Maringá, Conjunto Cidade Nova, 6-XII-1994, Costa 01 (HRCB); Porto Byington, Várzea of Rio Paraná, 20VI-1966, Lindeman \& Haas 1656 (HBR, NY);
Porto Rico, Rio Paraná, Ilha Porto Rico, 19-XI-1997, Melges 07 (HRCB); Querência do Norte, Porto Natal, Córrego Juriti, na capoeira, Furtado-Leite et al. 10 (HRB); São Mateus do Sul, Fazenda do Durgo, na várzea do Rio Iguaçu 22-IV-1986, Britez et al. 558 (MBM); Tibagi, Fazenda Mate Alegre, Foz do Rio Harmonia, nas margens do rio, 9-V-1963 Hatschbach 3163 (MBM, SI); Vila Alta, Ilha Bandeirante, próximo ao rio $1^{\mathrm{a}}$ ponte, local úmido, 29-IX-2006, Marchioretto 304 (PACA); Sine loco, Capão Grande, in fructicetis ad rivulum, 5-II-1909, Dusén 7717 (NY); Sine loco, Serrinha, locis humidis, 6-IV-1914, Johnsson 166 a (NY). Pernambuco: Santa Maria da Boa Vista: Faz. Milano, 28-VII-1984, Pinto 191 (ALCB, GUA, HRB, HUEFS, MBM, MG, RB). Rio DE JANeIro: Campos, 4-VII-1922, Sampaio 79 (R); Entre Barão de Juparaná e Sebastião de Lacerda, Rio Paraíba, vassouras, 5-III-1980, Vianna 1485 (GUA); Itatiaia, XII-1892, Kuntze s.n (NY); Paraíba do Sul, na margem do Rio Paraíba do Sul, perto da ponte Urbana, 25-VII-1974, Carauta et al. 4725 (GUA); Resende, Sítio Sarela, 1-VI-1987, Pineschi et al. 213 (GUA), Rio De Janeiro, Fio Cruz , Setor de Primatologia, canteiro 7, 8-VI-1999, Monteiro 211 (RB); Sine loco, s.d, Glaziou 13119 (NY). Rio Grande do Sul: Alegrete, 21-XII-1980, Sobral \& Stehmann 886 (HAS); Bagé, Estância mato do Recreio, na margem do arroio, 14-IV-2006, Lima 342 (PACA); Cachoeira do Sul, Irapuá, Agropecuária Coqueiro, próximo ao rio, 6-III-2006, Marchioretto 286 (PACA); Encruzilhada do Sul, no Passo do Branquilho, numa matinha ciliar, 16-XI-1978, Mattos et al. 1995a (HAS); Ijui, Granja Sodal, 18-XII-1966, Hagelund 5010 (CTES); Porto Alegre, Navegantes, 11-III-1902, Malme 1483 (R); Santo Angelo, estrada Entre Ijuis, XII-1997, Hanglund 11787 (HAS); São Francisco de Assis, Manoel Viana, 22-XII-1980, Sobral \& Stehmann 960 (HAS); São Gabriel, Fazenda Santa Cecilia, in campestribus dumetosis, II-1944, Rambo 25745 (PACA). RONDÔNIA: Cachoeira Misiricórdia, Rio Madeira at Ribeirão, 2-VIII-1968, Prance et al. 6717 (MG, NY, R); Costa Marques, Rio Cautário, na margem do rio, 27-X-1996, Lobato et al. 2364 (MG); E bank of rio Madeira at Abunã, 12-VII1962, Prance et al. 5916 (MG, NY, R); E bank of Rio Madeira between Penha Colorado and Cachoeira Araras, 20-XI-1968, Prance et al. 8700 (NY, R); Island in Rio Madeira at mouth of Rio Jaciparaná, 29-VI-1968, Prance et al. 5352 (MG); Rio Madeira 4 Km north of Mutumparaná, 2-VII-1968, Prance et al. 5461 (NY); Território Federal, 19-IX-1962, Duarte 
6985 (RB). Roraíma: Canta Galo, South bank of Rio Mucajaí, between Pratina and Rio Apiauí, 25-I-1967, Prance et al. 4081 (MG, NY). Santa Catarina: Porto União, em beira de rio, 6-I-1962, Reitz \& Klein 11661 (CTES, HRB, NY); idem, próximo ao Rio Iguaçu, 11-I-2006, Marchioretto 276 (PACA). São Paulo: Campinas, Jardim Guanabara, 3-XII-1993, Viégas s.n (IAC04475); Jacarei, 1991, Miyoshi s.n (ESA); Martinho Prado, Fazenda Campininha, 03-VIII1988, Romaniuc Neto et al. 1067 (NY); Piracicaba, 1991, Vencramini s.n (ESA7764); São José dos Campos, 18-I-1980, Tamashiro 10863 ( NY); Teodoro Sampaio, $35 \mathrm{Km}$ a Oeste em direção a Rosana, 11III-1981, Muniz 284 (SP).

Material adicional examinado: ARGENTINA. Buenos Aires: San Isidro, 16-I-1944, Boeleke 810 (CTES); idem, Palermo, III-1948, Crovetto 1884 (CTES); idem, Puenta Lara, 14-IV-1961, Cullen s.n (CTES); Caaguazú, 1905, Hassler 9111 (SI); Chaco, $1^{\circ}$ de Mayo, Campo Antiquera, XII-1936, Schulz et al. 2123 (HAS); Corrientes, Mercedes, 5-IX-1997, Ferrucci 1295 (CTES, SI); idem Huzaingó-Rincón Ombú Chico, Krapovickas at al. s.n (HAS50681); idem, Santo Tomé, Ayo Chimino y Rio Uruguau, 12XI-1974, Schinini et al. 10402 (HAS); ENTRE Rios: Colón, 15-XII-2003, Cocucci, 2958 (CTES, SI); idem, Empedrado, Estancia las Tres Marias, 18-V1952, Pedersen 1724 (CTES); idem, Mburucuyá, Estancia Santa Teresa, 23-XI-1950, Pedersen 873 (CTES); idem, Berón de Astrada, Campo Yaguá Cuá, 19-I-1957, Pedersen 4452 (CTES); idem, La Paz, Piedras Blancas, 17-IV-1967, Pedersen 8309 (CTES, SI); idem, Uruguay, Estancia La Selmira, 31-III-1967, Pedersen 8216 (CTES, SI); idem, Boca del Berungo, Estancia Herradura, 12-X-1951, Pedersen 1225 (CTES); idem, Goya, em campos areno-argilosos, 26-XI-1945, Boelcke 1427 (SI); Formosa, Laishí, 18IX-1998, Di Giácomo 395 (CTES); idem, Pilcomayo, 9-VII-1967, Piccinini 1037 (SI); Jujuy, El Carmen, Los Lapachos, 21-III-1984, Ahumada \& Castellon 5032 (CTES); idem, Santa Bárbara, El Fuerte, VIII-1983, Rotmann 768 (CTES); idem, San Pedro de Jujuy, 17-V-1945, Herrera 511 (SI); Misiones: Cainguás, 14-III-2000, Biganzoli 784 (CTES, SI); idem: Capital, 16-IV-1930, Rodríguez 193 (SI); idem, Candelária, 28-IX-1910, Rodríguez 396 (SI); idem, Iguazú, 10-VIII-1995, Vanni 3475 (CTES, SI); idem, Eldorado, 17-VIII-1997, Vanni 4062 (CTES, SI); idem, Iguazú, Parque Nacional Iguazú, picada al Hidrógrafo, 3-III-1995, Zuloaga et al. 5196 (SI); idem, San Ignácio, 14-XII-1983, Hunziker 11047
(SI); SAlta: Anta, 22-XI-1994, Krapovickas 46294 (CTES, SI); idem, San Fernando, Chaco, Isla Soto, 29-II-1967, Pedersen 8707 (CTES); San Pedro, Lima, Estancia Carumbé, 6-X-1967, Pedersen 8495 (CTES); idem, Anta, Parque Nacional El Rey, 12I-1979, Malmierca 110 (CTES); idem, Florestal, 2-XII-1987, Toledo 1503 (CTES); idem, Anta, 54 Km NE de J.V. González, camino a Puerta Blanca, 22XI-1994, Krapovickas \& Cristóbal 46294 (CTES); idem, Metán, 20-V-1905, Lillo 4467 (CTES); Salta, Rivadavia, Juan Solá Morillo, alredores de Tolderia, 02-I-1984, Arenas 2570 (CTES); idem, San Martín, Ruta 81, 6 Km W de Dragones, 8-III-2001, Schnini et al. 35395 (CTES); SANTA FÉ: San Jeronimo, Coronda, 27-I-1971, Krapovickas \& Irigoyen 17808 (CTES); idem, Colonias, Zona Rio Salado-Ruta, pradera, 24XI-1957, Achembach 338 (SI); idem, San Justo, Ruta Nacional 11, 7-V-2005, Deginani et al. 2011 (SI); idem, Cuneta de Ruta, Vera, 19-X-1987 Blanchoud 2359 (CTES); idem, San Martín, Ruta Nac. 34 entre Piquirenda y Auaray, XII-1986, Zuloaga et al. 2706 (CTES); Tucumán: Tafí, San Agustin, 1-X-1951, Rocha 3815 (CTES). BOLIVIA. PAUdO: W bank of Rio Madeira , 12 Km above Abunã, 20-VII-1968, Prance et al. 6218 (R); SANTA CRUZ: Andres Ibanez, Campus Universitário, jardim del campu, 11-XI1994, Arroyo \& Menacho 851 (CTES). PARAGUAI. Alto Paraguay: 31-III-1995, Degen 3293 (CTES, SI); AмамваY: Parque Nacional Central, Itororó, Wet groud, 11-XII-1969, Pedersen 9530 (SI); idem, Chaco, 1906, Fiebrig 1282 (B); Boquerón, 11-IX1990, Vanni, 1901 (CTES, SI); Cerro Corá, próximo al Monumento al Mariscal F.S. López, nela selva marginal del rio Aquidobán, 18-XII-1999, Ferrucci et al. 1714 (CEN); Presidente Hayes, frente a Concepción, Zona sujeta a inundación, aledafia al puente sobre el rio Paraguay, 28-II-1994, Krapovickas \& Cristobal 45116 (CEN); SAN PEDRo: 31-VII2001, Arbo 8908 (CTES, SI). URUGUAI. Cuñapirú p. Rivera, in dumetosis, 12-I-1941, Rambo 3951 (PACA); Rivera, Tranqueras, I.1941, Chebatataroff 9004 (BHCB); San José, s.d, Gibert 14 (SI).

Pfaffia glomerata é muito próxima de $P$. iresinoides (H.B.K.) Spreng., diferenciando-se desta em alguns caracteres morfológicos como forma do limbo foliar, pilosidade e, principalmente, pela distribuição geográfica. Segundo Eliasson (1987), $P$. iresinoides distribui-se principalmente na parte noroeste da América do Sul (Venezuela, Colômbia, Equador, Peru), mas se estende para o norte do México e ao sul da Argentina. Para Pedersen (1987, 
1999), P. glomerata é uma espécie muito variável e difundida no sul da América tropical e subtropical (Argentina, Bolívia, Brasil, Paraguai e Uruguai). Após o exame de um número considerável de exsicatas, provenientes da maioria dos Estados brasileiros e ainda da Argentina, Bolívia, Paraguai, Venezuela e Uruguai considera-se que, para uma definição mais completa destas espécies, torna-se necessário um estudo ao nível molecular, pois na impossibilidade de consultar os espécimens-tipo das mesmas, restringiram-se bastante as análises. O que se pode constatar é que os espécimes que ocorrem dentro do território brasileiro e na Argentina, Paraguai e Uruguai pertencem à $P$. glomerata. Para os demais países como Venezuela, Colômbia, Equador e Peru, somente é citada $P$. iresinoides. Neste trabalho, foram examinadas exsicatas do Equador e da Venezuela, todas identificadas como $P$. iresinoides.

Segundo Carlos Alberto Agudelo (comunicação pessoal), especialista em Amaranthaceae na Colômbia, neste país ocorre somente $P$. iresinoides.

Pfaffia glomerata e $P$. iresinoides possuem constituintes químicos diferentes, de acordo com Shiobara et al. (1993) e Nishimoto et al. (1987, 1988).

Neste trabalho, propõe-se a sinonimização de Pfaffia vana em favor de P. glomerata, pois após exame de vários espécimens incluindo o tipo, verificou-se que os mesmos não apresentam características morfológicas e distribuição geográfica distintas que justifiquem a manutenção de $P$. vana como uma espécie independente.

Pedersen (1967) fez uma nova combinação para Pfaffia glomerata apresentando uma lista de sinônimos da espécie e argumentando sobre cada um deles. Após esta data muitos trabalhos envolvendo diversos aspectos foram realizados com Pfaffia glomerata.

Vasconcellos (1986) comentou que a espécie é descrita como polígama, mas que Pedersen (1967), tendo examinado um considerável número de flores, denominou-as perfeitas. Vasconcellos (1986) argumentou que depois de examinar material do Rio Grande do Sul e da Argentina constatou que as flores eram sempre perfeitas, mas que ainda seriam necessárias novas observações para a devida confirmação. Pedersen (1999) relatou no Catálago de las Plantas Vasculares da Argentina, que Pfaffia glomerata apresenta um intenso polimorfismo.

Smith \& Downs (1972) comentaram ser esta espécie uma erva lianosa, característica do planalto catarinense onde apresenta uma dispersão irregular e descontínua, sendo seletiva higrófita e heliófita, bastante rara, ocorrendo principalmente em borda de rios e nas orlas de matas de galerias, onde pode receber bastante luz. Pedersen (1987), quando descreveu esta espécie para a Flora de Entre Rios (Argentina), comentou que $P$. glomerata é uma espécie bastante variável, apresentando hábito subarbustivo ao longo da beira de rios e herbáceo, de menor porte, no interior de montes.

Pfaffia glomerata é utilizada como antireumática, antinflamatória e analgésica, efeitos atribuídos às substâncias como ácido oleanólico, ecdisterona, nortriterpenóides, triterpenóides e ecdysteróides que, segundo Shiobara et al. (1993), encontram-se presentes em tecidos da planta. Por esta razão, tem ocorrido uma intensa exploração predatória dos hábitats naturais desta espécie.

Paris et al. (2000) testaram os efeitos do extrato alcoólico de raízes de Pfaffia glomerata em alguns animais e concluíram que este extrato apresenta uma atividade depressora do sistema nervoso central e efeito amnésico, contrariando a utilização popular desta espécie como estimulante.

Gosmann et al. (2003) utilizaram parâmetros para controle de qualidade de raízes de $P$. glomerata usando características químicas e botânicas. Também usaram um screening farmacológico direcionado às atividades relacionadas ao uso de tônico. Os autores concluíram que o ácido etanólico das raízes desta espécie não apresentou efeito citotóxico sobre linhagens de células tumorais, ação antiviral sobre o vírus do tipo herpes humano, efeito antifúngico, nem ação inibidora sobre monoaminoxidases cerebrais.

Nicoloso et al. (1999), ao analisarem a influência da estaca no ramo sobre o enraizamento de Pfaffia glomerata em dois substratos, concluíram que a estaquia é um método adequado para a propagação de Pfaffia. As estacas obtidas das porções mediana e basal apresentam maior capacidade de enraizamento que as apicais e que a combinação de solo mais casca de arroz carbonizada é um substrato viável para a estaquia e para posterior desenvolvimento das mudas a campo. Nicoloso et al. (2001) determinaram a influência do comprimento da estaca do ramo no enraizamento de $P$. glomerata e indicaram que o comprimento da estaca não afeta a percentagem de enraizamento, a produção de massa seca de folhas e raízes.

Franco Silva (2003), ao fazer a caracterização morfo-anatômica dos órgãos vegetativos de Pfaffia glomerata constatou que, na raiz, o crescimento 
secundário resulta da instalação do câmbio vascular de forma usual e o aumento de diâmetro do órgão se faz pela atividade de câmbios acessórios de atividade limitada. Já, o aumento do diâmetro do caule resulta da instalação de câmbios acessórios provenientes da retomada de divisão de células pericíclicas.

Russowski \& Nicoloso (2003) caracterizaram o efeito da variação isolada da concentração de $\mathrm{N}$ e do meio MS no crescimento de plantas de Pfaffia glomerata cultivadas in vitro e concluíram que o crescimento em altura, brotações, número de segmentos nodais, índice de área foliar, número de folhas, matéria seca de raízes da parte aérea e total da planta é maior na concentração de $\mathrm{N}$ e $\mathrm{P}$, em média próxima a $80 \%$ daquela do meio de cultura MS. Skrebsky et al. (2006) estudaram substratos para aclimatização de plântulas de $P$. glomerata produzidas in vitro sob diferentes concentrações de sacarose e concluíram que o cultivo in vitro com sacarose nas doses de $45-60 \mathrm{~g} \mathrm{~L} \mathrm{~L}^{1}$, promove maior índice de aclimatização de $P$. glomerata. Os substratos Vermiculita média+ solo e Plantmax + solo promoveram maior crescimento das plantas na última fase de aclimatização e o substrato Plantmax, usado isoladamente, proporcionou maior índice de sobrevivência das plantas cultivadas a campo.

Takada (2006) avaliou a diversidade genética de populações de Pfaffia glomerata por RAPD, caracteres morfológicos e teor de Beta-Ecdisona e concluiu que não é recomendável utilizar apenas um tipo de característica, seja fenotípica ou molecular, para estimar a diversidade genética no aspecto qualitativo, uma vez que as correlações entre as distâncias genéticas de cada característica foram baixas. O uso de marcador RAPD pode ser uma escolha favorável sob alguns aspectos, principalmente, quando não se dipõe de tempo e recursos para visitas freqüentes ao local de avaliação de populações.

\section{Agradecimentos}

Ao Dr. Pedro Ignácio Schmitz, Diretor do Instituto Anchietano de Pesquisas pelo apoio, incentivo e infraestrutura. Aos curadores dos herbários consultados, pela atenção e gentileza no empréstimo de material. À Maria Virgilia Farias Josende pela dedicação e carinho na confecção das ilustrações. A todos aqueles que, direta ou indiretamente, contribuíram para a realização deste trabalho.

\section{Literatura citada}

Andrade-Lima, D. 1981. The caatingas dominium. Revista Brasileira de Botânica 4: 149-153.

APG II. The Angiosperm Phylogeny Group 2003. An update of Angiosperm Phylogeny Group classification for the orders and families of flowering plants: APG II. Botanical Journal of the Linnean Society 141: 399-436.

Borsch, T. 1995. Three new combinations in Pfaffia (Amaranthaceae) from the New World Tropics. Novon 5: 230-233.

Borsch, T. \& Pedersen, T.M. 1997. Restoring the Generic Rank of Hebanthe Martius (Amaranthaceae). Sendtnera 4: 13-31.

Cabrera, A.L. \& Willink, A. 1980. Biogeografia de America Latina. 2 ed. OEA, Washington

Cuadrado, G.A. 1988. Granos de pólen de Amaranthacee del nordeste Argentino: 2. Gênero Pfaffia. Boletin de la Sociedad Argentina de Botánica 25: 385-394.

Eiten, G. 1977. Delimitação do conceito de cerrado. Arquivos do Jardim Botânico do Rio de Janeiro. 21: 125-134.

Eiten, G. 1990. A vegetação do cerrado. In: M.N. Pinto (org.). Cerrado: caracterização, ocupação e perspectivas., Ed. da Universidade de Brasília, Brasília, pp. 9-65.

Eliasson, U.H. 1987. Amaranthaceae In: G. Harling \& L. Anderson (eds.). Flora of Ecuador Gothenburg, Department of Systematic Botany. Museum of Natural History, Stockolm, vol. 28, pp. 52-60.

Eliasson, U. H. 1988. Floral morphology and taxonomic relation among the genera of Amaranthaceae in the New World and the Hawaiian Islands. Botanical Journal of the Linnean Society 96: 235-283.

Endlicher, S. 1837. Amaranthaceae. Genera Plantarum Secundum Ordines Naturales., Fr. Beck, Wien vol 4, pp. 300-304.

Fernandes, A. 1998. Fitogeografia Brasileira. Multigraf Editora, Fortaleza

Franco Silva, R.M.M. 2003. Caracterização morfoanatômica dos órgãos vegetativos de Pfaffia glomerata (Spreng.) Pedersen "ginsengbrasileiro"-Amaranthaceae. Dissertação de Mestrado, Universidade Estadual Paulista, Botucatu.

Fries, R.E. 1920. Revision der von Glaziou in Brasilien Gesammelten Amaranthaceen. Arkiv För Botanik 16: 1-21. 
Gosmann, G., Gattuso, S., Gattuso, M., Fenner, R., Pacheco, E.F., Ferraz, A., Savi, L.A., Barardi, C.R.M., Simões, C.M.O., Sortino, M., Zacchino, S., Gnerre, C., Testa, B. \& Rates, S.M.K. 2003. Botanical (morphological, micrographic), chemical and pharmacological characteristics of Pfaffia species (Amaranthaceae) native to South Brazil. Brazilian Journal of Pharmaceutical Sciences 39: 141-147.

Handro, W. 1965. Pollen grains of plants of the "Cerrado". X - Amaranthaceae. Anais da Academia Brasileira de Ciências 37: 557-565.

Handro, W. 1967. Contribuição ao estudo da venação e anatomia foliar das Amarantáceas dos Cerrados. II - Gênero Pfaffia. Anais da Academia Brasileira de Ciências 39: 495-506.

Hickey, L.J. 1974. Classificatión de la arquitetura de las hojas de dicotiledôneas. Boletin de la Sociedad Argentina de Botánica. 16: 1-25.

Hooker, J.D. 1880. Amaranthaceae. In: G. Bentham \& J. D. Hooker (eds.). Genera Plantarum, vol. 3, pp. 1011. London.

Judd, W.S., Campbell, C.S., Kellogg, E.A., Stevens, P.F. \& Donoghue, M.J. 2002. Plant sistematics. A Phylogenetic approach. 2 ed. Sinauer Associates, Sunderland.

Lindman, C.A.M. 1906. A vegetação no Rio Grande do Sul. Typografia Livraria Nacional, Porto Alegre.

Linnaeus, C. 1781. Supplememtum Plantarum Systematis Vegetabilis, Imprensis Orphanotrophaei, Brusviagae.

Marchioretto, M.S. \& Miotto, S.T.S. 2007. Pfaffia siqueiriana (Amaranthaceae), uma nova espécie para o Brasil. Pesquisas, Botânica 58: 383-388.

Marchioretto, M.S., Miotto, S.T.S. \& Siqueira, J.C. 2008. Pfaffia cipoana e Pfaffia rupestris (Amaranthaceae), duas novas espécies para o Brasil. Rodriguésia 59: 129-133.

Martius, C.F.P. 1826. Amaranthaceae. Nova genera et species plantarum. Typis C. Wolf, Monachii

v. 2, pp. 1-64.

Monteiro-Scanavaca, W.R. 1969. Anatomia floral de Pfaffia jubata Mart. Boletim de Botânica da Universidade de São Paulo 24: 255-271.

Monteiro-Scanavaca, W.R. 1971. Vascularização floral em Amaranthaceae. Ciência e Cultura 23: 339-349.

Moquin-Tandon, A. 1849. Amaranthaceae. In: A. De Candolle (ed.). Prodromus Systematis Naturalis
Regni Vegetabilis. Victoris Masson, Paris v.13, part 2, pp. 419-423.

Müller, K. \& Borsch, T. 2005. Phylogenetics of Amaranthaceae based on matK/trnK sequence data evidence from parsimony, likelihhod, and bayesian analyses. Annals Missouri Botanical Garden 92: 66-102.

Nicoloso, F.T.R., Furtunato. P \& Fortunato, R.P. 1999. Influência da posição da estaca no ramo sobre o enraizamento de Pfaffia glomerata (Spreng) Pedersen em dois substratos. Ciência Rural 29: 277-283.

Nicoloso, F.T.R., Cassol, L.F. \& Furtunato, P. 2001. Comprimento da estaca de ramo no enraizamento de ginseng brasileiro (Pfaffia glomerata). Ciência Rural. 31: 57-60.

Nishimoto, N. Shiobara, Y., Fujino, M., Takemoto, T., Oliveira, F., Akisue, G., Akisue, M.K., Hashimoto, G., Tanaka, O., Kasai, R. \& Matsuura, H. 1987. Ecdysteroides from Pfaffia iresinoides and reassignment of some 13C NMR chemical shifts. Phytochemistry 26: 2505-2507.

Nishimoto, N., Shiobara, Y., Inque, S.S., Fujino, M., Takemoto, T., Yeoh, C.L., Oliveira, F; Akisue, G., Akisue, M.K. \& Hashimoto. 1988. Three ecdysteroid glycosides from Pfaffia iresinoides. Phytochemistry 27: 1665-1668.

Paris, F., Neves, G., Salgueiro, J.B., Quevedo, J., Izquierdo, I. \& Rates, S.M.K. 2000. Psychopharmacological screening of Pfaffia glomerata Spreng. (Amaranthaceae) in rodents. Journal of Ethnophamacology 73: 261-269.

Pedersen, T.M. 1967. Studies in South American Amaranthaceae. Darwiniana 14: 448-449.

Pedersen, T.M. 1976. Estudios sobre Amarantáceas sudamericanas, II. Darwiniana 20: 269-303.

Pedersen, T.M. 1987. Amaranthaceae, Caryophyllaceae. In: A. Burkart (ed.). Flora Ilustrada de Entre Rios (Argentina). vol. 6, pp. 160-203, 251-291.

Pedersen, T.M. 1990. Studies in South American Amaranthaceae III (incluinding one amphiAtlantic species). Bulletin du Muséum National d'Histoire Naturelle Sér.4. 12 sect. B. Adansonia 1: 69-97.

Pedersen, T. M. 1997. Studies in South American Amaranthaceae. I. Bulletin du Muséum National d'Histoire Naturelle Sér.3. Adansonia 19: 217251.

Pedersen, T.M. 1999. Amaranthaceae. In: F.O. Zuloaga \& O. Morrone. (eds.). Catálago de las 
Plantas Vasculares de la República Argentina II. Acanthaceae-Euphorbiaceae (Dicotiledoneae). Missouri, Botanical Garden Press. pp. 621

Pedersen, T.M. 2000. Studies in South American Amaranthaceae V. Bonplandia 10: 83-112.

Radford, A.E., Dickson, W.C., Massey, J.R. \& Bell, C.R. 1974. Vascular Plant Systematics, Harper \& Row, New York.

Rambo, B. 1968. Amaranthaceae Riograndenses. Pesquisas-Botânica 26: 30

Rizzini, C.T. 1979. Tratado de Fitogeografia do Brasil. Editora da Universidade de São Paulo, São Paulo.

Rizzini, C.T., Coimbra Filho, A. F. \& Houaiss, A. 1988. Ecossistemas. Index Editora.

Russowski, D. \& Nicoloso F.T. 2003. Nitrogênio e fósforo no crescimento de plantas de ginseng brasileiro \{Pfaffia glomerata (Spreng.) Pedersen\} cultivadas in vitro. Ciência Rural 33: 57-63.

Senna, L.R. 2006. Amaranthoideae e Gomphrenoideae (Amaranthaceae Juss.) do estado da Bahia. Dissertação de Mestrado, Universidade Estadual de Feira de Santana, Feira de Santana.

Seubert, M. 1875. Amaranthaceae. In: C.F.P. Martius, Endlicher \& I. Urban (eds.). Flora Brasiliensis. Typografia Regia, Monachii,v.5, .pars1, pp. 188-202.

Shiobara, Y., Inoue, S.S., Kato, K., Takemoto, T., Nishimoto, N., Oliveira, F., Akisue, G., Akisue, M.K.\& Hashimoto, G. 1993.Anortiterpenoides, triterpenoides and ecdysteroides from Pfaffia glomerata. Phytochemistry. 32: 1527-1930.

Siqueira, J.C. 1981. Utilização popular das plantas do cerrado. São Paulo, Loyola.

Siqueira, J.C. 1987. Importância alimentícia e medicinal das Amaranthaceae no Brasil. Acta Biologica Leopoldensia 1: 99-110.

Siqueira, J.C. 1988. Considerações taxonômicas sobre as espécies brasileiras do gênero Pfaffia Mart. (Amaranthaceae). Acta Biologica Leopoldensia 10: 269-278.

Siqueira, J.C. 1994/1995. Fitogeografia das Amaranthaceae Brasileiras. Pesquisas, Botânica 45: 5-21.

Siqueira, J.C. 1997/1998. Amaranthaceae: Atualização taxonômica. Eugeniana 23: 15-17.

Siqueira, J.C. 2002. Amaranthaceae In: M.G.L. Wanderley, G. Shepherd \& A.M. Giulietti (eds.). Flora Fanerogâmica do Estado de São Paulo. FAPESP-HUCITEC, São Paulo pp.11-30.
Siqueira, J.C. \& Grandi, T.S.M. 1986. O gênero Pfaffia Mart. (Amaranthaceae) nos cerrados e campos rupestres de Minas Gerais. Acta Biologica Leopoldensia 8: 213-230.

Skrebsky, E.C., Nicoloso, F.T. \& Maldane, R.J. 2006. Substratos na aclimatização de Pfaffia glomerata (Spreng) Pedersen produzida in vitro sob diferentes doses de sacarose. Ciência Rural 36: 1416-1423.

Smith, L.B. \& Downs, R.J. 1972. Amarantháceas. In: R. Reitz, (ed.). Flora Ilustrada Catarinense. Santa Catarina. Itajaí.

Souza, V.C. \& Lorenzi, H. 2005. Botânica Sistemática: guia ilustrado para identificação das famílias de Angiospermas da flora brasileira, baseado em APG II. Instituto Plantarum. Nova Odessa.

Stützer, O. 1935. Die Gattung Pfaffia mit einem Anhag neur Arten von Alternanthera. Feddes Repertorium Specierum Novarum Regni Vegetabilis 88: 1-49.

Suessenguth, K. 1934. Neue und kritische Amarathaceen aus Süd und Mittelamerika. Repertorium Specierum Novarum Regni Vegetabilis 35: 298-337.

Suessenguth, K. 1938. Amaranthaceen-Studien. I. Amaranthaceae aus Amerika, Asien, Australien. Repertorium Specierum Novarum Regni Vegetabilis. 44: 40.

Takada, T. 2006. Avaliação da diversidade genética de populações de fáfia (Pfaffia glomerata (Spreng.) Pedersen) por RAPD, caracteres morfológicos e teor de Beta-Ecdisona. Tese de Doutorado Universidade Federal de Viçosa, Viçosa.

Thiers, B. 2010. Index Herbariorum: A global directory of public herbaria and associated staff. New York Botanical Garden's Virtual Herbarium. http://sweetgum.nybg.org/ih/. (acesso em 30/05/2010).

Townsend, C.C. 1993. Amaranthaceae, v. 2, pp. 70-91. In: K. Kubitzki (ed.). The families and genera of vascular plants, Springer Verlag, New York.

Vasconcellos, J.M.O. 1986. Amaranthaceae do Rio Grande do Sul, Brasil. -V. Gêneros Pfaffia Mart. e Gomphrena Mart. Roessléria 8: 75-127.

Veloso, H.P., Rangel Filho, A.L.R. \& Lima, J.C.A. 1991. Classificação da vegetação brasileira, adaptada a um sistema universal. Instituto Brasileiro de Geografia e Estatística, Rio de Janeiro. 